\title{
CONDENSED SCHEDULE
}

\section{Thursday Morning}

Vision I (1-15) . 8:30-12:35, Empire Room

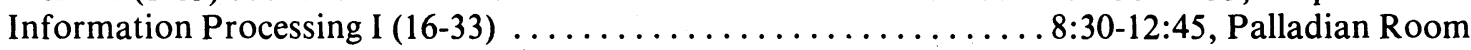

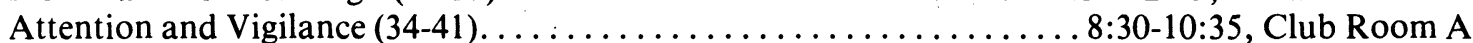
Performance and Reaction Time (42-48) . . . . . . . . . . . . 10:50-12:25, Club Room A

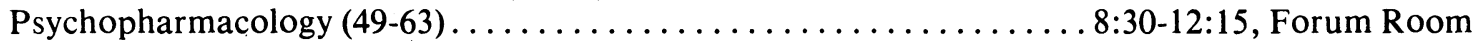
Animal Conditioning (64-78) . . . . . . . . . . . . . . . . 8:30-12:30, Diplomat Room Avoidance Learning (79-88) 8:30-11:15, Tudor Room

\section{Thursday Afternoon}

Perception I (89-107) 1:00-5:05, Empire Room Information Processing II (108-128). 1:00-5:35, Palladian Room Social-Personality Processes $(129-142 b) \ldots \ldots \ldots \ldots \ldots \ldots \ldots \ldots \ldots \ldots \ldots \ldots \ldots$ 1:00-4:40, Club Room A

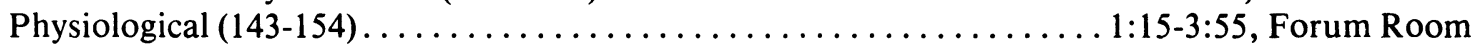
Animal Motivation $(155-163) \ldots \ldots \ldots \ldots \ldots \ldots \ldots \ldots \ldots \ldots \ldots \ldots \ldots \ldots \ldots \ldots \ldots$ 1:003:20, Tudor Room

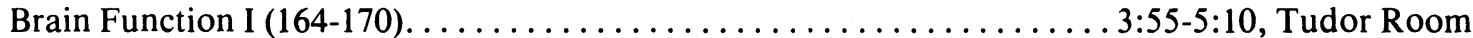
Memory and Recall I (171-185b) ............... D.

\section{Friday Morning}

Memory and Recall II (186-199) ..................... 8:30-12:30, Empire Room Information Processing III $(200-215) \ldots \ldots \ldots \ldots \ldots \ldots \ldots \ldots$. . . . . . . $\ldots \ldots$ 2:40, Palladian Room

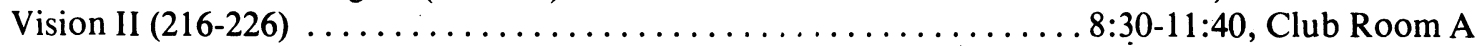

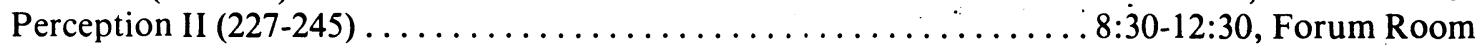
Animal Learning I $(246-259) \ldots \ldots \ldots \ldots \ldots \ldots \ldots \ldots \ldots \ldots \ldots \ldots \ldots \ldots \ldots \ldots$.30-12:40, Diplomat Room Problem-Solving and Concept Identification $(260-270) \ldots \ldots \ldots \ldots .30$ 30-11:50, Tudor Room

\section{Friday Afternoon}

Memory and Recall III (271-286) ..................... 1:00-5:15, Empire Room Information Processing IV $(287-301) \ldots \ldots \ldots \ldots \ldots \ldots \ldots \ldots \ldots \ldots \ldots \ldots \ldots \ldots \ldots$ :00-5:05, Palladian Room

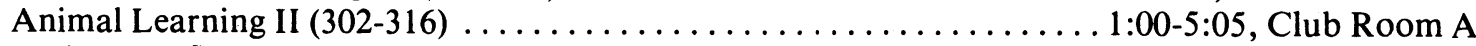
Brain Function II (317-331b) . . . . . . . . . . . . . . . . . . Animal Behavior I (332-348) $\ldots \ldots \ldots \ldots \ldots \ldots \ldots \ldots \ldots \ldots \ldots \ldots \ldots \ldots \ldots \ldots \ldots \ldots$ :00-5:40, Diplomat Room

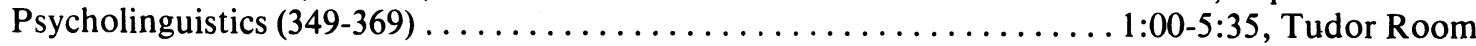

\section{Saturday Morning}

Memory and Recall IV (370-384) ..................... 8:30-12:25, Empire Room

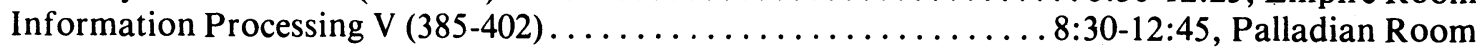

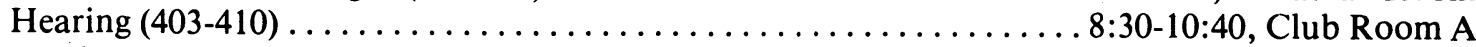

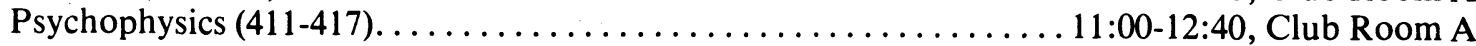

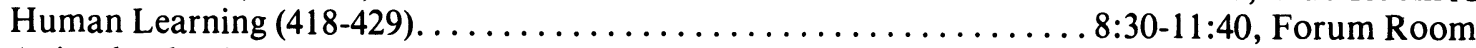

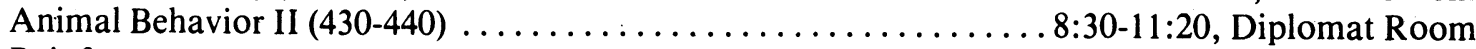

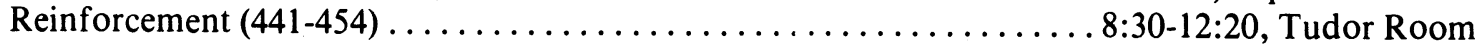




\section{Papers read at the 18th Annual Meeting of the Psychonomic Society The Shoreham Americana, Washington, D.C. November 10, 11, 12, 1977}

\author{
VISION I \\ Philip Salapatek, University of Minnesota, Minneapolis \\ Empire Room, Thursday morning, 8:30-12:35
}

\section{8:30-8:45 (1)}

Binocular Interactions in Human Vision. SANDRA A. LEMA \& RANDOLPH BLAKE, Northwestern University-Adaptation to a grating pattern produces a temporary elevation in contrast thresholds. We have measured the magnitude of this aftereffect both monocularly and binocularly following adaptation of either one or both eyes. Results reveal some new and interesting properties of mechanisms involved in binocular vision.

$$
\text { 8:45-9:00 (2) }
$$

Metacontrast and Paracontrast of a Contourless Area. ARNOLD E. STOPER, California State University, Hayward, \& GUY MANSFIELD, University of Oregon Medical School-The apparent brightness of an unbounded area of a large target figure was suppressed by a mask adjacent to this area. This "area suppression" was shown to follow a U-shaped function of onset asynchrony between target and mask similar to that of "classical" metacontrast, except that here the forward masking effect was as strong as the backward one. These results can be explained in terms of a filling-in process which lags behind the peripheral brightness sensing process.

$$
\text { 9:00-9:15 (3) }
$$

Foveal vs. Peripheral Metacontrast: A Parametric Study. BRUCE BRIDGEMAN \& STUART LEFF, University of California, Santa Cruz-We have measured the strength of metacontrast masking with three stimulus sizes, each located foveally and at two eccentric positions. Masking occurs in all locations; in the fovea, the smallest stimulus (target diameter 15') gives the strongest masking, while the reverse is true at the most peripheral position $\left(9.2^{\circ}\right)$. Results are interpreted in terms of physiological theories of masking.

\section{9:15-9:35 (4)}

The Effect of Refractive Error on Movement Detection. ROBERT POST \& H. W. LEIBOWITZ, Pennsylvania State University-The influence of refractive error on movement sensitivity was determined for a range of stimulus durations in the fovea and periphery. At short durations, threshold is determined by a constant stimulus displacement. At longer durations, a constant velocity is required. The correction of peripheral refractive error increases movement sensitivity in the displacement (short duration) component, but does not influence sensitivity in the velocity (long duration) component of the motion threshold.

$$
\text { 9:35-9:55 (5) }
$$

Is Dynamic Spatial Orientation Independent of Luminance and Refractive Error? H. W. LEIBOWITZ, Pennsylvania State University, \& J. DICHGANS, University of Freiburg, West GermanyAlthough luminance and refractive error are critical variables for many central visual functions, neither luminance (within $0.5 \mathrm{log}$ unit of absolute threshold) nor refractive error (20 diopters) alone, or in combination, has any effect on peripherally mediated dynamic orientation as measured by circularvection. The results are interpreted within the context of multiple modes of information processing, which argues for a dissociation of function between the central foveal and peripheral-ambient systems.

\section{$B R E A K-9: 55-10: 05$}

10:05-10:25 (6)

Monocular and Binocular Peripheral Acuity with Complex Stimuli at Photopic, Mesopic, and Scotopic Light Levels. JOHN R. BLOOMFIELD \& KURT GRAFFUNDER, Honeywell Systems \& Research Center-The peripheral acuity of six observers was measured in a display containing a $9 \times 22$ array of disk stimuli. The difference in diameter of a just discriminable target from the nontarget stimuli increased approximately linearly with retinal eccentricity, at photopic, mesopic, and scotopic light levels for both binocular and monocular viewing.

$$
\text { 10:25-10:35 (7) }
$$

The Influence of Target-Nontarget Separation on Discriminability. JOHN R. BLOOMFIELD, Honeywell Systems \& Research Center, \& JERRY WALD, University of Minnesota and Honeywell Systems \& Research Center-Displays containing nontarget stimuli and a single target that differed in color mixture were used in two experiments. Target discriminability was measured using optical blur techniques. Discriminability was found to be a function of the distance between stimuli, as well as of the physical characteristics of the target and nontargets.

10:35-10:55 (8)

An Economical Encoding for Size and Position Information. BARBARA SAKITT, Stanford University, \& HORACE B. BARLOW, University of Cambridge-A model is proposed for the first stage of the cortical transformation of the visual image. First, principles of engineering and signal detection theory are used to determine the minimum amount of information needed by the cortex. Second, we suggest a particular mathematical model by which the cortex might do this in the most economical way possible, subject to the restriction that the model conforms (approximately) to the psychophysical and electrophysiological evidence with regard to CSFs, size, position, and orientation selectivity. 10:55-11:10 (9)

Directional Selectivity: Tuning Functions and Discrimination Performance. KARLENE BALL \& ROBERT SEKULER, Northwestern University-Detection and reaction time experiments measured the tuning of human direction- and velocity-specific mechanisms. Mechanisms sensitive to upward movement generated narrower tuning curves than those sensitive to oblique directions. Tuning differences were paralleled by variation in ability to discriminate changes in direction of movement.

\section{1:10-11:25 (10)}

Paracontrast and Disinhibition. HALSEY H. MATTESON \& THOMAS C. PRAGER, Tulane University-Stimuli were two stripes flanking a central rectangle. With the rectangle test, there was no disinhibition or paracontrast. With the stripes as test, increased stripe brightness (disinhibition) occurred at test-mask asynchronies at which stripes (test) maximally masked the rectangle (mask), and there was some paracontrast.

$$
\text { 11:25-11:40 (11) }
$$

Interactions Between Sustained and Transient Channels in Humans. BRUNO G. BREITMEYER, University of Freiburg, West Germany-Employing the metacontrast paradigm, it was found that either ON or OFF transient activity can inhibit both ON and OFF sustained activity. Moreover, the inhibitory inter- 
action between sustained and transient channels was shown to be reciprocal. The functional significance of these findings was discussed.

\section{1:40-11:55 (12)}

Variations in the Perceived Velocity of Apparent Movement. KATHLEEN CARLSON, LINDA LAWLER, \& MARK S. MAYZNER, Loyola University of Chicago-A novel form of apparent movement, produced by presenting two spatially overlapping stimuli on a computer-based CRT, was examined. Points of light which comprised one stimulus appeared to move whenever they were preceded (in time) by a smaller, much shorter (duration), and vastly weaker stimulus. Subjective perceived velocity of apparent movement, which has not been measured heretofore, was found to be inversely related to ISI values between the two stimuli. The theoretical implications of these new findings are discussed.

\section{1:55-12:05 (13)}

Temporal Darkness Enhancement. THOMAS R. CORWIN, University of Rochester-An effect analagous to the Broca-Sulzer brightness enhancement phenomenon was found for luminance decrements varying in duration. When luminance was reduced by at least 4 to 1 , decrement-flashes of $30-50 \mathrm{msec}$ were judged $30 \%$ $40 \%$ darker than equivalent 1 -sec decrements. Similar results were found for both Ganzfeld and small spot targets.

$$
\text { 12:05-12:20 (14) }
$$

A Comparison of Length Illusions and Aftereffects. MITCHELL BRIGELL, Northeastern University, \& JOHN UHLARIK, Kansas State University-This study examined the influence of a horizontal contextual line on the apparent length of a horizontal test line. Contextual line length was manipulated. Simultaneous and sequential presentation of the lines produced opposite effects on the judged length of the test line. Results are discussed in terms of a model of the coding of length information.

$$
\text { 12:20-12:35 (15) }
$$

Visual Temporal Tuning: Effects of Adapting Flicker Modulation and Luminance. T. H. NILSSON, C. F. RICHMOND, \& T. M. NELSON, University of Alberta-Decreasing percent modulation has the same effect as decreasing luminance in reducing the frequency of an adapting flicker which maximally raises the modulation threshold of a test stimulus. This suggests that visual temporal tuning is not due to some single process sensitive to rate of luminance change but rather to various highpass-filter-limited pathways.

\section{INFORMATION PROCESSING I \\ Robert E. Hicks, SUNY at Albany \\ Palladian Room, Thursday morning, 8:30-12:45}

\section{8:30-8:45 (16)}

Cognitive Maps: Comparative Judgments of Imagined vs. Perceived Distances. DAVID R. BAUM, Man-Machine Sciences Division, Honeywell, Inc., \& JOHN JONIDES, University of Michigan-Subjects were required to judge which of two straight-line distances was shorter. In Experiment 1, these distances corresponded to imagined distances between geographic landmarks; in Experiment 2, the same (relative) distances were displayed visually. The results suggest that the processing of imagined and real distances is not mediated by the same mechanism.

\section{8:45-9:00 (17)}

Left and Right Hemispheric Superiority for Letter Discrimination. JOHN JONIDES, University of Michigan-Two letter discrimination experiments examine the hypothesis that lateral asymmetries in perceptual processing are sensitive to subtle changes in task demands. The first experiment reports a right visual field superiority for an easy letter discrimination, but a leftfield superiority for a difficult discrimination using the same stimuli. Experiment 2 demonstrates that the right-field superiority can be reversed under certain experimental conditions.
9:00-9:15 (18)

The Time-Course of Object-Superiority With Contexts Whose Local Environments are Similar. AMANDA WILLIAMS \& NAOMI WEISSTEIN, SUNY at Buffalo-Object-superiority (better discrimination among briefly flashed lines when the line is in a drawing with perceived depth than when it is in a flatterappearing design, or alone-Weisstein \& Harris, 1974; Williams \& Weisstein, 1976) is obtained even when the "objects" and flatter context provide the same local environment for the target lines. When the target line appears before the context, accuracy is equal for the "objects" and a locally similar flatter context at long delays, but diverges at short delays, suggesting that apparent threedimensionality enters in at a relatively late stage of processing.

$$
\text { 9:15-9:35 (19) }
$$

Frequency Effects and the Nature of the Perceptual Unit in Word Recognition. LARRY G. RICHARDS, University of Virginia-Details of word frequency effects found in several types of experimental tasks are reviewed. Situations in which frequency "helps" performance are distinguished from those in which it "hurts" performance. The asymptotes in the functions relating to both reaction times and recognition thresholds are discussed. Theoretical principles are presented which account for these findings.

\section{9:35-9:55 (20)}

Mental Rotation and the Invariance of Spatial Relations. HOWARD S. HOCK \& CHERYL TROMLEY, Florida Atlantic University-Using Cooper and Shepard's (1973) mental rotation paradigm, reaction time was nonlinearly related to amount of letter disorientation for rectilinear letters, but was linearly related to distorientation for circular letters. The results support the hypothesis that nonlinearity results from mental rotation being required only at disorientations that alter spatial relations within a letter.

$$
\text { 9:55-10:10 (21) }
$$

The Use of Visual and Phonetic Information in the Analysis of Letter Strings: An Experiment with Artificial Letters. MARTIN H. SINGER, University of Denver, \& JOSEPH S. LAPPIN, Vanderbilt University-Two experiments investigated a word/ nonword discrimination task where artificial letters composed all stimuli. When artificial letters represented probable sequences of English letters, they were more quickly and accurately identified as words than artificially represented, improbable, English letter sequences. This was true even when subjects were not given phonetic information. This result suggests that visual structure alone facilitates word identification.

$$
\text { 10:10-10:25 (22) }
$$

Harmonic Structure and Hemispheric Specialization for Musical Tones. JOHN J. SIDTIS, SUNY at Stony Brook (sponsored by Sally P. Springer)-Tonal stimuli varying in complexity from sinusoidal to square waves were played to right-handed subjects. Response times in a dichotic probe task indicate that left-ear advantages increase as a direct function of the number of overtones. The results are discussed in terms of right-hemisphere specialization for musical stimuli.

\section{BREAK-10:25-10:35}

\section{0:35-10:45 (23)}

Signal Detection and Duration Judgment as Indicators of Early Visual Processes: $d^{\prime}$ and $z^{\prime}$. LLOYD L. AVANT, THOMAS $\mathbf{W}$ BARTSCH, \& ALICE T. WOODS, Iowa State University-Subjects participated in a duration judgment task and a signal detection task. Stimuli for both tasks were degraded and masked letter, word, and nonword arrays presented for one-half of each subject's recognition threshold. $d^{\prime}$ showed a sensory distinction between the single letter and the two larger equal-sized arrays, while $\mathrm{z}^{\prime}$ from the duration judgment task showed a cognitive distinction between the letter, word, and nonword. $\beta$ was not systematically related to 
stimulus type. Cluster analysis showed greater commonality for the processes indexed by $z^{\prime}$ than for those indexed by $d^{\prime}$ or $\beta$. 10:45-11:00 (24)

Inhibitory Interactions in the Visual Recognition of Identity. ELIZABETH LIGON BJORK, $U C L A$-Subjects were asked to judge whether brief multielement visual displays did or did not contain two identical letters. Their identity-detection performance was worse than one would predict on the basis of their independently measured full-report performance. The results are discussed in terms of the relative contributions of processes at perceptual and decision levels.

11:00-11:15 (25)

Simultaneous vs. Successive Presentation of Visual Arrays Revisited. WILLIAM PRINZMETAL, Claremont Graduate School, \& WILLIAM P. BANKS, Pomona College and the Claremont Graduate School-Simultaneous presentation of elements in an array for visual detection of a target was compared with successive presentation of the elements in order to test for effects of Gestalt-like organizational properties of the array on processing. Variables which determine the relative advantage of successive over simultaneous presentation, and some of their implications, are discussed.

\section{1:15-11:30 (26)}

Control Processes, Structural Features, and the Word Superiority Effect. DEAN G. PURCELL, KEITH STANOVICH, Oakland University, \& AMOS SPECTOR, Unit of Military Psychology, Israel's Defense Forces (read by K. E. Stanovich)-The word superiority effect was obtained with a fixed set of alternatives, positional certainty, mixed words and nonwords, and instructions to fixate the critical letter. The effect was not obtained when the visual angle of the stimulus was increased. These results suggest that the visual angle of the stimulus display is a crucial factor in experiments on the word superiority effect.

$$
\text { 11:30-11:45 (27) }
$$

Perceptual Interactions Between Implosive and Explosive Formant Transitions of Intervocalic Stop Consonants. BRUNO $\mathrm{H}$. REPP, Haskins Laboratories-Intervocalic stop consonants provide an extreme example of temporally distributed information in speech: The spectral cues for place of articulation are separated by a period of silence (closure). To perceive all this information as a single phoneme, an integrative perceptual process ("coperception') is required. Several experiments were conducted to investigate the temporal limits of this coperception and to demonstrate how the spectral cues preceding the silent closure interval affect the perception of the information following it, and vice versa.

\section{1:45-11:55 (28)}

Judgments of Numerosity: Developmental Changes in the Integration of Length and Density. DIANE O. CUNEO \& NORMAN H. ANDERSON, University of California, San Diego-A judgment of numerosity of a linear array can be conceptualized in terms of the integration of two spatial cues: the length and the density of the array. Numerosity judgments were obtained from 3-, 4-, 5-, 6-, 7-, 9-year-olds, and adults. Functional measurement analysis showed that the two cues were integrated by simple algebraic models. Younger children obeyed an adding model, in line with previous results. The normative, multiplicative model emerged gradually with increasing age.

\section{1:55-12:10 (29)}

The Effects of Stimulus and Response Structure on Pattern Perception. RICHARD E. CHRIST, New Mexico State University-Subjects were required to organize and identify temporally repeating six-element visual patterns using different procedures for description. The speed of identification, the error rate, and the subjective organization of the patterns were analyzed as a function of structural properties of the pattern and response mode.

$$
\text { 12:10-12:25 (30) }
$$

Figural Characteristics in Visual Masking. JOSEPH B. HELLIGE, DAVID A. WALSH, VIRGINIA LAWRENCE, \& MICHAEL PRASSE, University of Southern California-Figural relationships between target and mask are shown to influence the amount of masking differently at different stimulus onset asynchronies. Effects attributable to luminance summation occur in both forward and backward masking. Figural relationship effects that cannot be attributed to luminance summation occur only in backward masking, suggesting a feature-specific interruption of target processing.

\section{2:25-12:30 (31)}

(Read by title only)

The Whole Work Fixation Effect is Partly a Whole Response Presentation Effect. DONALD A. SCHUMSKY, GWEN P. BRISCOE, JOEL S. WARM, \& RONALD SPRAGUE, University of Cincinnati-Two experiments were conducted to further evaluate the "whole-word fixation effect" (Johnston \& McClelland, 1974). In Experiment 1, subjects were asked to identify letters from word, pseudo-word, and letter-string stimuli presented over a range of fixed exposure intervals. With word and pseudo-word stimuli, identification was better fixating "whole" stimuli than "letter position." The opposite was true with letter strings. Experiment 2 was a replication of the design of Experiment 1 except that the response alternatives were the critical letter and a foil. In Experiment 1 and in Johnston and McClelland's experiment, response alternatives were whole stimuli. The interaction of stimulus type and fixation condition disappeared.

\section{2:30-12:35 (32)}

(Read by title only)

Semantic Categories: On the Nature of the Internal Code. LINDA S. SALA, University of Colorado (sponsored by I. E. Bourne, Jr.)-Whether the internal representations of superordinate categories are prototypes or more abstract schematic codes was investigated using a variation of Rosch's (1975) priming paradigm. Preliminary results show that the internal code activated by the prototype is not synonymous with that activated by the category name (category names facilitate more than do prototype pictures or names).

\section{2:35-12:45 (33)}

Memory for Simple Visual Patterns. JAMES P. CUNNINGHAM, Cornell University (sponsored by L. A. Cooper)-The way in which simple visual patterns are represented in memory is investigated with three tasks: reproduction, goodness ratings of parts, and the recognition of parts of patterns. The results are analyzed in terms of a theory which assumes that the memory representation of a visual pattern is a tree structure.

\section{ATTENTION AND VIGILANCE \\ E. Bruce Goldstein, University of Pittsburgh \\ Club Room A, Thursday morning, 8:30-10:35}

\section{8:30-8:45 (34)}

Selective Preparation: A Comparison of Cues and Predictions. ENRIQUE ACOSTA, JR., University of Oklahoma (sponsored by J. V. Hinrichs)-Two priming procedures (cues and predictions) for investigating selective preparation were compared in a twochoice RT task. The bases for comparison were: (a) their time course ( $0-4 \mathrm{sec})$, and (b) their relative facilitation and interference components. The time course of preparation for predictions and cues were similar. Equal amounts of facilitation and interference were produced by predictions except at the 0 -sec ISI, where interference exceeded facilitation. Cues produced only interference.

\section{8:45-9:05 (35)}

Response Processes in the Psychophysical Repetition Effect. ROBERT E. HICKS \& DEBORAH A. ALLEN, SUNY at Albany (read by D. A. Allen)-Magnitude estimations increase and magnitude productions decrease across blocks of trials. Using judgments of temporal duration and visual extent, a series of experiments were performed in which various response manipulations failed to effect this repetition effect. For example, conservative vs. liberal response instructions altered judgments, but did so invariantly over blocks of trials. 
9:05-9:15 (36)

How Does the Attentive Field Change with Target Size? ALEXANDER W. PRESSEY \& VINCENT Di LOLLO, University of Manitoba-Reliable changes in the patterns of results were found as the distance between the standard and comparison lines increased in the Mueller-Lyer configuration. The mathematical formula derived from assimilation theory was applied to the data, and excellent fits were obtained under the assumption that the attentive field is a constant ratio of target size.

$$
\text { 9:15-9:35 (37) }
$$

Is Encoding Really Effortless? HOWARD E. EGETH, JAMES R. POMERANTZ, \& STEVEN P. SHWARTZ, Johns Hopkins University-An additive-factors experiment requiring simultaneous performance of a primary (memory) and a secondary (perceptual) task indicated that none of three stages of the perceptual task (encoding, decision, or response selection) require processing capacity. This surprising result forces reconsideration of the logic of using spare capacity as a measure of attentional demands. 9:35-9:50 (38)

Monitoring Attention Deployment by Random Number Generation. FREDERICK J. EVANS, Institute of Pennsylvania Hospital, University of Pennsylvania-An index of randomness, based on 100 consecutive numbers, provides a sensitive measure of changes in the deployment of attentive effort. Thus, randomization deteriorates significantly during the acquisition of a two-hand coordination task, returning to baseline as mastery and overlearning is achieved $(\mathrm{N}=11)$. Related validation studies will be described briefly.

\section{9:50-10:05 (39)}

Meditation and Sustained Attention. JOEL S. WARM, WILLIAM SEEMAN, LESLIE H. BEAN, NEEOO CHIN, \& NOREEN F. WESSLING, University of Cincinnati-The claim that meditation training enhances attentiveness was assessed in a visual vigilance task. Twenty critical signals were presented in a 1-h session. Subjects experienced in Transcendental Meditation detected more signals, with no higher false alarm rates, than did novice meditators or those without meditation experience. This result was independent of background event rate ( 6 or 21 neutral events $/ \mathrm{min}$ ) and time on task.

\section{0:05-10:20 (40)}

Effects of Channel Predictability on Tone Identification. CAROL B. MILLS, Gallaudet College, DAVID L. HORTON, \& MICHELE KELLY, University of Maryland-The final tone (target) of a series of sine and square waves was better identified when all tones were presented to one ear than when they alternated unpredictably between ears. Targets were better identified in unpredictable sequences when preceding tones occurred in the same ear. These effects were greater for 25 - than 60 -csec intertone intervals. 10:20-10:35 (41)

Auditory Evoked Responses to Selectively Attended Speech. RANDALL L. LEMOINE, New Orleans Public Schools, JAMES G. MAY, \& ROBERT J. PORTER, JR., Kresge Hearing Research Laboratory of the South, LSU Medical Center (read by J. G. May) - Twelve subjects heard a sequence of speech sounds- $/ \mathrm{ba} /$, $/ \mathrm{da} /, / \mathrm{ga} /$-occurring randomly at each ear at short, random ISIs. Reaction time and AEPs (electrodes $\mathrm{C} 3$ and $\mathrm{C} 4$ ) were recorded to target stimuli while subjects attended: (a) the left ear, (b) the right ear, (c) both ears, or (d) neither ear. The latencies of N1 and P3 components revealed a small, but significant, asymmetry in the effects of selective attention by hemisphere and by ear, respectively; only latencies of the left-ear and right-hemisphere AEPs varied when selective attention was shifted from one ear to the other.

PERFORMANCE AND REACTION TIME

\section{N. John Castellan, Jr., Indiana University, Bloomington}

Club Room A, Thursday morning, 10:50-12:25

10:50-11:10 (42)

Blocked or Random Stimulus-Onset Delays: Effect on Fixation Duration in Visual Search. JONATHAN VAUGHAN, Hamilton
College-Exposure of the stimulus was delayed after each saccade in a simple visual search task using single-letter stimuli. Blocks of constant delays produced more nearly optimal fixation durations than randomly ordered delays. Thus, long-term strategies appear to contribute to the control of fixation durations in search.

\section{1:10-11:25 (43)}

Timing of Motor Responses. STUART T. KLAPP, California State University, Hayward-Reaction time prior to a motor response has been shown to depend on the nature of the response to follow when decision processes are controlled. The data to be presented suggest that this effect is attributed to advance establishment of control of response timing. Theories of timing which are consistent with this conclusion are discussed.

\section{1:25-11:40 (44)}

The Stimulus-Response Compatibility Effect Reconsidered. BILL COTTON \& OVID J. L. TZENG, University of California, Riverside-The stimulus-response compatibility effect was studied in a series of experiments in which subjects employed one hand to indicate the position of a visual onset. Differential patterns of response latencies associated with the various stimulus positions were found that could not be accounted for by current explanations of stimulus-response compatibility effect. An alternative model is considered.

\section{1:40-11:55 (45)}

How Experts Dictate. JOHN D. GOULD, IBM-It is commonly assumed that with extensive practice people dictate much faster than they write. To test this, novice and highly experienced (expert) dictators were given letters of various complexities to write or dictate. Results showed that the experts dictated $20 \%-65 \%$ faster than they wrote, but not the $500 \%$ faster that could be expected from potential rate differences in output modalities. Comparisons with the control group and separate analyses of generation, pause, and review times provide fundamental understanding of these composition methods.

\section{1:55-12:05 (46)}

Effects of Letter Pair Spatial Arrangement on Same-Different Judgments. JOHN R. MILLSPAUGH, Iowa State University (sponsored by Mildred Mason)-Same-different judgments of simultaneously presented letter pairs can be greatly affected by the spatial arrangement of the letters. Horizontally adjacent pairs exhibit faster "same" responses than "different" responses, while for diagonally offset pairs the opposite is true. This previously overlooked variable of letter spatial arrangement is shown to be a powerful determinant of performance in the same-different paradigm.

\section{2:05-12:15 (47)}

Confusion Matrices and Cerebral Hemispheric Asymmetry. JOSEPH SCHMULLER, Clark University (sponsored by David A. Stevens)-Single-letter stimuli were tachistoscopically presented either left or right of a fixation point. Significantly more errors were found for right-hemisphere presentation (i.e., to the left of fixation). The confusion matrices for each hemisphere were analyzed. Results are consistent with a model which postulates information loss during interhemispheric transfer.

\section{2:15-12:25 (48)}

Programming Two-Handed Movements. J. A. SCOTT KELSO, DAN L. SOUTHARD, \& DAVID GOODMAN, University of Iowa-Response programming was examined in single and twohanded movements varying in index of difficulty (ID). Initiation time (RT) was assumed to reflect the complexity of programming operations involved. Paired movements took more time to program than single movements except when ID was small. Simultaneity of initiation was demonstrated across all paired movement conditions. Movement time (MT) was the same for one- and twohanded movements of identical IDs. For paired movements of different IDs, MTs approached simultaneity, indicating that duration was a major determiner of the motor program. 
PSYCHOPHARMACOLOGY

John R. MacKinnon, Connecticut College, New London Forum Room, Thursday morning, 8:30-12:15

\section{8:30-8:40 (49)}

Behavioral Changes in Rats Following Sodium Nitrite Treatment. LYNN M. TONDAT, NANCY L. SILVA, \& DONNA M. VIVEIROS, Southeastern Massachusetts University (sponsored by Peter Galvani)-Rats administered various concentrations of sodium nitrite were observed for behavioral changes. Increased trends in open field at lower concentrations and heightened aggression at all concentrations were found. On a DRL task, nitrite rats obtained significantly fewer reinforcements. One interpretation is nitrite's tendency to produce greater responding to distractible cues. 8:40-8:55 (50)

Adverse Effects of Paternal Alcohol Consumption on Offspring in the Rat. W. DEAN PFEIFER, Abraham Ribicoff Research Center and Connecticut College, JOHN R. MACKINNON, Connecticut College, \& RICHARD L. SEISER, Adelphi UniversityMale rats were maintained on an $8 \%$ alcohol solution for 100 days and then mated to nulliparous females. Litters sired by alcoholconsuming males had fewer pups than control litters, and only $78 \%$ of the pups survived to weaning compared to a $93 \%$ survival rate in controls. Subsequent testing indicated that female progeny are more sensitive to the effects of paternal alcohol consumption than males.

\section{8:55-9:15 (51)}

Televised and Quantitative Evidence Concerning the Topographical Solutions to Counting Schedules by Rats Under Carbon Monoxide Exposure. ROGER W. McINTIRE, University of Maryland-Topographical solutions to fixed counting schedules and fixed-ratio discrimination problems were illustrated in rapid 35-mm exposures and video tapes. IRT distributions, other temporal measures, and run lengths confirmed that some levels of carbon monoxide disrupted such performance. Recovery was observed when probes with reinforcement signals occurred late in $\mathrm{CO}$ sessions.

$$
\text { 9:15-9:25 (52) }
$$

The Effects of Six Psychoactive Compounds on Easy and Difficult Discriminations. ELKAN GAMZU \& BARRY POLSKY, Hoffman-La Roche, Inc.-Pigeons were trained in a trials discrimination procedure using a white vertical line $(\mathrm{S}+)$, a white cross ( $\mathrm{S}$ - difficult), and a green disk ( $\mathrm{S}$ - easy). Amitryptyline, amphetamine, chlordiazepoxide, chlorpromazine, imipramine, mianserin, and tranylcypromine all increased suppressed pecking in the difficult discrimination. However, only the tricyclic antidepressants affected the easy discrimination.

$$
\text { 9:25-9:35 (53) }
$$

Naloxone Attenuates Rats' Preference for Signaled Shock. MICHAEL S. FANSELOW \& ROBERT C. BOLLES, University of Washington (read by R. C. Bolles)-Rats received signaled shock while confined to one side of a shuttlebox and unsignaled shock while confined on the other side. Preference tests revealed that rats injected with the morphine antagonist naloxone during training showed no consistent preference, like controls with unsignaled shock on both sides. Saline controls preferred the signaled side. Results suggest mediation by an endogenous analgesic.

$$
\text { 9:35-9:55 (54) }
$$

Effects of Morphine, Naloxone, Cyclazocine, and Amphetamine on DRL-Maintained Responding. ROGER STRETCH, DYANE ADAM-CARRIERE, \& Z. MERALI, University of Ottawa-The acute effects of several drugs upon responding maintained by a DRL 20 -sec LH 10-sec schedule of food presentation in rats will be described. Naloxone, at otherwise inactive doses (1-10 $\mathrm{mg} / \mathrm{kg} \mathrm{IP),} \mathrm{antagonized} \mathrm{the} \mathrm{rate-decreasing} \mathrm{effects} \mathrm{of} \mathrm{morphine}$ and reduced the rate-increasing effects of $d$-amphetamine. Data concerning the effects of naloxone upon responding in morphinetolerant animals will also be presented.

\section{9:55-10:10 (55)}

Drug-Induced Dizziness as $\mathbf{S}+$ or $\mathbf{S}-$. RONALD K. SIEGEL, $U C L A-$ Most psychoactive drugs and toxins produce side effects of dizziness. Observations from drug studies with adults suggest that dizziness is an $\mathrm{S}$ - when accompanied by pallor, sweating, nausea, and vomiting. These symptoms appear to be triggered by disturbance in sensory input or motor control. When conditions leading to the disturbances are not controlled, dizziness is perceived as $\mathbf{S}+$. Infants and young children who are not susceptible to motion sickness interpret drug-induced dizziness as $\mathrm{S}+$. These observations support the hypothesis that dizziness can be a positively reinforcing altered state of consciousness.

$$
\text { BREAK-10:10-10:20 }
$$

\section{0:20-10:35 (56)}

Some Effects of Nicotine on Pain Sensitivity in the Rat. GARY G. BERNTSON \& TONY SAHLEY, Ohio State UniversityNicotine $(0.16-0.50 \mathrm{mg} / \mathrm{kg})$ greatly reduced pain sensitivity to thermal stimuli in the rat, as measured by the tail-flick test and the hotplate test. Pain sensitivity to footshock or tail pinch was not reduced. Additional tests indicated that the nicotine effect on pain sensitivity was, at least in part, mediated by central nicotinic and muscarinic receptors. These results, together with the previously reported reduction in visceral pain following nicotine administration, raise the possibility that specific alterations in pain sensitivity or aversive motivation may contribute to the self-administration of nicotine.

$$
\text { 10:35-10:50 (57) }
$$

Blood Ethanol Levels and Caloric Intake in the Gravid Rat as a Function of Diurnal Period, Trimester, and Diet. JOAN MARTIN \& DONALD C. MARTIN, University of Washington-Blood ethanol levels, caloric intake, and weight gain were monitored over the 21-day gestational period in the gravid Sprague Dawley rat as a function of ethanol administration in either a liquid diet (Ensure) or a $0.1 \%$ sodium saccharin solution. The mean daily total caloric intake, percentage of ethanol consumed, and $\mathrm{g} / \mathrm{kg}$ of ethanol consumed were significantly higher for the liquid diet group. Ethanol consumption varied by the trimester for the Ensure, but not for the saccharin solution, rats. Both groups exhibited significant diurnal periodicity in ethanol consumption and the greatest caloric intake during the second trimester. Proportional maternal weight gain, live litter size, and live litter weight did not vary as a function of treatment

10:50-11:05 (58)

Addictive Agents and Intracranial Reinforcement: III. LARRY D. REID, MICHAEL A. BOZARTH, \& JUDITH E. GORMAN, Rensselaer Polytechnic Institute-At previous meetings, we have summarized our research concerning the effects of various addictive agents on pressing for intracranial stimulation (ICS). This presentation summarizes recent work with ICS and several drugs (e.g., pentazocine and naloxone) as well as data regarding voluntary consumption of sweetened morphine solutions.

$$
\text { 11:05-11:20 (59) }
$$

Morphine and Tonic Immobility: Nonnarcotic Effects. LARRY B. WALLNAU \& GORDON G. GALLUP, JR., SUNY at Albany -A single systemic injection of morphine $(1 \mathrm{mg} / \mathrm{kg})$ greatly potentiates the duration of tonic immobility in chickens. Naloxone, a powerful narcotic antagonist, has no effect on tonic immobility and completely fails to block the morphine potentiation. Thus the morphine effect may not be mediated by an opiate receptor system or by morphinomimetic substances endogenous to the brain.

$$
\text { 11:20-11:30 (60) }
$$

Enhancement of Discrimination Learning by Methylphenidate. GEORGE W. HANDLEY, Ohio State University, \& WILLIAM CALHOUN, University of Tennessee-Rats were trained in a serial discrimination reversal procedure until successive acquisitions had stabilized. Drug treatments consisting of saline or $.25,1.0$, 
$2.0,4.0,6.0$, or $8.0 \mathrm{mg} / \mathrm{kg}$ of methylphenidate were then administered 20 min prior to daily training sessions. Acquisition of the discrimination was enhanced by low doses $(1,2$, and $4 \mathrm{mg} / \mathrm{kg})$ and attenuated by higher doses $(6$ and $8 \mathrm{mg} / \mathrm{kg})$.

\section{1:30-11:40 (61)}

REM Sleep Deprivation and Subsequent Thermoregulatory Deficits in Mice. PAUL W. BISHOP \& JAAK PANKSEPP, Bowling Green State University - Brain biogenic amines have been established as important mediators of both sleep states and thermoregulation. A proposed function for REM sleep has been catecholamine replenishment. Present findings indicate that REMdeprived mice show a marked thermoregulatory deficit in response to cold stress. Various pharmacologic manipulations, however, did not indicate that this thermoregulatory impairment was mediated by a REM-deprivation-induced catecholamine deficit.

11:40-12:00 (62)

Movement Induced in Cataleptic Rats: Differential Effects Produced by Electrical Stimulation of the Lateral Hypothalamus, Substantia Nigra, and Reticular Formation. G. ANDREW MICKLEY \& HERMAN TEITELBAUM, Armed Forces Radiobiology Research Institute-Haloperidol catalepsy can be overcome by electrical stimulation of the lateral hypothalamus and, to a lesser extent, the substantia nigra. Stimulation of the reticular formation often induced movement in cataleptic rats. However, some sites (which supported activity in the undrugged rat) evoked little or no locomotion in spite of the presence of an activated cortical EEG.

\section{2:00-12:15 (63)}

Fenfloramine-Induced Anorexia. BARBARA STRUPP \& DAVID A. LEVITSKY, Cornell University-Rats were intubated with $20 \mathrm{mg} / \mathrm{kg}$ of Fenfloramine daily. Food intake showed an initial depression, then recovered in approximately 1 week. Body weight, however, remained depressed. The anorexia was reestablished when body weight was forced up by intubation of food.

\section{ANIMAL CONDITIONING \\ Kenneth B. Melvin, University of Alabama, University Diplomat Room, Thursday morning, 8:30-12:30}

\section{8:30-8:45 (64)}

Latent Inhibition with Sequentially Preexposed Stimuli. GARY A. SZAKMARY, Case Western Reserve University (sponsored by Stephen K. Reed)-The sequential preexposure of two CSs results in attenuated latent inhibition of the first (target) stimulus. This effect is a U-shaped function of the number of preexposures, and it occurs whether or not the target CS remains in compound during the conditioning test.

\section{8:45-8:55 (65)}

The Occurrence of Motor and Secretory Behaviors During Classical Appetitive Conditioning. EDWARD A. WASSERMAN, University of Iowa-Three hungry dogs received pairings of an accessible, illuminated panel with food. This resulted in the dogs' approaching the lighted panel and salivating. Unlike most research in autoshaping, however, the dogs never contacted the visual conditioned stimulus.

\section{8:55-9:10 (66)}

Psychophysics of Associations Between Neutral and Biologically Relevant Events. MARK RILLING \& R. C. HOWARD, Michigan State University-Pigeons were reinforced for pecking a white key when white was preceded by both food and a green key light. Otherwise, white produced extinction. Food was presented in a forward and backward conditioning relationship to the green key light. Food dominated stimulus control during test trials when food and green were presented in all possible permutations.

$$
\text { 9:10-9:25 (67) }
$$

Effects of Context and Stimulus Parameters on Autoshaping. F. G. OBERDIECK \& C. D. CHENEY, Utah State UniversityThree studies examined the role of ITI durations, magazine training context, and CS intensity on autoshaping in a dark chamber.
Performance was superior with a 60-sec VT ITI (vs. 25-sec VT ITI). Regardless of ITI duration, performance was best if magazine training occurred with the houselight on (vs. houselight off). With a bright CS, little autopecking emerged. Results are related to a context-blocking effect and to the cue localization hypothesis.

$$
\text { 9:25-9:45 (68) }
$$

Some Orderly Nonmonotonicities in the Trial-by-Trial Acquisition of Conditioned Suppression. JOHN J. B. AYRES, PAUL GROSS, ELIZABETH A. KOHLER, WILLIAM J. MAHONEY, \& SANDRA STONE, University of Massachusetts-Acquisition of conditioned suppression was examined under a wide range of conditions using 288 male albino rats. A persistent finding in conditions with four or more trials per session was that, once established, suppression tended to be significantly stronger on the first trial of a session than on one or more subsequent trials.

$$
\text { 9:45-10:00 (69) }
$$

"Salience" in Conditioned Taste Aversions: Role of Primary Memory. LEWIS M. BARKER, Baylor University-In trace conditioning experiments, rats learned sucrose aversions at 2-but not 4-h CS-US intervals. Coffee and saccharin solutions were effective CSs at 4- but not 8-h intervals, and aversions to cheese were learned at all intervals up through $8 \mathrm{~h}$. It is hypothesized that gustatory salience can be attributed to limitations of primary memory for certain flavors in a manner analogous to the primary memory limitations for exteroceptive events.

10:00-10:10 (70)

Strength of Illness-Induced Taste Aversion as a Function of Drug Dose and Phase of the Illumination Cycle. ROBERT $\mathrm{N}$. INFURNA, PAM STEINERT, \& JON FREDA, SUNY at Binghamton-Adult rats tested during the light phase (LP) displayed a stronger taste aversion when given a high dose $(3.0 \mathrm{mEq})$ of $\mathrm{LiCl}$ during conditioning than those treated during the dark phase (DP) of their illumination cycle. Significant, but milder, taste aversions were also demonstrated by LP animals given a low dose $(.36 \mathrm{mEq})$ of $\mathrm{LiCl}$ during conditioning but were not evidenced by a comparable group of DP animals. In extending prior research, the findings suggest that the effect of a $\mathrm{LiCl}$ dosage in taste aversion interacts with a circadian susceptibility rhythm.

\section{0:10-10:20 (71)}

Contextual Determinants of Conditioned Suppression. MARK E. BOUTON \& ROBERT C. BOLLES, University of Washington (read by R. C. Bolles)-Rats were fear conditioned in one context and subsequently given CS-alone trials in a second context until suppression extinguished. Upon return to the original context, these animals suppressed significantly more than a group given the same number of extinction trials in the original context, and as much as unextinguished controls.

$$
\text { BREAK-10:20-10:30 }
$$

\section{0:30-10:45 (72)}

The Effect of Food Duration on "Food-Avoidance" Behavior. DAVID LOPATTO, EDWARD T. GARDNER, PAUL LEWIS, \& RUSS WEAVER, Ohio University-After shaping, four pigeons were presented with a 4-sec auditory signal on the average of every $100 \mathrm{sec}$. A peck during the signal canceled the availability of response-contingent food $1.0 \mathrm{sec}$ after the signal. The pigeons pecked during the signal at high rates, and manipulations in quantity of food had no systematic effect on this "food-avoidance" behavior.

$$
\text { 10:45-11:00 (73) }
$$

Classical Conditioning of Cardiac Rate and Blood Pressure in Macaca mulatta. RONALD M. KADDEN, F.D.R. V.A. Hospital \& WILLIAM N. SCHOENFELD, Queens College of the CUNYA study is presented on simultaneously recorded heart rate and blood pressure responses in 16 rhesus monkeys during classical conditioning with a visual CS, electric shock US, and a 20 -sec CS-US interval. Group and individual data are offered, comparing the relative response magnitudes and rates of acquisition in the 
two response systems. Several aspects of the findings are relevant to the role of baroreceptors in mediating between the two systems.

$$
\text { 11:00-11:20 (74) }
$$

Drug-Drug Associations: Procedure Designed for Higher-Order Conditioning Produces Opposite Results. SAM REVUSKY, HARALD K. TAUKULIS, Memorial University of Newfoundland, \& LINDA A. PARKER, University of New Brunswick-On four or five occasions, a CS drug loses its capability of producing learned flavor aversions. When the US is lithium, this effect is obtained with CSs of amphetamine, chlordiazepoxide, ethanol, or pentobarbital; it also is obtained with an amphetamine US (very high dose) and a pentobarbital CS.

\section{1:20-11:35 (75)}

Chlordiazepoxide-Induced Attenuation of Food Aversions: Dipsogenic or Disinhibitory Effects? ANTHONY L. RILEY, American University, \& RICHARD H. LOVELY, University of Washington-Chlordiazepoxide attenuated food aversions if given prior to a one-bottle aversion test but had no effect if given prior to a two-bottle choice between water and the previously poisoned solution, suggesting that the attenuation resulted from chlordiazepoxide's dipsogenic effect, independent of its reported disinhibitory effect on suppressed behavior.

\section{1:35-11:50 (76)}

Classical Conditioning of the Rabbit Nictitating Membrane Response with Posttrial Electrical Stimulation of the Brain. W. RONALD SALAFIA, RICHARD W. LAMBERT, NICOLAS L. CHIAIA, JULIO J. RAMIREZ, \& KAREN A. SHANNON, Fairfield University-Results of several recent investigations employing a number of variations of stimulation intensity, posttrial delay, and anatomical locus of application are reported. Findings were: (1) subseizure stimulation of hippocampus is at least as effective as seizure-producing stimulation in disrupting NMR conditioning; (2) effects vary with posttrial delay; and (3) bilateral, but not unilateral, stimulation of amygdala also causes massive disruption.

$$
\text { 11:50-12:10 (77) }
$$

The Mechanism of the UCS Preexposure Effect. RILEY E. HINSON \& SHEPARD SIEGEL, McMaster University-Results of two rabbit eyelid conditioning experiments indicated that the deleterious effect of preconditioning experience with the UCS on $\mathrm{CR}$ acquisition is attributable to an association between the preexposed UCS and static background cues. The UCS preexposure effect was (a) specific to the conditioning environment, and (b) extinguishable prior to CS-UCS pairings.

$$
\text { 12:10-12:30 (78) }
$$

Brightness Contrast as a Configural Dimension for Discriminations by Pigeons. HECTOR C. SANTIAGO \& ANTHONY A. WRIGHT, University of Texas, Houston-Pigeons trained to discriminate colors and line orientations were tested in extinction with lines over colored backgrounds of different luminances and with lines over white backgrounds of different luminances. The tests showed that brightness contrast was the controlling dimension. The results are relevant to the issues of additivity of cues and stimulus control by the components of a visual stimulus.

\section{AVOIDANCE LEARNING \\ Robert J. Blanchard, University of Hawaii Tudor Room, Thursday morning, 8:30-11:15}

\section{8:30-8:45 (79)}

Inhibition of Avoidance Behavior During a Backward CS - and After a CS + for Shock. JOSEPH D. LaBARBERA \& WILLIAM F. CAUL, Vanderbilt University-The opponent-process theory assumes that a pleasurable reaction can follow termination of an aversive event. This study demonstrated that the presence of a backward CS - for shock, as well as the termination of a CS +, can inhibit unsignaled avoidance in rats, thus yielding a paradigm useful in testing alternative theoretical accounts.

\section{8:45-8:55 (80)}

Opponent-Process v. Safety Factors in Inhibition of Avoidance Behavior. WILLIAM F. CAUL \& JOSEPH D. LaBARBERA, Vanderbilt University-This experiment evaluated an opponentprocess view of the data in the previous study by eliminating potential safety-signal aspects of the two situations. The results for the backward CS group suggested the presence postshock of a nonassociative, fear-inhibitory process, consistent with the opponentprocess model.

\section{8:55-9:10 (81)}

The Effect of Brief Stimuli Preceding the Availability of Safety. EDWARD T. GARDNER, DAVID LOPATTO, PAUL LEWIS, \& MARY HAYES, Ohio University-Traditional accounts of avoidance focus on the role of a CS preceding an aversive stimulus. This study examined the role of a 4-sec stimulus preceding the availability of a safe period. Six rats barpressed at high rates during the 4-sec stimulus. Response rate during the stimulus decreased but did not stop when barpressing during the signal cancelled the availability of reinforcement.

$$
\text { 9:10-9:30 (82) }
$$

Variations in Current Type, Topograpy, and Intensity of Inescapable Shock Treatments: Effects on Two-Way, Discriminated Shuttlebox Escape/Avoidance Learning. J. VICTOR LUPO, D. CHRIS ANDERSON, \& CHARLES CROWELL, University of Notre Dame (read by D. C. Anderson)-Inescapable pulsed and continuous shocks factorially were crossed with 1-, 2.8-, and 4-mA $(\mathrm{rms})$ ac shock treatment intensities in Experiment 1, and with 1.4-, 4-, and 6-mA treatment intensities in Experiment 2. (No-shock controls were included for total of 132 restrained rats.) Magnitude of interference in two-way shuttle learning was: (1) a positive function of shock intensity, regardless of current type or topography, and (2) a positive function of amount of body movement recorded during ac, but not systematically related to movement recorded during the various de treatments.

\section{9:30-9:40 (83)}

Instrumental Avoidance Conditioning of Leg Extension in Spinal Rat. A. A. 'BUERGER \& BRIMMER SHERMAN, University of California-We have previously shown that spinal vertebrates are able to acquire and retain an instrumental avoidance task when flexion of a hindleg is the operant response. (See Adv. in Psychobiology, 1977, 11, 437-461, for review.) We will present controlled evidence indicating that spinal rats are capable of instrumental avoidance conditioning when extension is the operant response.

\section{9:40-9:50 (84)}

The Effects of Shock Intensity on Shuttlebox Avoidance Responding to Differentiated and Undifferentiated Background Cues. DONALD J. LEVIS, SUNY at Binghamton, \& THOMAS L. BOYD, Lafayette Clinic, Detroit-Previous work with shuttlebox avoidance tasks has found an inverse relationship between shock intensity and shuttlebox performance. The present study was an attempt to alter this effect by manipulating shock intensity and background apparatus cues. Three levels of shock $(0.5,1.0$, and $2.0 \mathrm{~mA}$ ) were tested at two levels of apparatus differentiation (high and low). Both shock level and apparatus manipulations reliably altered shuttlebox performance. Results were consistent with a fear interpretation.

\section{9:50-10:10 (85)}

The Role of Blocking and Opponent Processes in the US Preexposure Effect in Taste Aversion Learning. NORMAN S. BRAVEMAN, Memorial University of Newfoundland-Preexposure to a drug in the same environment in which that drug was administered following consumption of a novel saccharin solution disrupted the conditioning of taste aversions. When, however, preexposure occurred in an environment that differed from the training environment, no signs of disruption were observed. Additional experiments indicated that the cues which characterized the preexposure and training environments could be latently inhibited and that neophobia was also disrupted when rats were injected with an 
aversion-inducing drug prior to the test for neophobia in the same environment.

$$
\text { BREAK-10:10-10:30 }
$$

10:30-10:50 (86)

Avoidance of Higher Intensity Shock in the Absence of a Contingency Between Responding and Shock Occurrence. PHILIP J. BERSH, Temple University, \& LAUREN B. ALLOY, University of Pennsylvania-Rats were exposed to random shocks at an average rate of $1 / 6.5 \mathrm{sec}$. Leverpresses with an interresponse time (IRT) of $15 \mathrm{sec}$ or less resulted in $0.75-\mathrm{mA}$ shocks; IRTs greater than $15 \mathrm{sec}$ led to 1.6-mA shocks. The IRT limit was progressively reduced to $3 \mathrm{sec}$. Response rate varied inversely with the IRT limit. For two animals, exposure to high shock constituted less than $6 \%$ of session length $(100 \mathrm{~min})$ until the IRT limit was reduced to $3 \mathrm{sec}$.

\section{0:50-11:05 (87)}

Genetic and Endocrine Factors in Avoidance Learning. F. ROBERT BRUSH, Syracuse University, P. C. SAKELLARIS, University of Oregon Dental School, \& J. C. FROEHLICH, Syracuse University-Long-Evans rats were selectively bred for good and poor shuttlebox avoidance learning for 25 and 21 generations, respectively. Estimates of heritability are reported. Performance of the lines in other situations are compared, and correlated differences in pituitary-adrenal function are described.

\section{1:05-11:15 (88)}

Paradoxical Alleviation of Forgetting. GREGORY J. SMITH, NORMAN E. SPEAR, \& SALVADOR DeSTEFANO, SUNY at Binghamton-Rats receiving active avoidance training were put on a 7-, 14-, or 28-day retention interval. Rats that barpressed for food during the retention interval showed better retention of the active avoidance than rats given only equivalent handling and food deprivation or rats given equivalent barpressing experience without exposure to the avoidance contingencies.

\section{PERCEPTION I}

Daniel J. Weintraub, Human Performance Center, Ann Arbor Empire Room, Thursday afternoon, 1:00-5:05

\section{1:00-1:15 (89)}

Visual Search for Embedded and Nonembedded Targets in Pictures. C. F. NODINE \& D. P. CARMODY, Temple UniversityDo eye movements differ when an observer is searching for an embedded vs. a nonembedded target? This question was generated by our interest in whether eye movements lead or follow detection of the target. Can some eye-movement parameters such as fixation duration and saccadic displacement differentially predict detection of targets in two types of backgrounds?

$$
\text { 1:15-1:25 (90) }
$$

The Wundt-Hering Illusion with Moving Points. WALTER C. GOGEL, University of California, Santa Barbara-The WundtHering illusion was found to occur (although diminished in magnitude) when points moving in straight lines were substituted for the physically straight (but perceptually bowed) test lines usually used in this illusion. The implications of the results for explanations of this and perhaps other illusions are considered.

$$
\text { 1:25-1:40 (91) }
$$

Enhancement and Diminution of Simultaneous Brightness Contrast by Extended Practice. KENDON SMITH, REBECCA CRAIG McNEILL, \& KAREN AMICK CLARK, University of North Carolina, Greensboro-Two groups of nine observers made luminance equations under simultaneous brightness contrast, 15 sessions, 10 trials per session. Group 1 saw the result of each equation, Group 2 did not. Significant linear trends were exhibited by 15 of the 18 observers. Enhancement of contrast was more common $(n=12)$ than diminution $(n=3)$, which was confined to Group 1.
1:40-2:00 (92)

Order of Visual Processing: Top-Down, Bottom-Up, or MiddleOut? R. A. KINCHLA, Princeton University, \& J. WOLF, M.I.T. (sponsored by L. J. Kamin)-Visual processing has variously been described as "bottom-up" (details followed by more global forms) and "top-down" (the opposite). An experiment is reported which demonstrates that order of processing varies with visual angle. Components falling in an optimal spatial-frequency band are processed first with subsequent processing of both higher and lower frequencies. From a syntactical view of structure, this can be described as a "middle-out" process.

$$
\text { 2:00-2:15 (93) }
$$

Summation and Inhibition in Apparent Movement. JACOB BECK \& CHARLES SILVERSTEIN, University of OregonSummation and inhibition effects in a two-flash display are used to analyze the mechanisms underlying apparent movement. The paper will present a model to account for the relevant phenomena.

$$
\text { 2:15-2:25 (94) }
$$

Illusory Shifts in Perceived Orientation in Depth Dependent upon Motion and Texture Gradients. EUGENE R. WIST \& BEATRICE E. HUNT, Franklin \& Marshall College-A textured rotating disk viewed obliquely was found to perceptually reverse its orientation in depth under a variety of conditions, none of which were able to completely eliminate reversals. Changes in perceived size and speed of the texture elements during reversals consistent with constancy mechanisms involving perceived distance were observed.

$$
\text { 2:25-2:35 (95) }
$$

Subjective Contours in Three-Dimensional Objects. JOHN M. KENNEDY \& COLIN WARE, University of Toronto-Heretofore, flat graphic displays have been used to creat subjective contours. We have made a series of objects in which these contours cross empty three-dimensional space. Some of the objects emulate classic subjective contour figures, others are new. The objects have special advantages in research on subjective contours.

$$
\text { 2:35-2:50 (96) }
$$

Trajectories of Apparent Transformations. ROGER N. SHEPARD, Stanford University - The continuous rigid transformation perceived between two alternately presented views of the same object can be represented by a geodesic trajectory on a curved topological manifold. Breakdown of apparently rigid motion, for faster rates of alternation, corresponds to short-circuiting across a shorter path not on the manifold.

$$
\text { BREAK-2:50-3:00 }
$$

\section{(97 withdrawn)}

\section{3:00-3:15 (98)}

Are there Sex Differences in the Perception of Visual-Geometric Illusions? CLARE PORAC, STANLEY COREN, University of British Columbia, JOAN S. GIRGUS, Princeton University, \& MICKEY VERDE, University of Victoria-Experiment 1 investigated illusion magnitude in $\mathbf{4 5}$ classical illusions and their variants as a function of sex using a sample of 221 observers. Experiment 2 looked at illusion decrement and the ability to transfer decrement training from one figure to another. In all instances, there were no significant differences between the performance of the male and the female observers.

\section{3:15-3:30 (99)}

"Overadditivity" in Prism Adaptation with Single and Multiple Exposure Targets. GORDON M. REDDING, Illinois State University, \& BENJAMIN WALLACE, Western Illinois UniversityViewing through 20-D prisms, subjects engaged in $15 \mathrm{~min}$ of saggital pointing at a single, optically straight-ahead target or at three targets, located optically straight-ahead and $5^{\circ}$ to each side. Tests for visual shift (VS), proprioceptive shift (PS), and negative aftereffect (NA) revealed additivity (VS + PS $=$ NA) for multiple tar- 
gets, but "overadditivity" (VS + PS > NA) for the single target. Possible explanations of overadditivity are discussed.

$$
\text { 3:30-3:45 (100) }
$$

The Relative Nature of Proximity in the Grouping of Ambiguous Lines. BARBARA GILLAM, PAUL HUNDLEY, \& DANIEL McGRATH, SUNY College of Optometry-Two ambiguous lines change state in a more coordinated fashion if close together. However, a series of converging experiments established that the absolute proximity of the lines was unimportant. Separation relative to line length was the critical factor in determining grouping of the lines. This achieves perfect size constancy grouping wihout mediation by registered or perceived distance. Grouping showed no orientation constancy.

\section{3:45-4:00 (101)}

Induction of Orientation-Specific Colored Aftereffects with a Single-Colored Grating. KAREN G. FOREIT \& BRUCE AMBLER, University of Texas, Arlington-Exposure to a single color superimposed over a grating produces an orientation-specific negative afterimage which may persist $45 \mathrm{~min}$ after induction; the same color without the grating produces no afterimage, even $1 \mathrm{~min}$ later. Dichoptic induction with complementary colors and orthogonal orientations produces a McCullough-like effect under binocular viewing conditions.

\section{4:00-4:10(102)}

Motion Parallax Cues Improve Monocular and Binocular Equidistance Judgments. A. M. PRESTRUDE \& MARY DeCICCO, Virginia Polytechnic Institute \& State University-Equidistance judgments on the Howard-Dolman apparatus were made by 50 observers while viewing monocularly or binocularly with the head held stationary or with side-to-side movements. Motion parallax improved both monocular and binocular equidistance judgments. The results were reliable when retested after 2 weeks.

\section{4:10-4:20 (103)}

The Mueller-Lyer Illusion from Age 8 to Age 80. STANLEY COREN, University of British Columbia, CLARE PORAC, SHERRI GREEN, \& ISABELLE DAWSON, University of Victoria-The Mueller-Lyer illusion was assessed over the life-span. Experiment 1 separately measured the over and underestimation distortions in 688 observers aged 8 to 80 . Experiment 2 assessed rate of illusion decrement in 140 observers aged 15 to 85 . Almost all changes in static illusion magnitude had occurred prior to age 20. There were no age trends in rate of illusion decrement.

$$
\text { 4:20-4:35 (104) }
$$

Linkages Between Apparent Depth and Motion in Linear Flow Fields. JAMES FARBER \& ALAN McCONKIE, Cornell University (sponsored by Julian Hochberg)-Optical flow fields consisting of two sets of random dots moving with different velocities produce the impression of two planes separated in depth. The apparent motion of elements in these displays covaries with the direction of apparent depth. The phenomenon has implications for induced motion and kinetic depth effects.

$$
\text { 4:35-4:55 (105) }
$$

The Mathematical Structure of Gibson's Literal and Semiotic Perception. WILLIAM C. HOFFMAN, Oakland University-As shown by the author, Gibson's "literal" constancies can be formulated as invariances of certain Lie transformation groups acting over the visual manifold. Higher form vision and perception of texture and gradient then follow naturally as contact structures. Integration with other sensory modalities leads to the topological entity of fibre bundle, which in turn leads, via appropriate functorial maps, to higher "semiotic" conditions. Correlates in the CNS of these mathematical structures are adduced.

4:55-5:00 (106)

(Read by title only)

The Magnitude of Pattern-Contingent Color Aftereffects Predicted from Two-Dimensional Fourier Analysis. JAMES G. MAY, P. CASTELLANOS, G. AGAMY, University of New Orleans, \& HALSEY H. MATTESON, Tulane UniversityMcCollough effects were established with oblique magenta checker- boards and green gratings in various orientations. Aftereffect magnitude was measured using a color cancellation technique. At high spatial frequencies $(3.0 \mathrm{c} / \mathrm{d})$, largest color aftereffects occurred when major Fourier components of adapting stimuli were oriented at $45^{\circ}$ angles to one another, but at low spatial frequencies $(0.8 \mathrm{c} / \mathrm{d})$ the greatest effects occurred when the major Fourier components had the same orientation. The results are discussed in terms of mechanisms involved in spatial frequency analysis.

$$
\text { 5:00-5:05 (107) }
$$

(Read by title only)

Perception of Structure in Auditory Patterns. WENDY L. IDSON, University of Texas, Austin (sponsored by William Epstein)-A series of studies found that perception of an auditory pattern is based upon the relational structure of the pattern. Only when this higher-order structure is negated will the component tones be perceived individually. The results suggest that perception entails abstraction of the structure intrinsic to a pattern, rather than construction of the pattern from smaller independent units.

\section{INFORMATION PROCESSING II}

Lauren B. Resnick, University of Pittsburgh Palladian Room, Thursday afternoon, 1:00-5:35

\section{1:00-1:10(108)}

The Role of Conceptual Categories in Letter Detection: An Alphanumeric “Word" Superiority Effect. JOSHUA D. STALLER \& JOSEPH S. LAPPIN, Vanderbilt University-Subjects searched for consonant targets embedded in strings of consonants, consonants and vowels, or consonants and numbers. Detection was better in the consonant-vowell and consonant-number strings than in the consonant strings. Presumably subjects ruled out vowels and numbers as potential targets at an early stage of processing. This and some other demonstrations of the "word superiority effect" can be interpreted as a conceptual category phenomenon.

$$
\text { 1:10-1:30 (109) }
$$

Effects of Display Field on Visual Braille and Print Reading. ROBERT M. LAMBERT, Concordia University, \& THOMAS S. WALLSTEN, University of North Carolina, Chapel Hill-Subjects visually read standard printed paragraphs approximately 4,5 , or 6 times faster than they read comparable paragraphs written in braille, depending on whether they are allowed to see either 1,5 , or 15 characters during each single fixation. Some possible explanation and implications of these experimental results are considered. 1:30-1:45(110)

New Target-Mask Interaction Effects. JAMES K. HABINEK \& MARK S. MAYZNER, Loyola University, Chicago-To attempt to demonstrate complex interactive effects of target and mask geometry upon target recognition in a backward masking paradigm, six different simple geometric targets were masked by four differently shaped masking patterns (square, rounded, triangular, and random dot). Stimulus presentation, via a computercontrolled CRT, was either completely random (with respect to targets and masks) or blocked (with respect to masks). The resulting interactions indicate that care must be taken in the selection of masking stimuli for visual information processing experiments. 1:45-2:00 (111)

Redundancy Gains with Separable Stimuli: A Problem for the Integrality Concept. WAYNE P. SILVERMAN, $N$. Y. State Institute for Basic Research in Mental Retardation-Redundancy gains in constrained classification tasks usually occur only with integral stimuli, which must be processed holistically. Such gains were found with visually presented multiletter sequences, clearly separable stimuli that can be processed by dimensional analysis. Performance was not state limited, suggesting that the integral/separable distinction requires modification.

\section{2:00-2:15 (112)}

Connecting Two Vertices and Object Superiority. KEVIN BERBAUM, University of Iowa, \& NAOMI WEISSTEIN, SUNY at Buffalo-A line segment connecting two vertices was presented 
briefly before, simultaneously with, or after the vertices. Detection accuracy followed a different time course with a two-vertex context than with a single vertex. This difference resembles that for detection of a line segment embedded in an apparently threedimensional pattern vs. in a less coherent flat design (object superiority-Weisstein \& Harris, 1974; Williams \& Weisstein, 1976), suggesting that two connected vertices are sufficient to activate at least one of the mechanisms involved in object superiority.

$$
\text { 2:15-2:35 (113) }
$$

Partial Report Superiority, Rod Icons, and Nonvisual ShortTerm Memory. BARBARA SAKITT \& IRA APPELMAN, Stanford University-Subjects participated in a Sperling task. The independent variables included delay of report cue, dark vs. light background (duration of the rod icon), and whether or not subjects were required to retain a list of letters (memory load) while performing the Sperling task. The results indicate a relationship between partial report superiority, existence of the rod icon, and the nonvisual loads on short-term memory.

\section{2:35-2:45 (114)}

The Effect of Noise Grouping in Letter Detection. CAROL L. KRUMHANSL \& EWART A. C. THOMAS, Stanford University (sponsored by Roger N. Shepard)-In a letter detection task, performance depended more on noise grouping than on noise redundancy. This result suggests that the effect of noise redundancy may be related to similarity grouping. This hypothesis is further supported by the effects of target-noise similarity. The implications for models of letter identification are discussed.

$$
\text { BREAK-2:45-2:55 }
$$

\section{2:55-3:05 (115)}

The Role of Rods in Iconic Storage. EDWARD H. ADELSON, University of Michigan (sponsored by John Jonides)-Letters of one color against a background of another color were made discriminable only to cones, or only to rods, or to both. Under dark adaptation, rods were quite important in subjective persistence, but were of small importance in partial report performance. With light adaptation, rods played no role in either type of persistence. 3:05-3:15 (116)

Serial Processing of Spoken One- and Two-Syllable Words. CLEMENT V. LATZ \& LAWSON H. HUGHES, Indiana University (read by $\mathbf{L}$. $\mathrm{H}$. Hughes)-Each of eight listeners decided on 768 occasions whether pairs of adjectives had similar or different (antonymous, unrelated) meanings. Interstimulus interval (ISI) between words of a pair varied from 0.0 to $0.7 \mathrm{sec}$. Reaction time (RT) was measured from onset of the second word. Results from both short and long words suggested serial processing, but RT of antonyms varied with word length.

\section{3:15-3:35 (117)}

The Event-Related Cortical Potential as a Measure of Tracking Difficulty. CHRISTOPHER D. WICKENS, JACK ISREAL, \& EMANUEL DONCHIN, University of Illinois-The amplitude of the P-300 component of the event-related brain potential (ERP) elicited by tones in a Bernoulli sequence reflects the preceding stimulus sequence. When subjects are engaged in a concurrent tracking task, the extent of sequential processing of the tones depends upon tracking difficulty. The results provide insight into the relation between the ERP and availability of processing resources.

$$
\text { 3:35-3:50 (118) }
$$

Can Pictures and Words Prime Each Other? JUDITH F. KROLL, Swarthmore College, \& MARY C. POTTER, M.I.T. (sponsored by Herbert H. Clark)-Differences between representations based on pictures and words were explored using a priming technique. Nonattended word or drawing primes were presented in the visual field while subjects named word or drawing targets. The primes varied in semantic relatedness to the targets. Primes affected naming latencies for drawings only. Incidental recall, however, revealed priming effects for both modalities.

\section{3:50-4:05 (119)}

On the Nature and Development of Alertness. FREDERICK J. MORRISON, University of Minnesota, Institute of Child Development-Developmental differences in the alerting process were examined in 5- and 8-year-olds and adults. Younger children took longer to become optimally alert and maintained alertness less well than older subjects. In a masking paradigm, level of alertness in adults fluctuated in an apparently cyclical fashion. Alertness, as one component of information acquisition, appears to affect amount of information available and may come under progressive cognitive control with development.

\section{4:05-4:20 (120)}

Attention and the Detection of Visual Signals. MICHAEL I. POSNER, CHARLES R. R. SNYDER, \& BRIAN J. DAVIDSON, University of Oregon-Studies indicate faster responding to luminance changes at expected positions. Our results show that visual detection latency is not improved by knowledge of form and that attention cannot be allocated to two high-probability targets unless they are spatially contiguous. These findings are consistent with a separate attentional mechanism constrained by characteristics of sensory systems.

$$
\text { 4:20-4:35 (121) }
$$

A Two-Stage Model of Visual Search. JAMES E. HOFFMAN \& GEORGE CICALA, University of Delaware-Two paradoxes in the visual information processing literature are the high speed of visual search in the presence of several slow stages and the plasticity of search behavior. Two experiments utilizing a sequential presentation technique suggested a two-stage model of visual search in which a parallel initial stage guides the operation of a slower serial discrimination stage. A computer simulation provided a good quantitative fit to the results of both experiments. The two-stage model shows how the paradoxes may be resolved as well as providing a framework for integrating results from visual search and spatial selective attention research.

\section{4:35-4:50 (122)}

Is Reading Aloud Automatic? A Cost-Benefit Analysis. RAYMOND KLEIN, GARY COUGHTRY, \& JOHN BARRESI, Dalhousie University-Subjects pronounced frequent and infrequent words preceded by neutral $(+)$, valid (same word), and invalid (different word) cues. Expecting to pronounce a word produced substantial benefits (valid $100 \mathrm{msec}$ faster than neutral) but no costs (invalid equals neutral), suggesting that retrieval of word pronunciation is an automatic process.

\section{4:50-5:10 (123)}

Word Length and Word Shape as Sources of Information in Reading. RALPH NORMAN HABER \& LYN R. HABER, University of Rochester-Subjects read passages that appeared a few lines at a time, each ending in the middle of a sentence. Each time they had to guess the next word. A powerful scoring system was developed for both syntactic and semantic accuracy of guesses. Accuracy improved substantially when the length of the target word was specified, and even more when its outline shape was provided. Results for passage difficulty, part of speech of the target word, and position in the passage are reported.

5:10-5:15 (124)

(Read by title only)

Integral Processing of Words. JOHN S. MONAHAN, Central Michigan University, \& CARL G. CHENKIN, Michigan State University-First letters in visually presented words can be processed as individual letters in speeded classification. Second and later letters cannot. Adding an asterisk before and after words prevents separable processing of first letters. Results are taken as support for visual word recognition, including first letters, as an automatic perceptual process.

$$
\text { 5:15-5:20 (125) }
$$

(Read by title only)

Personally Relevant Right-Ear Cues Enhance Right-Handed People's Cognitive Processing. STEVEN G. BARTA, ERIC 
KLINGER, \& THOMAS W. MAHONEY, University of Minnesota, Morris-During dichotic listening, participants more often attend to, recall, and incorporate into thought material that is related semantically to their current concerns than material that is not. Despite approximately equal overall responding to right- and left-ear cues, personally relevant cues presented to right-handed participants' right ears drew more attention, recall, and thought incorporation than personally relevant left-ear cues. Right-ear relevant cues also produced more attention and recall for simultaneous less relevant left-ear cues, but had no similar effect on thought incorporation. These results suggest a dominant hemisphere nonspecific arousal response to concern-related stimulation. 5:20-5:25 (126)

(Read by title only)

Time of Training and Associative-Nonassociative Processes as Determinants of the Kamin Effect. JEFFREY A. SEYBERT, MARK A. WILSON, \& ALAN L. ARCHER, University of Missouri, Kansas City-A U-shaped retention function (Kamin effect) was demonstrated for subjects in an active avoidance procedure trained either in the morning or afternoon, although the effect was more marked for the morning-trained subjects, indicating a close correspondence between Kamin and multiphasic retention effects. Data from control groups had interesting implications for the associative-nonassociative controversy in relation to the nature of the mechanism underlying retention.

\section{5:25-5:30 (127)}

(Read by title only)

Modeling Enhances Keypeck Acquisition and Discrimination Learning in Pigeons. HAROLD L. MILLER, JR., \& DAVID F. FOSTER, Brigham Young University (sponsored by Donovan E. Fleming)-One group $(n=4)$ of naive pigeons and a second group which had received prior positive automaintenance training viewed a live model performing an automaintained color discrimination task. Two similar groups served as yoked controls; only the model was absent. All animals subsequently acquired the discrimination. Modeling enhanced both keypeck acquisition and discrimination learning.

$$
\text { 5:30-5:35 (128) }
$$

(Read by title only)

Factors Influencing Rate of Readout. CONG CHOE SUH \& JEAN CHAMBERLAIN, University of North Carolina, Greensboro (sponsored by Robert G. Eason)-The rate of readout was examined under a memory load and under a no-memory load condition. Words, pronounceable pseudowords, and nonwords were used in the stimulus display for foveal, left, and right visual field presentations of five different durations. Hemispheric differences were observed in processing different types of stimulus material. These differences were more pronounced when the memory was imposed.

\section{SOCIAL-PERSONALITY PROCESSES \\ Jeffrey D. Fisher, University of Connecticut, Storrs \\ Club Room A, Thursday afternoon, 1:00-4:40}

\section{1:00-1:15 (129)}

An Individual Differences Examination of Facial Expression Judgment. G. ALFRED FORSYTH, DINA ANSELMI, \& MICHAEL E. TIRRELL, University of New Hampshire-Thirtyfive human faces were judged by 280 subjects for degree of annoyance, interest, understanding, and spontaneity expressed. Multidimensional scaling analyses indicated independence of these expressions. Homogeneous subgroups of like-perceiving subjects differed in use of dimensions within as well as between expressions and differed in a test of figural creativity.

$$
\text { 1:15-1:30 (130) }
$$

Increased Death Rates and Blood Pressures as a Function of Institutional Crowding. GARVIN McCAIN, PAUL B. PAULUS, \& VERNE COX, University of Texas, Arlington-An 8-year mortality survey of a prison system indicated significantly higher death rates for inmates over 45 with larger institutional populations. In a psychiatric unit, with an older population, death rates were highly correlated with the overall institutional population. Systolic blood pressures of inmates, in more crowded conditions, were higher. Both spacial and social density seem to be important factors. 1:30-1:45 (131)

Predicting Contraceptive Behavior Among Undergraduate Females. DONN BYRNE, WILLIAM A. FISHER, Purdue University, MARILYN EDMUNDS, Indiana University, CAROL MILLER, Purdue University, \& LEONARD A. WHITE, University of Connecticut-The sexual and contraceptive practices of 240 unmarried undergraduate females were assessed. Among the 52\% actively engaged in intercourse, nonuse of contraceptives was associated with involvement in casual and nonexclusive relationships, relatively less frequent intercourse, negative attitudes about birth control and their own sexual activities, and avoidance of gynecological visits and breast self-examination.

1:45-2:05 (132)

Simulated Attraction and Self-Presentation in Mixed-Sex Dyads. ROBERT J. PELLEGRINI, ROBERT A. HICKS, \& MARK WEBSTER, San Jose State University-Female subjects were randomly assigned to approval-seeking, approval-avoiding, or no-set control conditions in an interview-like situation with a male "listener." Results of the experiment supported the hypotheses that: (1) self-disclosure may serve as an instrumental affiliative act associated with both interpersonal approach and avoidance motives; and (2) simulated attraction facilitates actual attraction. Methodological implications for validity of disclosure measurement, and a program for future research are discussed.

2:05-2:15 (133)

Developmental Shifts in Helping Friend or Kin. HARVEY J. GINSBURG, SANDRA HENSE, \& BRIAN BIELEFELD, Southwest Texas State University-Kinship genetics may provide the evolutionary underpinnings of human altruism. Seventy children (3-10 years) were presented with hypothetical danger situations in which they had to choose between saving the lives of either friend or kin. Friends were consistently the recipients of aid for children less than 6 years old. The helping preference was significantly reversed by older children in favor of altruism toward kin. Results are considered in the context of human social evolution.

$$
\text { BREAK-2:15-2:30 }
$$

\section{2:30-2:45 (134)}

The Influence of Attitudes and Recall of Impressions on Memory for Faces. A. DANIEL YARMEY \& HANS BEIHL, University of Guelph-Photographs of attractive and unattractive male and female faces were shown to 80 female subjects. Half of the subjects were instructed to generate attitudes toward the faces during the inspection trial. Following inspection, all subjects completed an interpersonal judgment test on the "last" face they had viewed. One week later, a recognition test for faces and a recall test of judgments were given. Attitude generation to faces significantly facilitated their recognition, and female faces were more easily recognized than male faces. Recall of interpersonal judgments of target persons was not related to recognition for faces.

\section{2:45-3:00 (135)}

Effects of Nurse-Patient Touch in a Hospital Setting. JEFFREY D. FISHER \& SHERYLE WHITCHER, University of Connecticut (read by S. Whitcher)-A 2 (touch vs. no touch) by 2 (male vs. female) between-subjects design was employed in a hospital setting to assess the effect of nurses touching patients during preoperative instruction, on patients' self-report, and on behavioral and physiological responses. Female patients in touch conditions experienced lower presurgical anxiety, less worry concerning complications, rated hospitalization as less unpleasant, and responded more favorably on physiological dimensions (e.g., blood pressure) than female controls. Males' responses were ambivalent, with touch males reporting more fear of surgery than control males. Conceptual and applied implications are discussed. 
3:00-3:10 (136)

Factorial Structure of the Dogmatism Variable. SHELDON G. LEVY, Wayne State University-The dogmatism variable has been redefined more directly in terms of political processes. Factor analyses on a number of different samples indicate three factors: (1) reliance on those in power, (2) reliance on significant others, and (3) commitment to an ideology.' In addition, alternative measures have been devised for the variable.

$$
\text { 3:10-3:25 (137) }
$$

Personality Correlates of Resistance to Extinction in ViciousCircle Behavior. BETSEY B. RANDS, Virginia Polytechnic Institute and State University (sponsored by E. Scott Geller)-Viciouscircle behavior was obtained with female college students in an avoidance learning task. Regression analysis indicated that, next to extinction condition, scores on the Masculinity scale of the Bem Sex Role Inventory was the second most important predictor of the number of extinction trials completed.

$$
\text { 3:25-3:45 (138) }
$$

Basic and Applied Human Research on Auditing Behavior. DON F. HAKE, West Virginia University, \& RON VUKELICH, University of Delaware-Basic human research has shown that considerable behavior can be maintained by making access to one's own (self-audit) or another's (coactor audit) scores responsedependent. Audit research was extended to application by making access to self- and coactor token economy scores response-dependent to determine the reinforcing value of these scores and the pattern of the coactor audit responses.

\section{3:45-4:00 (139)}

Associative Interference and Persistence of Persuasion. MICHAEL R. LEIPPE, MICHAEL H. BAUMGARDNER, \& ANTHONY G. GREENWALD, Ohio State University-Subjects rated fictitious brands of consumer products at various delay intervals after reading persuasive messages on 48 (Experiment 1 ) or 18 (Experiment 2) brands. Message impact decayed more rapidly when clustered messages all involved brands in one product category than when messages involved brands in different categories. The results support an associative interference model of persistence of persuasion.

$$
\text { 4:00-4:10 (140) }
$$

Planned Sin: Sex Guilt and Contraception. ELIZABETH RICE ALLGEIER, DAVID P. PRZYBYLA, \& MARY E. THOMPSON, SUNY at Fredonia (sponsored by Donald Lehr) - Two studies to explore the problem of premarital pregnancy indicated that lowsex-guilt students (LSGS) are far more positive toward contraceptive use and have intercourse at an earlier age $(M=16.3)$ than do high-sex-guilt students (HSGS) $(M=17.5)$. More HSGS, however, tended to use contraception at first intercourse than did LSGS.

\section{4:10-4:20(141)}

Attitude Similarity and Anxiety Effects on Interpersonal Attraction and Affect. JOHN M. DAVIS \& RAYMOND B. STONE, Southwest Texas State University (sponsored by Coleman Merryman)-The hypotheses that affective states and interpersonal attraction are functions of manifest anxiety level and attitude similarity were investigated. Both between-subjects and within-subjects design experiments showed a clear relationship between subject's anxiety level and preexperimental affective states. Anxiety and attitude similarity influenced affective states. Only attitude similarity influenced interpersonal attraction.

$$
\text { 4:20-4:25 (142a) }
$$$$
\text { (Read by title only) }
$$

Individual Differences in Pollyannaism. MARGARET W. MATLIN, SUNY at Geneseo, \& VALERIE J. GAWRON, University of Illinois-The Pollyanna principle states that performance is superior for pleasant items in contrast to less pleasant items. This experiment investigates individual differences in Pollyannaism by examining relationships among 14 measures of Pollyannaism. The results showed: (1) Optimism and happiness were correlated with positive self-rating on personality characteristics, other measures of happiness, selective recall, listing pleasant items first, supplying higher frequency estimates for pleasant items, and supplying more free associates for pleasant stimuli; and (2) positive self-rating on personality characteristics was related to social desirability, positive rating of others, supplying higher frequency estimates for pleasant items, and supplying more free associates for pleasant stimuli.

\section{4:25-4:40 (142b)}

The Effects of Physical Attractiveness and Race on Essay Evaluations. NORMEN MILLER, University of Southern California, \& GEOFFREY MARUYAMA, University of Minnesota-Appearance seems to provide information sufficient to generate a stereotype about other characteristics possessed by an attractive or unattractive person. When other cues that also elicit stereotypes are presented along with the appearance cue, an evaluation should reflect their combined effects. While the evaluation of a White female essaywriter has been found to correspond directly to her attractiveness, a Black female's evaluation as an essay-writer should reflect stereotypes based upon her racial background as well as upon her attractiveness. Three experiments, using a total of 330 subjects, found the evaluation of White females to be consistently related to her attractiveness, but the evaluation of Black females to be inconsistent with ratings of attractiveness.

\section{PHYSIOLOGICAL}

Paul Ellen, Georgia State University, Atlanta

Forum Room, Thursday afternoon, 1:15-3:55

\section{1:15-1:30(143)}

The Short- and Long-Term Effects of Thiamine $\left(B_{1}\right)$ Deficiency in Adult Rats. ANTHONY R. TAGLIAFERRO \& DAVID A. LEVITSKY, Cornell University-Twenty-eight rats matched for body weight were divided into four groups and fed a diet containing $0,1.0$, or $4.0 \mu \mathrm{g}$ thiamine per gram diet. Food spillage and body weight was inversely related to the thiamine levels. During recovery, spillage rapidly normalized, but weight remained permanently depressed.

$$
\text { 1:30-1:45 (144) }
$$

Neonatal Testosterone Abolishes Sex Difference in Effect of Dexamethasone on Open-Field Defecation. RENE LeBLANC, Framingham State College, \& JUSTIN M. JOFFE, University of Vermont-Previously, (a) dexamethasone (DEX) increased openfield defecation (OFD) in female rats but not in males, and (b) the females' response was unaffected by circulating gonadal hormones. To examine the role of hormones during development, female rats were injected neonatally with testosterone propionate (TP) or oil. In adulthood, DEX produced a significant increase in OFD of oil-treated females but not of TP-treated females.

$$
\text { 1:45-1:55 (145) }
$$

Epileptiform Seizures by Gerbils Fed Different Levels of Magnesium. ARTHUR E. HARRIMAN, Oklahoma State University -Epileptiform seizures can occur in gerbils undergoing environmental stress. An error in magnesium metabolism may predispose gerbils to seize. The possibility was explored by feeding different groups of gerbils diets containing 0 to 2,000 ppm magnesium. Day of onset and frequency of seizing were inversely related to amount of dietary magnesium.

$$
\text { 1:55-2:10 (146) }
$$

Schedule-Induced Polydipsia in Desalivate Rats as a Function of Percent Free-Feeding Weight. TIMOTHY ROEHRS \& JOSEPH D. ALLEN, University of Georgia-Desalivate and control rats maintained at $80 \%$ of free-feeding weight were delivered $45-\mathrm{mg}$ pellets on a fixed-time 1-min schedule for 14 sessions of polydipsia testing. Desalivate rats acquired polydipsia immediately but had lower asymptotic intakes than controls. Body weight increases to $105 \%$ of free-feeding levels over 21 additional sessions resulted in similar decreasing intake functions for desalivates and controls. 


\section{2:10-2:25 (147)}

Disruption of Lithium-Chloride-Induced Taste Aversion by Subdiaphragmatic Vagotomy. DANIELLE GREENBERG, EARL E. DOWDY, JR., \& L. J. PEACOCK, University of Georgia-Acquisition of a $\mathrm{LiCl}$-induced taste aversion was tested in vagotomized, sham-operated, and nonoperated rats. Animals were injected with either $\mathrm{NaCl}$ or $\mathrm{LiCl}$ after primary exposure to saccharin. In a two-bottle preference test conducted over a 7-day period, $\mathrm{LiCl}$-injected vagotomized animals failed to form an aversion to saccharin, while LiCl-injected control animals showed saccharin avoidance. The Neutral Red Test was used for assessment of completeness of vagotomy.

$$
\text { 2:25-2:35 (148) }
$$

Activity-Stress Gastric Lesions in the Chipmunk (Tamias striatus). WILliAM P. PARÉ \& GEORGE P. VINCENT, V.A. Hospital, Perry Point, Maryland-After 13 days of 1.5-h daily feeding in running-wheel activity cages, chipmunks died and revealed lesions of the glandular stomach. Food control animals, not allowed to exercise showed minimal signs of stomach damage. The activity-stress procedure is thus capable of producing stomach ulcers in a wild animal species.

$$
B R E A K-2: 35-2: 50
$$

\section{2:50-3:05 (149)}

The Modulation of Cortical Hypersynchronous Bursting as an Index of Change in Behavioral State. DONOVAN E. FLEMING \& GREGG P. STANDAGE, Brigham Yaung University-Photically evoked cortical bursting in the rat (termed photically evoked afterdischarge, PhAD) has been examined during short-term sensory and behavioral habituation procedures for changes in burst parameters which may indicate shifts in behavioral state. Several experiments indicate PhAD bursting to be a sensitive index of behavioral state change.

\section{3:05-3:20 (150)}

Within-Treatment Correlations of Abnormal Behavior with Prenatal Brain Damage. PATRICIA M. RODIER, University of Virginia (sponsored by Donna M. Zahorik)-Lesions produced by interference with neuron formation in developing animals are morphologically different from adult lesions, but may have similar behavioral consequences. The lesions include many structures, but within-groups analysis suggests that changes in a given behavior are related to specific parts of the lesion pattern.

\section{3:20-3:30 (151)}

Drug-Induced Enhancement of Learned Helplessness. JOHN E. KELSEY, Indiana University - The magnitude of the escape deficit observed 3 days after exposure to inescapable shocks was larger in rats injected with $10 \mathrm{mg} / \mathrm{kg}$ FLA-63, a dopamine-B-hydroxylase inhibitor, during the inescapable shocks than in rats injected with saline or with $25 \mathrm{mg} / \mathrm{kg}$ PCPA, a tryptophan hydroxylase inhibitor. This effect suggests that enhanced depletion of norepinephrine during the inescapable shocks may enhance the development of learned helplessness.

$$
\text { 3:30-3:45 (152) }
$$

Quinine as an Appetite Stimulant. CONSTANCE M. KRATZ \& DAVID A. LEVITSKY, Cornell University-Quinine, sucrose octaacetate, lithium chloride, apomorphine, and water were administered intragastrically to rats. Quinine and lithium chloride produced ingestion of nondigestible substances (pica) where other substances had no effect. Surprisingly, however, the intubation of quinine hydrochloride and sucrose octaacetate resulted in a $35 \%$ increase in subsequent 24 -h food intake.

3:45-3:50 (153)

(Read by title only)

Effects of Hexoses on Feeding in the Rabbit. PAULA J. GEISELMAN, GERLINDA H. ROGERS, \& DONALD NOVIN, University of California, Los Angeles-Female rabbits were presented with $10 \mathrm{ml}$ of either $0.32 \%$ saccharin or an isosmotic concentration of glucose, fructose, sucrose, mannose, or urea. Meal patterns and amount of food intake were monitored for the subsequent 2 -h period. Animals showed elevated food intake after drinking either sucrose, glucose, fructose, or mannose; while food intake following saccharin consumption did not differ from the control condition (urea). The present results indicate that, rather than having a satiating effect, the ingestion of the above hexoses enhances subsequent food intake. Further experimentation has provided evidence that this effect is vagally mediated. 3:50-3:55 (154)

(Read by title only)

Serum Testosterone Concentrations in Pregnant Rats. FREYA A. WEIZENBAUM, Virginia Polytechnic Institute \& State University, NORMAN T. ADLER, \& VENKATESESHU K. GANJAM, University of Pennsylvania (sponsored by Charles D. Noblin) - Serum testosterone concentrations were measured daily throughout pregnancy in the female rat. Testosterone levels were significantly elevated $24 \mathrm{~h}$ after mating and remained high through Day 14 of pregnancy. After a peak on Days 13-14, testosterone concentrations declined to levels that were similar to those of cycling female rats. The present findings are consistent with earlier data showing that exogenously administered testosterone can induce a progestational state in the rat (Weizenbaum, 1976). Together, these investigations suggest that testosterone may be biologically significant in gestational processes.

\section{ANIMAL MOTIVATION \\ Milton A. Trapold, University of Minnesota, Minneapolis Tudor Room, Thursday afternoon, 1:00-3:20}

\section{1:00-1:20(155)}

An Opponent-Process Interpretation of Multiple Peer Separations in Rhesus Monkeys. SUSAN MINEKA \& STEPHEN J. SUOMI, University of Wisconsin-Six groups of young rhesus monkeys raised together since infancy were subjected to multiple separations. The changes in pattern of responding exhibited across repeated separation/reunion cycles are consistent with predictions of Solomon and Corbit's opponent-process theory: There is a dampening of the A state (attachment behaviors during reunion) and an intensification of the B state (depressive behaviors during separation).

\section{1:20-1:30 (156)}

Temporal Energization of Behavior. ALLEN D. BOSTWICK \& JOHN J. PORTER, University of Wisconsin, Milwaukee-Eating patterns of rats were measured during the diurnal cycle. Food was removed and activity measured during dark, light, or transition phases of the 12-h diurnal cycle. Activity increased during the dark phase and decreased during the light and transition phases, relative to control subjects. Results were related to drive change studies. 1:30-1:45 (157)

Pulse-Frequency Effects in Electrical Brain Stimulation. J. W. KLING, Brown University-The efficiency with which electrical stimulation produces a given behavioral effect varies according to the pulse frequency. One frequency is best for inducing eating, another for drinking; one is best for septal reinforcement, another for $\mathrm{LH}$ reinforcement. Implications of these findings for current theories of motivation will be discussed.

\section{1:45-2:00 (158)}

Self-Punitive Behavior: Fear Motivated, Secondarily Punished. KENNETH B. MELVIN, STEVEN PRENTICE-DUNN, \& THOMAS K. IRVING, University of Alabama-Rats were given fear conditioning to (a) a tone in a startbox and/or (b) to a buzzer. Groups punished with a buzzer CS established through delay or trace conditioning exhibited self-punitive running relative to four control groups. A second experiment found similar "allsecondary" vicious-circle behavior with a different UCS and partial secondary punishment.

\section{2:00-2:20 (159)}

Nutritive vs. Nonnutritive Suckling: The Ontogeny of Preferences in the Albino Rat. ELLIOTT M. BLASS, MICHAEL L. 
STOLOFF, \& JOHN T. KENNY, Johns Hopkins University (read by M. L. Stoloff)-Deprived rat pups, 15 days and older, preferred the arm of a Y-maze which permits nutritive suckling in contrast to one allowing nonnutritive suckling. Such preference may not be solely a function of the experience of pairing the suckling act with milk letdown.

$$
B R E A K-2: 20-2: 30
$$

$$
\text { 2:30-2:45 (160) }
$$

The Economics of Magnitude of Reinforcement. GEORGE COLLIER \& LYNN KAUFMAN, Rutgers University-In a freefeeding situation (24-h access), animals were required to barpress in order to obtain access to food. The duration of hopper access was combined factorially with fixed ratio size. Rate of eating and barpressing were inverse functions of duration. Food intake and body weight were defended.

$$
\text { 2:45-3:00 (161) }
$$

Self-Punitive Behavior: Nonreinforcement Definition of Extinction. R. CHRIS MARTIN, WAYNE MITCHELL, \& CARL ROGERS, University of Missouri, Kansas City-Reported investigations of self-punitive behavior have been conducted with a drivereduction definition of extinction as opposed to the nonreinforcement definition employed in most appetitive motivation studies. To compare appetitive vs. aversive motivation laws of behavior, it is important to utilize similar operations. The results showed that the punished group was more resistant to extinction.

\section{3:00-3:15 (162)}

Schedule-Induced Hyperphagia: A Model of Compulsive Eating. MICHAEL B. CANTOR \& JOSEPHINE F. WILSON, Columbia University - In a chamber containing a plate of wet mash, five food- and water-satiated rats pressed a lever on an FI 2-min schedule of signaled brain stimulation reinforcement. Animals ate twice the amount of food $(40 \mathrm{~g})$ that controls ate. They were neither stimulus bound eaters nor drinkers.

\section{3:15-3:20(163)}

(Read by title only)

Peripheral Trigeminal Mechanisms and Ingestive Behavior in the Rat. MARK JACQUIN, Hunter College, CUNY, \& $\mathrm{H}$. PHILIP ZEIGLER, Hunter College, CUNY and American Museum of Natural History-Bilateral sections of trigeminal motor root and ganglion in rats were carried out and effects upon intake, body weight, and ingestive behavior were examined, using a variety of diets. Rats with motor root sections sustained severe impairments in their ability to bite and chew but compensated for their reduced consummatory efficiency by increased responsiveness to food and water. Deafferented animals, although their ability to eat and drink is relatively unimpaired, show a significant reduction in food and water intake, which is accounted for by a decreased responsiveness to food and a reduction in total daily drinking time.

\section{BRAIN FUNCTION I \\ Leslie H. Hicks, Howard University \\ Tudor Room, Thursday afternoon, 3:55-5:10}

\section{3:55-4:05 (164)}

The Similarity of Basic Learning Mechanisms in the Normal and Brain-Damaged Rat. N. DAVIS \& T. E. LeVERE, North Carolina State University-There is a general belief that the acquisition and/or recovery of learned visual behaviors in the visually decorticate rat is different from that observed in its normal counterpart. In the present experiment, we wished to determine whether this difference might be related to changes in brain chemistry following the neurological insult. Our procedure involved the use of the RNA antimetabolite 8-azaguanine, which we have shown will interfere with the acquisition of, but not the performance of, a twochoice brightness discrimination in unlesioned rats. Our present question was whether this drug would produce similar effects in visual decorticate rats. However, the results demonstrated that the drug has identical effects in both the destriate and the normal brained rat. From this, we conclude that whatever behavioral differences may exist between the normal and the visual decorticate rat, these most probably do not reflect any modification of the involvement of RNA metabolism in the learning process.

\section{4:05-4:15 (165)}

Effects of Cortical Ablations on State-Dependent Learning. HAROLD E. MODROW, Southern Illinois University, KARL D. SKALA, \& DAVID K. BLISS, School of Medicine, Southern Illinois University - We trained rats given either frontal, parietal, or dorsal polysensory cortical ablations in a state-dependent learning paradigm using either Nembutal or saline. Polysensory and parietal ablations lead to significant transfer between the two drug states. Animals with frontal ablations did not show more transfer than the sham-operated control animals.

\section{4:15-4:25 (166)}

Effects of Thalamic (Centre Medianum) Lesions on StateDependent Learning and Transfer. KARL D. SKALA, Southern Illinois University School of Medicine, HAROLD E. MODROW, Southern Illinois University, \& DAVID K. BLISS, Southern Illinois University School of Medicine-We trained rats on signaled shuttle avoidance in a state-dependent learning (SDL) paradigm using Nembutal or saline. Half the animals had small prior thalamic (centre medianum) lesions. The lesioned animals displayed significant transfer of learning across drug states, while the sham-operated animals showed dissociation between the states. 4:25-4:40 (167)

Using Peripheral and Central Masking to Infer the Locus at which Perceptual and Hemispheric Asymmetries Emerge. MORRIS MOSCOVITCH, University of Toronto (sponsored by F. I. M. Craik)-Masking functions plotting critical ISI against target duration were derived for three-letter words presented vertically in either the right or left visual fields. Laterality differences favoring the right visual field were produced by pattern, but not by brightness, masking. The results suggest that perceptual and hemispheric asymmetries emerge only at later, more central, processing stages.

Ontogeny of Drinking Behavior: Effects of Third VentricleMedial Preoptic Area Destruction. ROBERT L. WYATT \& C. ROBERT ALMLI, Ohio University-Rats sustaining bilateral destruction of the third ventricle-medial preoptic area at 10 days of age were hyperdipsic on a daily ad-lib basis and in response to various dipsogenic challenges (e.g., $\mathrm{NaCl}, \mathrm{PG}, \mathrm{H}_{2} \mathrm{O}$ and food deprivation). This hyperdipsia persisted throughout adulthood and may be related to endocrine dysfunction.

\section{4:55-5:05 (169)}

Attenuation of Electroconvulsive Shock-Induced Retrograde Amnesia by Infant Stimulation. HOWARD B. BOOKIN, Connecticut College, W. DEAN PFEIFER, A. Ribicoff Research Center \& Connecticut College, \& CORNELIUS C. MEYER, Quinnipiac College-Rats handled for 3 min daily for the first 2.1 days of life and control animals not subjected to this treatment were compared on a passive avoidance task at about 60 days of age. Animals given sham electroconvulsive shock following acquisition did not difer in passive avoidance performance as a function of early experience. Control animals given electroconvulsive shock following acquisition were amnesic at the 24 -h retention test, while animals handled in infancy were resistant to the amnesic effects of electroconvulsive shock.

\section{5:05-5:10(170)}

(Read by title only)

Clinical and Polygraphic Studies of Electroconvulsive Therapy (ECT). VICTOR MILSTEIN, MICHAEL J. DEAL, \& JOYCE G. SMALL, Larue D. Carter Memorial Hospital and Indiana University School of Medicine-Multichannel EEGs and recordings of EKG and respiration were accomplished before and during ECT in 15 psychiatric patients. Twenty-four-hour Holter EKG monitoring was accomplished before and after the seizures, and standard rat- 
ings of psychopathology were obtained at comparable points in time. Clinical changes were associated with variations in ictal and interictal EEG characteristics. Contrary to expectations, minimal EKG changes were observed, possibly because autonomic stimulation of ECT was blocked by psychotropic drugs and/or premedications. A comparably examined series of drug-treated patients is being accumulated.

\section{MEMORY AND RECALL I \\ John Barresi, Dalhousie University \\ Diplomat Room, Thursday afternoon, 1:00-5:05}

1:00-1:10 ((171)

Age Changes in Recognition Memory: Retention of Frequency Judgments. SHEILA A. MITCHELL \& LINDA R. WARREN, University of Alabama (read by L. R. Warren)-Two age groups, 18-30 and 60-75, saw a list of words that varied in number of repetitions $(0,2$, or 4$)$ and level of background frequency (high, medium, or low). Immediately or after a 20 -min retention interval, the subjects judged the presentation frequency of the study list words. Accuracy of judged frequency decreased with age but not retention interval. As predicted by frequency theory, accuracy of judged frequency was a function of background frequency in both groups.

1:10-1:20(172)

Long-Term Memory for a Common Object. RAYMOND S. NICKERSON \& MARILYN JAGER ADAMS, Bolt Beranek \& Newman (read by M. J. Adams)-People were asked to: draw a penny by themselves; draw a penny given a list of its visual features; indicate which from a list of possible features were on a penny; and indicate what was wrong with various distorted pictures of pennies. Performance was surprisingly poor in all cases. Implications for theories of long-term memory are discussed.

1:20-1:35 (173)

The Effects of Sentence Complexity on Word Recognition. RONALD P. FISHER \& FERGUS I. M. CRAIK, University of Toronto-In previous work, it was found that words learned in a complex sentence were better recalled than words embedded in a simple sentence; to our surprise, we found that sentence complexity had no effect on word recognition, however. It was hypothesized that complexity would enhance word recognition only when the retrieval information either reinstates the complex context (by re-presenting the sentence) or allows redintegration of the context. These hypotheses were confirmed in two experiments.

\section{1:35-1:50 (174)}

Memory for Comparative Sentences. BASABI R. MUKHERJI, MARCIA K. JOHNSON, SUNY at Stony Brook, \& ROGER W. SCHVANEVELDT, New Mexico State University-Comparative acquisition-sentences were followed by a memory test. Recognition instructions required either a literal or a meaning judgment about the test sentences. Data from literal and paraphrased sentences point to both literal and interpretive components of the memory trace. Further, presuppositions inherent in the nouns, but not the relations, influenced performance.

\section{1:50-2:05 (175)}

Facilitating Learning in Interactive Free Recall. MICHAEL E. FRIENDLY \& PATRICIA E. FRANKLIN, York University (sponsored by Peter A. Ornstein)-This paper explores whether free recall performance and organization can be facilitated using computer-controlled interactive presentation. Two responsecontingent presentation orders and a selective reminding manipulation were used. One experiment showed that selective reminding increased subjective organization and the probability of recalling new items. Another experiment found positive results for both the reminding and the interactive presentation orders.

$$
\text { 2:05-2:20 (176) }
$$

Further Tests of Prior Cueing in Human Memory. MICHAEL L. MACHT, State University College at Utica/Rome (sponsored by Norman E. Spear)-An experiment is reported in which the effects of prior cueing, or priming, were investigated in an episodic memory task. The results indicated that prior cueing facilitated retention for high-frequency category instances; for low-frequency instances, prior cueing tended to inhibit recall in certain conditions. These results are discussed in relation to spreading activation models of semantic processing.

2:20-2:40 (177)

A Theory of Cortical Learning, Consolidation, and Amnesia. WAYNE WICKELGREN, University of Oregon-Cognitive and S-R learning are defined in an associative network. A psychological and neural theory of cognitive memory consolidation is described to account for normal storage dynamics and the amnesic syndrome (retrograde and anterograde) in humans and higher vertebrates.

$$
\text { 2:40-2:55 (178) }
$$

The Role of Organization and Instructional Set on Story Memory. NANCY L. STEIN, University of Illinois, \& TERESA NEZWORSKI, University of Minnesota-The effects of the deliberate use of story schemata were tested by varying the amount of temporal organization in story material and the instructional set given prior to stimulus presentation. The results showed that prior instructions to recall material in "good" story form or in a "verbatim" sequence did not affect the temporal output in recall. However, the amount of accurately recalled material was significantly influenced by instructions.

\section{2:55-3:10 (179)}

Overgeneralization in Memory for Quantified Discourse: Simplification of Thematic Encoding. RUSSELL REVLIN, University of California, Santa Barbara-This study examines whether students overgeneralize in their memory for quantified discourse. In a recognition paradigm, students read narratives that varied in both the ambiguity of the quantified relations and the theme. The findings argue that overgeneralization is a consequence of the initial representation of critical lexical items-the quantifiers-and not a result of "simplification" processes as claimed previously (e.g., Frederiksen, 1975).

$$
\text { 3:10-3:25 (180) }
$$

Processing Artificial Set Inclusion Relations. RICHARD A. GRIGGS, LAWRENCE J. OSTERMAN, University of Florida, \& THOMAS M. GRUENENFELDER, Indiana University-The processing of artificial set inclusion information given in text was investigated. Contrary to some recent findings, forced-choice recognition results indicated that subjects could differentiate presented from nonpresented, deducible information. In addition, logical errors were observed on true-false tests, even when subjects were given a practice paragraph describing real set inclusion information and feedback on performance.

$$
B R E A K-3: 25-3: 35
$$

\section{3:35-3:50 (181)}

Levels of Processing in Preschool Children. MARION PERLMUTTER, University of Minnesota (sponsored by Tom Trabasso)-Two studies were carried out to examine levels of processing in 2-to 5-year-olds. The results indicated that preschool children encode both color and category information. Contrary to findings with older subjects, however, when an incidental recall task was used, neither depth of processing effects nor attenuated age effects were observed. Further results suggested retrieval difficulties in this age group.

\section{3:50-4:05 (182)}

Visual and Verbal Memory for Objects and their Location. KATHY PEZDEK, California State College, San Bernardino (sponsored by Leah Light)-Adult subjects viewed a model of a city with 16 functionally and physically different buildings on it. The representation of the buildings was varied between subjects such that physical complexity of the buildings was manipulated as well as the presence of a verbal name on each building. Performance on later recall and recognition tests, as well as a test of relocating the 
buildings on the model was better in the name than in the no-name conditions, but not affected by the complexity of the buildings. The relative strength of verbal vs. visual processing in memory for various instances within a class of objects is discussed.

$$
\text { 4:05-4:15 (183) }
$$

A Reversal of the PI Effect. JOHN YUILLE \& RAYMOND CORTEEN, University of British Columbia (sponsored by Lawrence Ward)-Depending on prior exposure, very different recall patterns were obtained in a traditional PI task. Two word categories (A, B) were used. Subjects previously exposed to $5 \mathrm{~min}$ of continuous A words showed normal PI on B word groups but an increase in recall on A word groups. The reverse was also true. The result was replicated, but the reason for the effect is not clear. 4:15-4:30 (184)

Change in Prose Memory Schemata: Integration of Reconstructive Recall Errors. LINDA S. OHLWEILER, Kent State University (sponsored by Joseph H. Danks)-Are reconstructive recall errors integrated with the memory schema of the original input message? Two studies examined this question with presentation and recall of prose passages: one in a laboratory setting and the other in a classroom lecture. Results of recognition tests and confidence ratings supported the conclusion that reconstructive errors are fully integrated with the memory schema.

$$
\text { 4:30-4:45 (185a) }
$$

Memory for Multiple-Episode Stories: A Developmental Study. CHRISTINE G. GLENN, Carnegie-Mellon University (sponsored by Robert S. Siegler)-First and third graders were asked to recall stories consisting of four episodes (the basic informational unit of recent story grammars) which were either causally or noncausally related. Differences in the amount recalled and the organization of recall were reported as a function of age and story structure. The results support a model which assumes that (1) stories are organized into episodic chunks in memory, and (2) interepisodic relationships affect comprehension and recall.

$$
\text { 4:45-5:05 (185b) }
$$

Rehearsing in an Imagined Voice: The Eventual Consequences on Recognition. ROBERT A. BJORK \& RALPH E. GEISELMAN, University of California, Los Angeles-Subjects were asked to imagine themselves rehearsing word trigrams in a particular prefamiliarized male or female voice. Whether the voice on a later recognition test matched or mismatched the rehearsal voice heavily influenced performance on trigrams given primary (maintenance) rehearsal, but had no influence on trigrams given secondary (elaborative) rehearsal.

\section{MEMORY AND RECALL II}

Nancy L. Stein, University of Illinois, Champaign Empire Room, Friday morning, 8:30-12:30

\section{8:30-8:50 (186)}

Perception and Memory for The Red Balloon when Presented as either Movie or Text. PATRICIA BAGGETT, Florida International University (sponsored by Walter Kintsch)-A technique based on subjects' judgments is devised to equate episodic story structure (to obtain "story equivalence") of The Red Balloon in movie and text. The two media influence recall differently: Movie subjects recall the structure of episodes (exposition, complication, resolution) better; text subjects recall the correct order in time better.

$$
\text { 8:50-9:10 (187) }
$$

Face Recognition and Verbal Description of Faces from Memory. ALVIN G. GOLDSTEIN, KAREN S. JOHNSON, \& JUNE CHANCE, University of Missouri-Recognition memory for faces plays a critical role in eyewitness identification procedures. Eyewitness testimony often provides a verbal description of the culprit, and eyewitnesses may identify a suspect after he is apprehended by the police. This research explored the relationship between accuracy in describing faces from memory and face recognition performance.

\section{9:10-9:25 (188)}

Evidence for a Strength Hypothesis Explanation of the Ranschburg Effect. S. DAVID LEONARD, G. WILLIAM HILL, IV, \& CHARLES H. EVANS, University of Georgia-When words selected for high distinctiveness were repeated within a string of seven words, immediate recall of the repeated items were low in distinctiveness. These results are supportive of the hypothesis that recall of a repeated item in immediate memory is a function of the strength of the item.

\section{9:25-9:40 (189)}

Integration of New and Old Information. WILLIAM G. COLE \& ELIZABETH F. LOFTUS, University of Washington-Subjects looked at slides of natural scenes. Afterwards, they were exposed to new (verbal) information about those scenes. Finally, reaction times were taken during a test of memory for the visual details in the scenes. It was found that the presence of new information affected both those reaction times and overall accuracy. 9:40-9:55 (190)

Did I Do It or Did I Imagine Doing It? RITA E. ANDERSON, Memorial University of Newfoundland-Subjects had more difficulty selecting drawings they had previously traced when context drawings were ones they had previously imagined tracing than when they had simply looked at the context drawings. The influence of instructional variations and level of imaginal control on the development of confusions between memories of doing and of imagining doing will also be considered.

\section{9:55-10:10 (191)}

Perceptual Schema Formation Without Classification. JOHN BARRESI, Dalhousie University-Dot patterns were viewed for $5 \mathrm{sec}$ each and immediately reproduced. In E1, reproduction error decreased more rapidly for category-related patterns (Posner) than for unrelated patterns. In E2, reproductions of patterns from two related categories were initially worse but eventually better than reproductions of patterns from two unrelated categories.

\section{0:10-10:30 (192)}

Effects of Rehearsal on Picture Recognition. CASSANDRA B. WRIGHT \& WAYNE L. SHEBILSKE, University of VirginiaRehearsal improves memory for words. Does it improve memory for pictures? Several investigators have obtained conflicting results on this question. We suggest that their common procedure is contributing to the confusion. Using a unique method, which was adapted from directed forgetting paradigms, we provide new evidence for the existence of visual rehearsal.

$$
\text { BREAK-10:30-10:40 }
$$

10:40-11:00 (193)

Storage Losses from LTM: A Problem for Dichotomous Memory Theory. RICHARD A. CHECHILE \& KIMBERLEY EHRENSBECK, Tufts University-The Chechile and Meyer (1976) storage-retrieval analysis was used to study the retention of 18 paired associates. Prior to testing on each trial, subjects digitshadowed for $20 \mathrm{sec}$ to assure that testing was from LTM. Subjects learned the first A-B list to either a partial learning or an overlearning criterion and then had six trials on a second A-D or C-D list. The overlearning subjects showed only retrieval difficulties, whereas the partial learning subjects showed independent difficulties with both storage and retrieval.

\section{1:00-11:20 (194)}

Unconfounded Measurement of Encoding and Retrieval in Immediate Recall. WARREN H. TEICHNER, New Mexico State University-A method for separating encoding time from retrieval time will be presented and illustrated with the results of five experiments of immediate recall using briefly exposed displays.

$$
\text { 11:20-11:35 (195) }
$$

The Relative Contribution of Perceptual Encoding and Response Factors to the Stroop Phenomenon. EVELYN WILLIAMS, New Mexico State University (sponsored by Warren H. Teichner) -A series of experiments involving a Stroop color-word task 
with a limited stimulus duration will be presented. In these experiments, stimulus encoding and response retrieval time were separately measured in order to determine the relative contribution of perceptual and response factors in the Stroop phenomenon.

\section{1:35-11:45 (196)}

Does "The Head Remember What It Does?" Memory for “Mental Operations." D. L. CHMIELEWSKI, MARGARET H. COOPER, SLATER E. NEWMAN, \& KATHRYN O. PARKER, North Carolina State University (read by S. E. Newman)-Experiment 1 found recall performance superior when subjects answered semantic questions rather than nonsemantic questions. Experiment 2 used identical questions, but asked subjects to identify which kind of question they had answered for each word. Results paralleled Experiment 1. Implications for depth-of-processing models and for memory for mental operations are discussed. 11:45-12:00 (197)

Suffix Effects on Nonverbal Tactual, Visual, and Auditory Sequences. SUSAN KARP MANNING, Hunter College of CUNYThe effects of inter- and intramodal suffixes on the recall of eightunit series of right and left stimuli was studied using sequences presented in the tactual, auditory, and visual modalities. Performance decrements for the more recently presented stimuli occurred with intramodal, but not intermodal, suffixes. This modal specificity is consistent with a sensory trace interpretation of the suffix effect with nonverbal tactual and auditory stimuli. Further work on the visual effect is suggested.

12:00-12:15 (198)

The Propositional Structure of Sentences. R. RATCLIFF, Dartmouth College, \& G. McKOON, University of Toronto (sponsored by B. B. Murdock, Jr.)-Subjects were shown two proposition sentences, then tested for recognition of single words. When a test word was immediately preceded by another word from the same sentence, a 100 -msec priming effect was obtained. The priming effect was larger when the preceding word was from the same proposition than from the other proposition, when surface distance differences were controlled.

\section{2:15-12:30 (199)}

Orthographic and Semantic Access to the Memory Trace. MARCIA EARHARD \& BRUCE EARHARD, Dalhousie University-Access to two sets of memory traces of English words was attempted by the initial letter of the name of the word, and/or by a meaning of the word, in order to compare the retrieval characteristics of these two types of retrieval cues. Several differences between orthographic and semantic access were found, including: (a) A trace established to be recalled according to the initial letter of its name carries with it a semantic retrieval instruction, and (b) a trace established to be recalled semantically is not directly accessible through its initial letter.

\section{INFORMATION PROCESSING III \\ John Jonides, University of Michigan, Ann Arbor \\ Palladian Room, Friday morning, 8:30-12:40}

\section{8:30-8:50 (200)}

Selective Visual Attention: The Perception of Superimposed Line Drawings. E. BRUCE GOLDSTEIN \& SUSAN FINK, University of Pittsburg-These experiments ask: (1) Can subjects selectively attend to one of two superimposed pictures? and (2) Can subjects attend to both of two superimposed pictures? The results indicate that the answer to both of these questions is "yes" but that some subjects perform better than others. The implications of these results for theories of visual information processing will be discussed.

\section{8:50-9:10 (201)}

Selective Processing in Preperceptual Visual Storage. STEPHEN J. LUPKER \& DOMINIC W. MASSARO, University of Wisconsin-Is it possible to switch attention and selectively perceive a foveally presented stimulus held in preperceptual visual storage? Partial-report cueing and backward masking provided an answer to this question by eliminating possible confoundings of short-term memory and decision processes.

$$
\text { 9:10-9:20 (202) }
$$

Additional Considerations of the "Category" Effect. GIDEON KEREN, University of Southern California (sponsored by Steven Madigan)-Previous studies demonstrated the category effect, in which the "between" and "within" conditions result in different regression lines (Jonides \& Gleitman. 1972). The present paper provides additional insight into this phenomenon. It is proposed that for "absent" responses the effect is solely due to differences in physical features, but that for "present" responses higher cognitive processes might be involved.

$$
\text { 9:20-9:30 (203) }
$$

Sorting Perceptual Sets. PAUL J. GRUENEWALD \& GREGORY R. LOCKHEAD, Duke University-Subjects were given a many-to-one mapping task in which the discriminabilities of items within and between sets were orthogonally varied. A quantitative model is presented which predicts sorting times in these tasks. The model will be related to attention shifting vs. range effects models of the mapping process.

\section{9:30-9:45 (204)}

Direction of Picture-Word Interference is Task-Dependent. L. MAGEE, M. C. SMITH, \& D. KLEIN, University of TorontoWhen conflicting information is provided by pictures and words in a Stroop-like interference task, the nature of the resulting interference is found to be task-dependent. In a naming task, incongruent words interfere with picture-naming, whereas pictures do not interfere with word-naming. In contrast, a categorization task requiring subjects to indicate whether or not the stimulus is a member of a particular category yields the opposite result-incongruent pictures interfere with word categorization, but incongruent words do not interfere with picture categorization. The data are interpreted in terms of a levels-of-processing model.

\section{9:45-10:00 (205)}

Memory for Pictures and Words is Task-Dependent. MARILYN C. SMITH \& LOCHLAN MAGEE, University of TorontoFollowing either the naming of categorizing of pictures or words, subjects were given a surprise recognition test. Recognition for pictures was better following naming than following categorization, whereas the reverse was true for word recognition. When incongruent pictures and words were presented simultaneously in a Stroop-like interference task, the pattern of recognition memory for attended and unattended stimuli could be accounted for by the differential processing of pictures and words in the naming and categorization tasks.

\section{0:00-10:10 (206)}

The Locus of Spatial Redundancy Effects: Perception or Inference? MILDRED MASON, Iowa State University-Twelve symbols were used to construct three sets of 144 six-symbol strings. In the no-redundancy control set, each symbol occurred equally often in each serial position. The two spatial redundancy sets differed from each other only in respect to which symbols were constrained in which serial positions. Results show that facilitation in a yes-no reaction time task is dependent upon the perceptual consequences of the constraint rather than upon the constraint itself. The constraint is effective only when it serves to separate symbols that share common visual features.

$$
\text { 10:10-10:20 (207) }
$$

Word Superiority Effects in Visual Search. ROBERT J. CHABOT, Kent State University, \& JAMES F. JUOLA, University of Kansas-Subjects searched for single target letters in 3-, 4-, 5-, and 6-letter visual displays. The display durations were manipulated to vary accuracy of the range of $71 \%$ to $91 \%$ correct. The visual displays were either common words, pronounceable pseudowords, or nonwords. RT, percent error, and d' measures indicated an advantage for word displays over pseudowords and nonwords.

BREAK-10:20-10:30 


\section{0:30-10:50 (208)}

Components of Geometric Analogy Solution. TIMOTHY MULHOLLAND, University of Brasilia, JAMES W. PELLEGRINO, \& ROBERT GLASER, University of PittsburghAdults were tested on the speed and accuracy of verifying the truth of geometric analogies systematically varying in the number of individual elements and element transformations represented in each item. The data are fit to models specifying the component processes necessary for solution with estimates of the contributions of these processes to overall solution accuracy and latency. 10:50-11:10 (209)

Memory-Item Probability as a Determinant of Sternberg Reaction Time: Evidence for Separate Memory Retrieval Processing. E. SCOTT GELLER, MARK L. ALBERT, Virginia Polytechnic Institute and State University, \& PAUL H. HAMLIN, University of Maryland, European Division-On each trial of a Sternberg RT paradigm, memory-set size was 1 or 3 (Experiment 1), or 1, 3, or 5 (Experiment 2); and the memory-set digits were sampled from different populations with probabilities of $.60, .30$, or .10 (Experiment 1$)$ or .80 or .20 (Experiment 2). For both experiments $(20$ subjects each), RT was an inverse function of memory-item probability.

\section{1:10-11:30 (210)}

Psychometric Abilities and Cognitive Development: Processing Speed as a Component of Intelligence. LAUREN B. RESNICK, University of Pittsburgh, FREDERICK DANNER, University of Wisconsin, \& JEFFREY BISANZ, University of Pittsburgh-EXperiments with children and adults were used to determine the relationships among processing speed, age, and performance on psychometric tests. A visual search task yielded measures of localization and identification speeds; a picture-matching task yielded measures of name coding speed and two types of inteference. Processing measures associated with high measured intelligence did not always increase with age, and vice versa. Implications for the relationship between psychometric "abilities" and cognitive development are discussed.

\section{1:30-11:45 (211)}

Interference Between Processing Demands Within a Cerebral Hemisphere. JOANNE GREEN \& ARNOLD D. WELL, University of Massachusetts - In contrast to reaction time studies demonstrating facilitation between stimulus and response processing within a single cerebral hemisphere, our research demonstrates significant interference when one hemisphere both receives the stimulus and controls the response. The results support Dimond's notion of the "double brain," and suggest that each hemisphere may have an independent nonsharable attentional capacity.

$$
\text { 11:45-12:05 (212) }
$$

A Comparison of Explicitly and Implicitly Known Alphabets. LEE R. BROOKS, McMaster University-For one of three alphabets in this experiment, the spelling to sound correspondences were explicitly taught. For another alphabet, the spelling correspondences were not taught (and apparently not discovered). For the third, there were no correspondences in the material. After initial learning, the words written in the implicit alphabet were identified most rapidly. The results are discussed in terms of perceptual organization and implicit knowledge.

\section{2:05-12:20 (213)}

Chinese Readers Show More Stroop-Type Interference than Readers of English. IRVING BIEDERMAN, SUNY at Buffalo, \& YAO-CHUNG TSAO, Rennsselaer Polytechnic Institute-The greater susceptibility of Chinese readers to Stroop-type interference may reflect some fundamental differences in the perceptual demands of reading Chinese and English. This result can have wide-ranging implications for human information processing.

$$
\text { 12:20-12:35 (214) }
$$

Configural and Dimensional Effects in Multiple-Cue Decision Tasks. N. JOHN CASTELLAN, JR., Indiana University at Bloomington-Subjects used four patterns made from two binary cues to predict binary events. Across conditions, pattern validity

was held constant while the validity of component dimensions was varied. Subjects' solutions were more dependent upon the constituent dimensions than upon the patterns, supporting a hypothesis generation model of multiattribute decision making.

$$
\text { 12:35-12:40 (215) }
$$

Estimation of the Likelihood of Events as a Function of the Degree of Personal Impact of the Events. ANTHONY J. RUCCI \& LOWELL SCHIPPER, Bowling Green State University-Probabilistic information from two sources was presented to subjects who were required to combine the information and make a single probabilistic estimate of one of two possible outcomes. Some of the information was related to events which would have a rather high impact on a person's life and some of the information was related to quite low impact events. Some of the differences in the use of the high-impact vs. low-impact information were (1) statistically reliable, (2) of very small magnitude (about .02), and (3) contingent upon whether or not the impact of the event was favorable or unfavorable.

\section{VISION II \\ Elizabeth L. Bjork, University of California, Los Angeles Club Room A, Friday morning, 8:30-11:40}

\section{8:30-8:45 (216)}

The Apparent Spatial Frequency Shift Phenomenon: Evidence for Attraction as well as Repulsion Effects. EDWARD $M$. BRUSSELL, MELVIN K. KOMODA, \& STEPHEN R. STOBER, Concordia University, Montreal (sponsored by Jane Steward)We report that not only can the perceived spatial frequency of a grating be made to shift away from that of an adapting grating (repulsion effect), but toward that of an adapting grating (attraction effect) as well. The attraction effect can be elicited when: (a) the test contrast is near threshold, (b) the adapting contrast is high, and (c) the test frequency is one to two octaves lower than the adapting frequency. These findings imply that the distribution of neural activity in response to a grating pattern may have two peaks. The implications and an elaboration of this hypothesis will be discussed.

$$
\text { 8:45-8:55 (217) }
$$

Wavelength Effects on Simple Reaction Time. MARY JO NISSEN \& JOEL POKORNY, Eye Research Laboraties, University of Chicago-When spectral lights are presented on a dimmer achromatic background, simple RT shows no wavelength effect. When the chromatic lights and the background are matched in luminance, RT shows a large wavelength effect with longest latencies to yellow. Results are discussed in terms of achromatic and chromatic processing channels.

$$
\text { 8:55-9:05 (218) }
$$

Pupillary Response in 1- and 2-Month-Old Infants. PHILIP SALAPATEK, A. GORDON BECHTOLD, \& JOANNE BERGMAN, Institute of Child Development, University of Minnesota-The pupils of 11 1-month-old and 10 2-month-old human infants were photographed as they were exposed to seven luminance levels following dark adaptation. Luminance was varied from .06 to $60.74 \mathrm{fL}$ in $.5 \mathrm{log}$ unit steps. Pupil size was generally small and varied parametrically with luminance for both age groups. It is argued that pupil size should not be a significant factor limiting infant acuity during normal viewing.

\section{9:05-9:25 (219)}

Response Saturation and the Psychophysical Brightness Function. DONALD C. HOOD, MARCIE FINKELSTEIN, \& EUGENE BUCKINGHAM, Columbia University-Recent psychophysical detection experiments argue that the response of the human cone system reaches a maximum, or saturates, to flashes of light. Brightness estimates over the same intensity range are usually fit by Stevens' power function. Our magnitude estimation data deviate from a power function in ways consistent with the detection studies. 
9:25-9:40 (220)

Masking by Light in Single Photoreceptors. GARY FELSTEN \& GERALD S. WASSERMAN, Purdue University (read by G. S. Wasserman)-The intensity required for a $30-\mathrm{msec}$ test flash to produce a criterion receptor potential increment in the presence of a 400 -msec mask flash was determined over a range of stimulus onset asynchronies. The variation of the criterion intensity with SOA yielded a masking function quite similar to that obtained in human psychophysics. The criterion test flash intensity increased with receptor potential increases, but these two variables could best be described by a bilinear function. We suggest that the upper limb of the bilinear function is produced by receptor saturation. These results are consistent with the notion that masking by light is a special case of the increment threshold, and that receptor dynamics adequately account for dynamic factors in masking at this level of the visual system.

9:40-9:55 (221)

Foveal Two-Flash and Flicker-Fusion Thresholds as a Function of Pulse Luminance. NORA NICOTERA, IRA BERENHÄUS, STUART GOLDBERG, JOSEPH E. HERSKOVIC, \& MITCHELL L. KIETZMAN, Queens College-Foveal critical flicker fusion thresholds and two-flash thresholds at five pulse luminance levels were determined for four subjects using the random method of limits (Herrick, 1973). All stimulus conditions were presented in each of eight sessions for each subject. Using threshold interpulse interval as the measure for both methods, results indicated: (1) threshold interpulse interval was shorter for critical flicker fusion threshold than two-flash threshold at all luminance levels tested and (2) increasing pulse luminance decreased critical flicker fusion threshold markedly but decreased two-flash threshold slightly. Critical fusion threshold and two-flash threshold may reflect two different visual temporal resolving mechanisms.

BREAK-9:55-10:10

\section{0:10-10:30 (222)}

Discrimination of Illumination Edges from Reflectance Edges in the Katz Paradigm. ALAN GILCHRIST \& STANLEY DELMAN, SUNY at Stony Brook (sponsored by Irvin Rock)-In a Katz-type lightness constancy experiment, the data obtained (luminance matches) when the backgrounds differed in reflectance were radically different from that when the backgrounds differed in illumination (ratio matches). Since the retinal projection was essentially constant across these conditions, constancy cannot be reduced to contrast but must involve the sorting of illumination edges from reflectance edges.

10:30-10:45 (223)

The Effects of Meridional Variations on Steady State VEPs. JAMES G. MAY, University of New Orleans, ANNE MOSKOWITZ-COOK, \& JOHN B. SIEGFRIED, Pennsylvania College of Optometry-VEP correlates of the oblique effect were obtained with phase-alternated $3.0 \mathrm{cpd}$ checkerboard, as well as grating, stimuli. Obliquely oriented checkerboards gave rise to greater amplitude VEPs than did normally oriented checkerboards, suggesting that the major Fourier components contribute significantly to the elicitation of such responses. This conclusion was supported by a second experiment which revealed that the latency of steady-state VEPs was increased when a normally oriented checkerboard was viewed through cylentrical lenses aligned such that they obscured the fundamental, but favored the higher, harmonic spatial components of the stimulus.

\section{0:45-11:05 (224)}

Iconic Memory in Stereo Space: Seeing Without Storing. ROBERT FOX \& STEVE LEHMKUHLE, Vanderbilt UniversityThe presence of iconic memory from briefly presented letter arrays ( 3 x 5 matrix) formed from continuously generated dynamic random element stereograms was tested by standard partial report methods. Unlike their physical counterparts stereoscopic letters left no iconic residue, a result consistent with the hypothesis that conventional icons are ephemeral after-images.
11:05-11:20 (225)

Sustained and Transient Contributions to Short-Term Visual Storage. GLENN E. MEYER, Lewis \& Clark College, \& WILLIAM MAGUIRE, SUNY at Buffalo (sponsored by Erwin Segal)-With sine wave gratings $(.4-6.4 \mathrm{cpd})$, presented for $50 \mathrm{msec}$, the stimulus image lasts longer as spatial frequency increases. Increased stimulus duration $(500 \mathrm{msec})$ or spatial frequency specific adaptation reduces iconic duration selectively for high frequencies. A minimum persistence was locked to stimulus offset and was not shortened by adaptation. This suggests sustained and transient channel contributions to the visual icon.

11:20-11:40 (226)

How Does Our Perception of a Picture Change as We Walk Around It? E. BRUCE GOLDSTEIN, University of PittsburghHorizontal rods in a picture appear to rotate as viewing angle changes, and this rotation is greater for more foreshortened rods than for less foreshortened rods. Thus, as we walk around a picture containing different objects, the more foreshortened ones rotate more than the others, and this changes the relationships between objects in the picture.

\section{PERCEPTION II \\ Clare Porac, University of Victoria \\ Forum Room, Friday morning, 8:30-12:30}

\section{8:30-8:45 (227)}

The Interpretation of Auditory Polyrhythms. JAMES S. OSHINSKY \& STEPHEN HANDEL, University of Tennessee, Knoxville-Polyrhythms, the simultaneous presentation of two pulse trains, are ambiguous in that either pulse train or some combination of the two may determine the perceived meter. Polyrhythms are unique perceptual figures, in that the rhythmic resolution depends in different ways on the polyrhythm configuration, pitch structure, and tempo.

$$
\text { 8:45-9:05 (228) }
$$

Perceived Distance and Loudness. DONALD H. MERSHON \& DOUGLAS DESAULNIERS, North Carolina State UniversityThe apparent distance to a noise was varied by moving a dummy loudspeaker. Independent groups of observers judged apparent loudness under different conditions. Both anechoic and reverberant situations were examined to determine the presence of a perceived loudness-distance relationship. Some of the results have implications for the "proximity image" effect.

$$
\text { 9:05-9:20 (229) }
$$

Simple and Contingent Aftereffects in the Kinesthetic Perception of Length. JAMES T. WALKER, University of Missouri, St. Louis-Contingent aftereffects are usually weaker than simple aftereffects, possibly because of differences beteen the typical procedures for producing those two varieties of aftereffects. When the procedures were made more nearly comparable, a simple aftereffect of kinesthetically perceived length was no stronger than a corresponding contingent aftereffect.

\section{9:20-9:40 (230)}

An Invariant for Gait Perception Without Familiarity Cues. JAMES E. CUTTING, Wesleyan University-Using a technique developed by Johansson, I have found that viewers can identify the gender of a walker without familiarity cues. That is, when point-lights are attached to joints and the surroundings darkened, viewers have no difficulty telling male from female. Results are discussed in terms of structural differences, torso torque, and center of moment.

\section{9:40-9:55 (231)}

Visual vs. Auditory Pattern Processing: Where Do We Look, Where Do We Listen? LEONA S. AIKEN \& MARIANNE M. LONO, Temple University-How observers scan visual vs. auditory patterns was examined in a classification task in which the first, second, or final third of to-be-classified patterns was randomized. Disruption of performance by randomization of particular pattern thirds depended on modality and prototype structure, with large interelement transitions most salient in both modalities. 
9:55-10:10 (232)

Parafoveal Facilitation of Naming Foveally Presented Words: The Role of Eye Movements. KEITH RAYNER, University of Rochester, GEORGE W. McCONKIE, Cornell University, \& SUSAN EHRLICH, University of Rochester-Prior parafoveal information facilitated the naming of a word in the fovea. The effect was obtained when the subject made an eye movement and when the saccade was simulated. There was also evidence that when programming a saccade to a given region of the display, subjects directed attention to that area.

\section{BREAK-10:10-10:20}

\section{0:20-10:30 (233)}

Effects of Setting on Subliminal Perception. W. H. TEDFORD, JR., \& G. L. GAYLORD, Southern Methodist University-A sexually ambiguous slide was evaluated on a masculinity-femininity scale by 84 subjects, divided into six groups. Variables were: formal vs. informal setting crossed with superimposed 8-msec HE, vs. HE embedded in slide, vs. control. Both subliminal HEs produced a significantly more masculine evaluation, but only in the informal setting.

$$
\text { 10:30-10:40 (234) }
$$

The Effects of Distinctive Features on Incomplete Picture Recognition. FRANK S. MURRAY \& JOANNA M. SZYMCZYK, Randolph-Macon Woman's College-Two sets of fragmented representations, preserving $25 \%$ or $75 \%$ of the distinctive features of 20 objects, were presented to subjects of different age groups. Each set consisted of a complete (C), an intermediate (I), or a most incomplete (MI) representation of the objects. Results showed significant differences in age groups and stimulus sets.

$$
\text { 10:40-10:50 (235) }
$$

Priming with Nonprototypical Colors. GREGORY R. LOCKHEAD, SUSAN A. GAYLORD, \& NANCY J. EVANS, Duke University (read by N. J. Evans)-Rosch's work on the interaction of priming and goodness of example of colors was replicated using color chips, rather than color names, as primes. When the prime matches the stimulus pair, there is facilitation of response time regardless of whether or not the prime is the prototype. Implications for the processing of colors are explored.

\section{0:50-11:10 (236)}

The Abstraction of Meaning from Complex Pictures. MICHAEL G. JOHNSON, University of Minnesota-Groups of subjects were shown a number of reproductions of paintings by the Belgian surrealist Magritte, which they were required to deal with in a variety of relevant tasks. Taken together, the data show many parallels with phenomena encountered in verbal metaphor, and are consistent with certain theoretical perceptual positions taken by Garner, Gibson, and Neisser.

$$
\text { 11:10-11:30 (237) }
$$

A Poggendorff Prescription: Consider all the Angles. DANIEL J. WEINTRAUB, DAVID H. KRANTZ, University of Michigan, \& THOMAS P. OLSON, Cornell University-Poggendorff displays varying every 15 deg the angle between transversal and parallels, and the orientation of the entire display with respect to the subject, provided systematic data for a model of collinearity misjudgments. The outcome can be interpreted as the effect of the angle between transversal and parallels, a smaller meridional effect, and an interesting interaction.

\section{1:30-11:45 (238)}

Metacontrast as a Function of Internal Contour and Target Thickness. PATTI L. KELLY \& ROBERT H. POLLACK, University of Georgia-Extent of metacontrast was examined as a function of target internal contours and target thickness. Forty college students participated in a spatial forced-choice method of presentation with target-mask interstimulus intervals ranging from 1 to $100 \mathrm{msec}$. Masking decreased as both target thickness and target internal contour increased.

\section{1:45-11:55 (239)}

Hemispheric Differences in Processing Emotional Stimuii. ROBERT G. LEY \& M. PHILLIP BRYDEN, University of Waterloo-Two studies investigating visual field differences in emotional expression and face recognition were carried out. Cartoon line drawings of faces with definite emotional expressions, positive, neutral, and negative, were tachistoscopically presented. Significant left visual field (LVF) superiorities for emotional expression and face recognition were found. These effects seem to be independent. The LVF superiority for emotional judgments is related to the degree of affective expression.

11:55-12:05 (240)

Prospective Temporal Judgment of Tachistoscopic Flashes as a Function of Stimulus Complexity and Recognizability. GEORGE W. MILLER, Iowa State University, \& ROBERT E. HICKS, SUNY at Albany-In order to resolve recent conflicting findings concerning the relationship between apparent duration and stimulus familiarity, this study examined the role of stimulus recognizability. Although the variable had no effect, the results in the context of earlier studies suggested that judgments of long and short durations are governed by very different processes.

12:05-12:10 (241)

(Read by title only)

Comparison of Mueller-Lyer and Horizontal-Vertical Illusions. A. M. PRESTRUDE, CINDY WHITE, \& WILLIAM FINNIE, Virginia Polytechnic Institute \& State University-Attempted to determine whether the $\mathrm{M}-\mathrm{L}$ and $\mathrm{H}-\mathrm{V}$ illusions were additive by displaying the $\mathrm{M}-\mathrm{L}$ figures in the $\mathrm{H}-\mathrm{V}$ configuration. Forty-eight combinations of illusion and configuration were tested. The M-L figure, which was overestimated, was judged to be even longer when displayed vertically, but there appeared to be no H-V effect when the two illusions were opposed. There also appeared to be a significant bisection error which contributed to the magnitude of the M-L illusion.

\section{2:10-12:15 (242) \\ (Read by title only)}

Effect of Context Circle Number on the Ebbinghaus Illusions. TED JAEGER \& ROBERT H. POLLACK, University of Georgia - The magnitude of the simultaneous and successive overestimated and underestimated Ebbinghaus illusions was investigated as a function of the number of surrounding circles. Increasing the number of surrounding circles reduced the magnitude of the reversed illusion produced by the normally overestimated simultaneous Ebbinghaus figure and increased the magnitude of the illusion produced by the successive underestimated figure. The results were interpreted as inconsistent with a size contrast explanation of the Ebbinghaus illusions and suggested that these illusions may be produced by a contour interaction process.

$$
\begin{aligned}
& \text { 12:15-12:20 (243) } \\
& \text { (Read by title only) }
\end{aligned}
$$

Prior Knowledge Does Not Aid the Detection of Coherent Motion of Dynamic Random-Dot Patterns. JOSEPH S. LAPPIN \& JOSHUA D. STALLER, Vanderbilt University-Experiments evaluated the effects of uncertainty about the direction of motion on the detectability of coherent motion of random-dot patterns. Surprisingly, the effects of uncertainty were consistently less than predicted for an ideal observed. Self-organizing characteristics of the visual system seem involved in detecting these patterns.

\section{2:20-12:25 (244)}

(Read by title only)

Pattern Organization and Situational Specificity. DIANE T. FELDMAN, RICHARD G. BURRIGHT, \& LAURIE E. SINGER, SUNY at Binghamton (sponsored by C. James Scheirer)Identical or complementary spatio-temporal patterns of visual and auditory elements were presented. Individuals either verbally described or tapped out the location of the elements. More exposure to the complementary patterns was needed for accurate verbal description but not for manual reproduction. Task demands thus influence spatio-temporal organization. 
12:25-12:30 (245)

(Read by title only)

The Effect of Letter Number on Foveal Discriminability. BRUCE AMBLER, RAYMOND KEEL, \& ELAINE PHELPS, University of Texas, Arlington-In several experiments, foveal letter discriminability was studied as a function of the number of letters in the display. When letter number was increased from one to four, RTs increased for a T-L discrimination but not for a Ttilted-T discrimination. This interaction was unaffected by manipulation of acuity or retinal area.

\section{ANIMAL LEARNING I \\ Edward A. Wasserman, University of Iowa, Iowa City Diplomat Room, Friday morning, 8:30-12:40}

\section{8:30-8:50 (246)}

Comparative Psychology and Language Acquisition: I. Comparisons with Human Children. BEATRICE T. GARDNER \& R. ALLEN GARDNER, University of Nevada-When chimpanzees are exposed from birth to a true human language, American Sign Language, in an intellectually rich environment, with adult human native signers as models, the normal stages of child language acquisition can be used to measure achievement, and the parallels with early child development are striking.

\section{8:50-9:10 (247)}

Comparative Psychology and Language Acquisition: II. Rigorous Testing Under Naturalistic Conditions. $R$. ALLEN GARDNER \& BEATRICE T. GARDNER, University of Nevada-So far, the results of "linguistic" experiments with chimpanzees, using caged subjects, forced-choice tests, and synthetic "languages," can be more parsimoniously interpreted in terms of rote memory, learning sets, and Clever Hans cues. Tests developed for free-living subjects using American Sign Language rule out these interpretations.

\section{9:10-9:30 (248)}

Substance Invariance in Macaques. ROBERT PASNAK, George Mason University-A progressive series of learning sets was used to induce formation of a concept similar to substance conservation by two rhesus macaques. The generalization of this concept and the effects of size cues, experimenter familiarity, and methods of problem presentation were assessed. The monkeys acquired conceptual prerequisites of substance conservation as a result of the learning set training.

$$
\text { 9:30-9:50 (249) }
$$

Crows Learn Not To Respond Under Response-Independent Reinforcement. ROBERT W. POWELL \& WILLIAM KELLY, University of South Florida-Seven fish crows were trained to respond under either fixed or variable interval schedules. Subsequently, the response dependency was systematically eliminated and then reinstated. The distribution of reinforcers in time was the same under the response-independent schedules as had prevailed under the response-dependent schedules. Responding was successfully maintained for all birds when the response dependency was in effect, but eventually ceased under the response-independent procedure. Responding resumed when the response dependency condition was reinstated. Terminal patterns of responding under each of the interval schedules were similar to those displayed by pigeons, except that two of the crows responded much more slowly under fixed interval schedules. However, compared to pigeons, fish crows showed substantially less responding under responseindependent procedures. An explanation of this result is offered which stresses differences between crows and pigeons in their natural feeding patterns in relation to the type of response (pecking) required to obtain food in the experiment.

\section{9:50-10:10 (250)}

Correlations Between Events Revisited. PETER W. D. DODD \& R. G. WEISMAN, Queen's University, Kingston, Ontario-The sequential relationship between two neutral stimuli was a discriminative event for pigeons in an operant procedure. Forward pair- ings, both forward and backward pairings, or presentations of either stimulus alone preceded an opportunity to obtain food. Extinction and maintained generalization tests suggested that pigeons readily learn about the two relevant stimuli, but learn the sequential relationship somewhat less readily.

\section{0:10-10:20 (251)}

Delayed Matching in the Pigeon: Intertrial Inhibition. THOMAS R. ZENTALL \& DAVID E. HOGAN, University of Kentucky -Pigeons experienced delayed matching trials involving (1) positive transfer transitions (sample, incorrect comparison, or both from trial $n$ remained the same on trial $n+1)$, (2) negative transfer transitions (sample, incorrect comparison, or both from trial $n$ switched roles on trial $n+1$ ), or (3) mixed positive and negative transitions. Significant differences were found only when the ITI was short and the sample observing response was minimal.

$$
\text { 10:20-10:35 (252) }
$$

A Bowed Serial Position Function in the Habituation to Sequential Stimuli. PENN L. PFAUTZ \& ALLAN R. WAGNER, Yale University-Rabbits received multiple exposures to an invariant list of stimuli and were later tested with the item that had consistently occupied either the first, middle, or last position in the list. A bowed serial position function was obtained, with the largest vasomotor orienting responses (poorest retention of habituation) occurring for the middle item. The results are considered in light of an account of habituation offered by $A$. R. Wagner.

$$
\text { BREAK-10:35-10:45 }
$$

\section{0:45-11:05 (253)}

An Ecological Approach to the Comparative Analysis of Learning. ALAN C. KAMIL, University of Massachusetts-Detailed knowledge of the behavioral ecology of different species can provide the basis for a powerful research strategy for evaluating the species generality and/or specificity of learning processes. Ecological information can be used in the design of animal learning experiments and in the selection of particular species for comparative study. The results of such ecologically based research would contribute significantly to our understanding of the distribution of learning abilities among species and the adaptive significance of different types of learning in natural settings.

\section{1:05-11:25 (254)}

Rat Spatial Working Memory is Independent of Response or of Food Presentation. JOHN A. WALKER \& DAVID S. OLTON, The Johns Hopkins University - Rats trained to run for food at the end of each arm of a four-arm radial maze were placed at the end of one, two, or three arms with or without food, and then allowed to choose among the arms. Choice accuracy indicated that placements were sufficient to establish accurate working memory.

$$
\text { 11:25-11:40 (255) }
$$

A Comparison of Schedule-Induced Polydipsia in the Guinea Pig and the Mongolian Gerbil. WILSON E. BRYANT, JR., JOSEPH H. PORTER, THOMAS P. MOESCHL, Virginia Commonwealth University, \& JOSEPH D. ALLEN, University of Georgia-Two of three food-deprived guinea pigs displayed schedule-induced polydipsia when $45-\mathrm{mg}$ food pellets were delivered according to a FT 60 -sec food schedule. Both guinea pigs displayed the typical postpellet pattern of adjunctive drinking. Of five gerbils tested on FT 30 -sec and FT 60 -sec food schedules, only one animal displayed schedule-induced polydipsia.

\section{1:40-11:55 (256)}

Enhancement of Conditional Choice Performance by Expectancies of Reward/Nonreward. GAIL B. PETERSON, University of Minnesota, RUTH L. WHEELER, Grinnell College, \& MILTON A. TRAPOLD, University of Minnesota-When pigeons received food after a correct choice on only one kind of trial of a conditional two-choice task, they chose correctly more often on both kinds of trials then when correct choices of both kinds yielded reward. The results were interpreted in terms of the stimulus-support properties of different outcome expectancies. 
11:55-12:15 (257)

Effects of Prior Noncontingency on Memory for the CR: Variations in Stimulus or Response Elements. CAROL D. WICKENS, DELOS D. WICKENS, \& DAVID S. TUBER, Ohio State University-Prior experience with unpredictable (CSs) and forepaw shocks (UCSs) drastically affected memory for a CR generated by the same CSs and the same forepaw shock. Additional experiments attempt to identify the locus of the effect-in the stimulus or in the response, to extract specific postulates concerning unpredictability, and to consider several theoretical interpretations.

$$
\text { 12:15-12:35 (258) }
$$

Sucrose-Alone (CS) Exposure as a Source of Interference in a Taste Aversion. STEPHEN B. KLEIN \& PETER J. MIKULKA, Old Dominion University-Unpaired sucrose exposures presented prior to conditioning attenuated the acquisition of an aversion, while taste-only experiences following a single-illness pairing interfered with the reacquisition of the sucrose aversion. It is suggested that the rat learns that a taste cue predicts no illness during CS familiarization or extinction which interferes with either the acquisition or reacquisition of an aversion.

\section{2:35-12:40 (259)}

(Read by title only)

Stimulus Properties of Conspecific Behavior: Conditional Discrimination. W. J. MILLARD, University of Massachusetts, JUDY KOLLMAN-MARGOLIN, University of Jerusalem, LINDA LINDQUIST, \& ERNEST DZENDOLET, University of Massachusetts-A conditional discrimination procedure was developed to assess the stimulus properties of conspecific behavior. Pairs of pigeons were exposed to independent but synchronous multiple schedules of reinforcement that differentially reinforced keypecking. For two of the components, distinctive hues were perfectly correlated with schedules that maintained either high or low pecking rates. In the other two components, a white stimulus (i.e., the conditional stimulus) was presented. In any one stimulus period, a bird was exposed to one of the chromatic simuli, while the other bird was exposed to the white stimulus. Thus, the animate behaviors of one bird came to control the differential responding of the second bird that was exposed to the conditional stimulus. A more detailed report is available from the first author.

\section{PROBLEM SOLVING AND CONCEPT IDENTIFICATION Kent L. Norman, University of Maryland, College Park Tudor Room, Friday morning, 8:30-11:50}

\section{8:30-8:50 (260)}

Means-Ends Analysis in Peschool Children. DAVID KLAHR, Carnegie-Mellon University-A modified version of the three-disk (seven-move) Tower of Hanoi puzzle was presented to 30 children between 3 and 5 years of age. Some 3-year-olds solved problems starting four moves from the goal. All the 5-year-olds solved fivemove problems, and one could solve the full seven-move problem. In addition, several children described up to six-move sequences before actually making them.

$$
\text { 8:50-9:10 (261) }
$$

Sequences and Synchrony in Development. ROBERT S. SIEGLER, Carnegie-Mellon University-The chronological order in which concepts emerge is one of the most basic data in the study of cognitive development. Surprisingly, unambiguous data on such orderings prove hard to obtain. The present paper is an attempt to (a) define exactly what is meant by "Concept A precedes Concept B"; (b) overcome measurement problems that are common in the area; and (c) determine when empirical research on development sequences is necessary and when it can be bypassed.

\section{9:10-9:30 (262)}

An Introduction to Spatial Problem Solving. MARVIN LEVINE \& IRWIN N. JANKOVIC, SUNY at Stony Brook-Movement in space by human adults was analyzed in terms of conditioning and cognitive formulations. According to the cognitive position, subjects convert serially presented spatial information into a cognitive map, i.e., into a simultaneous representation of the information. The data, that subjects inferred appropriate shortcuts and that original and novel information were equally available, are consistent with the cognitive view.

9:30-9:50 (263)

Movement in Space: Aligning the Cognitive Map. IRWIN N. JANKOVIC \& MARVIN LEVINE, SUNY at Stony Brook-Following training in a given space (producing, presumably, a cognitive map), the relationship between the subject and the space was transformed either by a rotational transformation or a translational (lateral displacement) transformation. Logically minimal information was sufficient to overcome the effects of translation but not the effects of rotation. Performance in the latter condition was improved by supplementary, redundant information.

\section{9:50-10:10 (264)}

Human Problem Solving: A View from the Top. JOSEPH M. SCANDURA, University of Texas-In spite of the shift toward cognition, theories of complex human behavior still tend to be highly restrictive. Piagetian structuralism provides a major alternative, but it fails to make contact with the more specialized theories of cognitive psychology. The structural learning theory helps to bridge this gap. This talk will emphasize the interrelationships that exist among content, cognition, and individual differences and the constraints which these interrelationships impose on the form of any comprehensive theory of human problem solving. 10:10-10:25 (265)

Subjective Strategies in Anagram Formation and, Perhaps, Solution. ROY B. WEINSTOCK, JACKIE GRAY, \& SANDY MIDDLETON, Mary Washington College-Naive female college subjects were asked to convert high- or low-frequency five-letter words into "hard" and "easy" anagram problems. These subjects systematically manipulated letter moves and digram frequencies in their conversion efforts. Implications of these data on anagram formation as they relate to anagram solution will be discussed.

$$
B R E A K-10: 25-10: 35
$$

\section{0:35-10:55 (266)}

Negation and Conditional Reasoning. JOHN E. TAPLIN, University of New South Wales-This study aims to examine the processing of negation in the context of reasoning with conditional sentences. An attempt is made to extend the response change or verification model of Trabasso, Clark, and Chase to account for premise-reading and conclusion-evaluation times in such deductive reasoning. Predictions derived from this model receive clear support from the data.

$$
\text { 10:55-11:15 (267) }
$$

Memory for Problem Solutions. STEPHEN K. REED \& JEFFREY JOHNSON, Case Western Reserve University-Súbjects in an intentional learning group improved more than subjects in an incidental group when resolving a problem. The results were due to differences in memory for subgoals and general strategies. The two groups did not differ in their ability to recognize problem states, recall moves, or identify the best move at a problem state.

\section{1:15-11:30 (268)}

Relevant Redundant Cue Utilization in a Probabilistic Concept Attainment Task. GEDIMINAS NAMIKAS, University of Windsor, \& DAVID A. MAINPRIZE, Windsor Western Hospital Centre, Ontario-College students attempted to solve an affirmative four-category concept problem with $0.0 \%, 12.5 \%, 25.0 \%$, or $37.5 \%$ misinformative feedback. The set of stimuli was so constructed that a second dimension was either $75 \%$ or $50 \%$ relevant, redundant. Errors increased with amount of misinformative feedback except for $75 \%$ cue redundancy at the intermediate level of misinformative feedback.

$$
\text { 11:30-11:45 (269) }
$$

Combining Rules in Information Integration. FREDERIC $M$. SCHEMMER \& KENT L. NORMAN, University of MarylandSubjects formulated two previously learned component rules into 
a complex rule in an information integration task. The judgment rules are viewed as the mapping of subjective partial derivatives within a cognitive algebra of function processing. Data were examined for the strategies subjects used in their inferences.

11:45-11:50 (270)

(Read by title only)

Psychotropic Drugs, Anxiety, and Depression in Cognitive Performance. VLADIMIR PISHKIN, STEVEN M. FISHKIN, \& WILLIAM R. LOVALLO, V.A. Hospital, University of Oklahoma School of Medicine-Seventy-two hospitalized psychoneurotics who were high in depression and anxiety or low on these measures were compared on ability to solve a concept identification $(\mathrm{CI})$ problem. The subjects were divided into three groups with chlordiazepoxide, doxepin, or no drug taken for 15 days. The main effect of drug regimen upon CI was not significant. Those who were high in depression and anxiety showed fewer errors to solution of the problem than those who were low. This finding was not attributable to differences in years of education, drug regimen, or any apparent demographic variables.

\section{MEMORY AND RECALL III \\ Nancy L. Stein, University of Illinois, Champaign \\ Empire Room, Friday afternoon, 1:00-5:15}

\section{1:00-1:20 (271)}

Word Frequency Effect in Memory. STEVEN P. SCHWARTZ, University of Texas Medical Branch, \& TIMOTHY C. WIEDEL, University of Texas, Austin (read by T. C. Wiedel)-Currently popular explanations for the effects of word frequency on recognition and recall focus on the assertion that rare words have fewer associated "meanings" than common words. These explanations are shown to be in conflict with experimental results. An explanation for word frequency effects based on episodic memory for context is offered to account for seemingly disparate experimental findings.

$$
\text { 1:20-1:40 (272) }
$$

Maintenance Rehearsal, Elaboration, and Long-Term Recency. DEWEY RUNDUS, University of South Florida-A series of studies investigating maintenance rehearsal and single-level processing will be described. Results of particular interest include the observation of: (1) positive effects on recall as a function of processing level and number of presentations, but not rehearsal time; (2) no effects of elaboration; and (3) a pronounced long-term recency effect.

\section{1:40-1:55 (273)}

Does a Learner Know More About His/Her Own Acquisition Processes than an Observer? JAMES F. VOSS \& GREGG VESONDER, University of Pittsburgh-One subject learned sentences by the study-test method. Two additional subjects observed, one hearing and one not hearing Subject 1's responses. All three subjects, on each trial, predicted whether Subject 1 would be able to recall each sentence. The results are considered in terms of the awareness one has of his/her own learning processes as compared to the awareness an observer has of the same processes.

$$
\text { 1:55-2:15 (274) }
$$

Has Ebbinghaus Decayed with Time? MATTHEW HUGH ERDELYI, Brooklyn College, CUNY-Ebbinghaus's "forgetting curve" is psychology's best known law. But what does it mean? Scholars have been cagy on the point, preferring to bypass the theoretical issue by restating the empirical finding that retention decreases with time. Interference criticisms (that forgetting is not caused by "time" but by psychological correlates of time) falsely suggest that forgetting is an inevitable process which can only be retarded by slowing psychological time (interfering cognitive processes). It is shown, however, that memory can dramatically increase (hypermnesia) over periods of days. Ebbinghaus's curve represents only a special case; memory over time is a fan-shaped family of curves which may increase, decrease, or stay constant.

\section{2:15-2:35 (275)}

Remembering. KEITH N. CLAYTON, Vanderbilt UniversityA general theory of remembering is proposed and used to analyze several laboratory tasks, empirical phenomena, and theoretical issues. Three constructs and 21 assumptions are needed, and the sources of forgetting are traced through acquisition, interpolation, and test events. Discussion will emphasize processes produced by queries for events which occurred within a specified period of time.

\section{2:35-2:50 (276)}

Organizational Effects on Learning, Speeded Recall, and Delayed Recall. WILLIAM B. WHITTEN, II, SUNY at Albany (sponsored by Judith Reitman)-A set of 24 words was presented as (1) a labeled hierarchy, (2) triples of related words, (3) triples of unrelated words, or (4) a list. Degree of provided organization affected original learning, speeded recall performance, and 1-week delayed recall. Hierarchical clustering analysis was used to discover subjective organizational differences which might underlie these performance effects.

\section{BREAK-2:50-3:00}

\section{3:00-3:10 (277)}

The Airplane List. H. F. CROVITZ, V.A. Hospital, Durham, North Carolina-A list of 10 common English nouns which are serially related in a story format will be presented once, and the audience will be able to retrieve it forwards or backwards. Data from patients with disorders of memory will be given, along with the success of cuing for retrieval in an alcoholic Korsakoff amnesic.

\section{3:10-3:30 (278)}

The Implications of Finding Cue Recognition as Good as Cued Recall. WILLIAM B. WHITTEN, II, SUNY at Albany (sponsored With weak associates and under conditions which insure a high level of response availability, cue recognition can be as good as cued recall. The implications of this finding for generation recognition models of cued recall will be discussed.

\section{3:30-3:40 (279)}

Relative Difficulty and the Shape of the Serial-Position Curve as a Function of Age. DANIEL B. BERCH, Morehead State University-The most appropriate dependent measure for comparing serial-position curves exhibited by different age groups is Jensen's Index of Relative Difficulty. This method was used for representing the serial-position data of several published, probetype studies of short-term memory development, and the shapes of the resulting curves were contrasted with those of functions previously derived from absolute levels of performance.

\section{3:40-4:00 (280)}

Identifying the Functional Units of Cognition. HERMAN BUSCHKE \& ARON SCHAIER, Albert Einstein College of Medicine-Content and structure of cognition can be analyzed in terms of component ideas that are the functional units involved in retrieval from semantic memory, narrative recall, and other forms of cognition. Repeated two-dimensional recall (Buschke, $J V L V B, .1977,16,201-215)$ can be used to identify each subject's own component ideas and delineate their changing organization.

$$
\text { 4:00-4:15 (281) }
$$

How Recall Facilitates Subsequent Recall: A Reappraisal. CHARLES P. THOMPSON, STEVEN K. WENGER, \& CARL A. BARTLING, Kansas State University-Evidence is presented supporting the hypothesis that recall provides information about the recallability of each item, provides a re-presentation of each item recalled, and does nothing else. Some apparently contradictory evidence is experimentally reconciled with this hypothesis, and some problems involved in interpreting other evidence are briefly discussed.

4:15-4:35 (282)

Primacy and Recency Effects in Free Recall Tasks with Interspersed Arithmetic. DELBERT A. BRODIE, University of Alberta 
- Primacy and recency effects have been obtained in free recall tasks where subjects were instructed to rehearse each word only while it was being presented, and each word was both preceded and followed by arithmetic. Recent experiments in which rehearsal was more carefully monitored indicate that these primacy effects are due to differential rehearsal, and the recency effects result from differential interference.

\section{4:35-4:45 (283)}

Individual Differences in Recall and Recognition. RONALD LEY \& JURGEN KARKER, SUNY at Albany-Individual differences in the ability to generate associations is positively related with recall; and the time required to generate associations is negatively correlated with recognition. The relationship between individual differences in academic achievement and recognition depends on how recognition is measured.

$$
\text { 4:45-4:55 (284) }
$$

Image Detail and Recall: Evidence for Elaboration Within Meaning Representations. GARY H. RITCHEY, CAROLE R. BEAL, \& JEAN M. MANDLER, University of California, San Diego-Two experiments investigated the relationship between image detail and feature activation in meaning representations. In both experiments, greater image detail facilitated recall of items from an uncategorized list, but not from a categorized list. Results are discussed in terms of a semantic memory model which considers levels of activation both within and between lexical items.

$$
\text { 4:55-5:10 (285) }
$$

Developmental Changes in the Use of Semantic Information for Recall. KATHLEEN CORSALE \& PETER A. ORNSTEIN, University of North Carolina-Children sorted pictures into groups prior to recall. Third graders given a surprise recall test after instructions to form meaning-based groups recalled more than peers instructed to sort to facilitate recall. Sorting instructions did not influence seventh graders' recall. Results are discussed in terms of children's production deficiencies and the measurement of organization at both input and output.

5:10-5:15 (286)

(Read by title only)

Children's Recall and Recognition Memory for Seriated Sticks. GEORGE MARSH, California State College, Dominguez Hills, \& JULES DOMBROWER, University of Southern CaliforniaChildren from preschool through second grade were given longterm recall and recognition tests for a display of seriated sticks. The recall results for younger children show a memory improvement as reported by Piaget and Inhelder. In contrast, the recognition test showed a stable memory for all ages. The results suggest that retrieval factors, rather than changes in the memory schema during storage, are responsible for the memory improvement reported by Piaget and Inhelder.

\section{INFORMATION PROCESSING IV \\ Janet L. Lachman, University of Houston \\ Palladian Room, Friday afternoon, 1:00-5:05}

\section{1:00-1:10 (287)}

Positional Judgment in Chess. DENNIS H. HOLDING, University of Louisville-With or without forward search, move selection must follow an evaluation function. Human evaluations were obtained for five quiescent middle-game positions and five endgame positions with material equality, from tournament players in USCF classes $\mathrm{A}, \mathrm{B}, \mathrm{C}, \mathrm{D}$, and $\mathrm{E}$. Positional discrimination increased markedly with playing strength, corresponding highly with computed mobility and square control measures.

\section{1:10-1:20 (288)}

Contextual Processing in Good and Poor Readers. IRA $\mathbf{H}$. BERNSTEIN \& GAIL BERWICK SMITH, University of Texas, Arlington-It is possible that good readers are more efficient in analyzing contextual information than poor readers, regardless of its relevance. It is also possible that they are more sensitive to context and may thus be more easily misled when it is irrelevant. Our findings support the former position.
1:20-1:40 (289)

A Transitive Chain Theory of Deductive Reasoning. ROBERT J. STERNBERG, MARTIN GUYOTE, \& MARGARET TURNER, Yale University-A new theory of deductive reasoning is proposed that represents information about set relations by pairs of informational components. Information about the set relations is integrated by applying a small set of rules to transitive chains formed by rearranging the components. The theory is quantified, and tested against alternative theories in seven experiments varying item type, format, and content. The theory gives a superior account of both latency and error data.

1:40-1:55 (290)

Prototype Abstraction and Conceptual Structure. DONALD HOMA, DEBBIE RHOADS, \& FRED REED, Arizona State University, \& DANIEL CHAMBLISS, Yale University-A spatial model for the evolution of conceptual structure and prototype abstraction was explored. Multidimensional scaling was used to assess the transformation of the conceptual space from a relatively undifferentiated state to one that reflected the requisite category learning. The impact of specific learning variables on this spatial transformation was also investigated.

\section{1:55-2:10 (291)}

Detecting Plans from Data: Best Laid Plans That Go Astray. ROBIN JEFFIES, PETER G. POLSON, \& LYDIA RAZRAN, University of Colorado-Some claim that subjects solve simple sequential problems such as Missionaries-Cannibals by planning move sequences, whereas we assert that performance on this task is best described as involving the selection of one move at a time. We have examined another set of tasks for which we feel it is intuitively obvious that subjects are planning. How do these intuitions translate into hard experimental facts? What kinds of measures give useful information about whether people are planning?

\section{2:10-2:25 (292)}

A Developmental Study of the Concept of Numerosity. RICHARD PRINGLE \& JUDY A. ANDREWS, Kansas State University (sponsored by John J. Uhlarik)-A functional measurement approach was used to examine development of the numerosity concept. First and fourth graders and undergraduates made category estimations of number of dots in an array. Children weighted density (dots/sq in.) more than area. Adults weighted both equally. While most adults were "multiplicative," most children were "additive."

$$
B R E A K-2: 25-2: 40
$$

\section{2:40-2:50 (293)}

Learning to Read Inverted Text. SANDRA R. PALEF, University of Toronto-Subjects learned to read inverted text by training on letters, approximations to words, words, approximations to text, or complete text. Training on words was better than training on word approximations, while text and approximations to text were no better than words in random order. Implications for theories of fluent and beginning reading are discussed.

\section{2:50-3:05 (294)}

Concurrent Priming of the Lexical Store. GEORGE PORTER \& GEORGE WOLFORD, Dartmouth College-Using the lexical decision task, we investigated the effect of concurrent presentation of a nontarget string. Several surprising results occurred. Facilitation varied with the location of the nontarget string and no facilitation occurred when the nontarget was identical to the target. The implications of these results for current models are noted.

$$
\text { 3:05-3:25 (295) }
$$

Toward the Analysis of Comprehension Processes During Reading. WAYNE L. SHEBILSKE, L. STARLING REID, \& CASSANDRA B. WRIGHT, University of Virginia-We measured eye movements during the reading of a 1,888 -word narrative text We found that reading rate per sentence depended on how the sentence is related to macro-structure and that the magnitude of this intra-passage flexibility was correlated with a separate measure of inter-passage flexibility. 


\section{3:25-3:40(296)}

Frames of Mind. JOHN A. ROBINSON \& CARL D. BENNINK, University of Louisville-The qualitative differences which distinguish different occasions of remembering, thinking, speaking, etc., can best be explained by reference to a theory of cognitive modes. Modes are generic organizing structures which qualify and integrate stage-dependent processes. Two primary modes (participant and spectator) will be described.

3:40-4:00 (297)

Visual Information and Orthographic Structure in Letter and Word Recognition. GLEN A. TAYLOR, DOMINIC W. MASSARO, University of Wisconsin, \& RICHARD L. VENEZKY, University of Delaware-We assessed the psychological reality of extant descriptions of orthographic structure of English, using accuracy and latency of letter perception and ratings of orthographic structure. A rule-governed approach based on graphemic conventions and phonological constraints was contrasted with a probabilistic approach based on frequency of tokens sampled from text.

\section{4:00-4:10 (298)}

Word Recognition, Lexical Decision, and Visual Field. GLORIA J. BRADSHAW \& ROBERT E. HICKS, SUNY at Albany-Right-handed subjects were presented with three-letter words and permutations of the letters in a single visual field for $20 \mathrm{msec}$. Word-nonword decisions were better than chance, and were superior in the left visual field than in the right visual field. The same subjects demonstrated superior right-visual-field recognition of words, however.

\section{4:10-4:25 (299)}

Orthographically Regular and Irregular Words and Pseudowords: Pronunciation by Analogy? ROBERT J. GLUSHKO \& DAVID E. RUMELHART, University of California, San DiegoSubjects pronounced orthographically regular words, words which violate orthographic rules, and matched pseudowords formed by changing letters in the regular and "exception" words. Pronunciation latencies and the distribution of pronunciations indicate an analogical mechanism in pronunciation, but "exceptions" aren't that exceptional.

\section{4:25-4:45 (300)}

Heuristics in Learning to make Univariate Linear Predictions. ALEXANDER J. WEARING, Melbourne University, MICHAEL KUBOVY, Yale University, \& SHANE THOMAS, Melbourne University-Participants were given values of a predictor for which they were to predict another variable related to the predictor by a linear function. Feedback was provided, but no hint was given as to the deterministic nature of the function. Values of the slope and intercept affected the task's difficulty. Analysis uncovered stages through which learning proceeds.

\section{4:45-5:05 (301)}

Functional Cerebral Distance: An Illustration from Pianists' Divided Performance. M. KINSBOURNE, University of Toronto -Pianists simultaneously played separate tunes with each hand. They then hummed along with one while playing both tunes simultaneously. More humming and playing errors occurred when subjects hummed along with the left hand. The result illustrates the concept of "functional cerebral distance," which will be discussed.

ANIMAL LEARNING II

Robert W. Powell, University of South Florida Club Room A, Friday afternoon, 1:00-5:05

1:00-1:15 (302)

Delayed Matching to Sample (DMTS) in Monkeys with TwoSample Stimuli. JACQUILYN K. COX \& M. R. D'AMATO, Rutgers University (read by M. R. D'Amato)-Cebus monkeys were tested with single-sample and two-sample (presented sequentially) trials in a DMTS task with delay intervals of 1-60 sec. The single-sample retention gradient was uniformly higher than the two-sample gradient. Both elements of current two-sample trials produced interference on the immediately following trial.

$$
\text { 1:15-1:30 (303) }
$$

Association of Conditioned Stimuli During Serial Conditioning. EDWARD A. WASSERMAN, DONALD L. CARR, \& JAMES D. DEICH, University of Iowa-CS2-CS1-US autoshaping was given to hungry pigeons, and evidence of CS2-CS1 association was sought. Pigeons pecked that key of a two-key compound CS2 located where the upcoming CS1 was to occur. Such CS2-CS1 association was: (a) quickly acquired, (b) quite durable, and (c) stronger with simultaneous than with successive discrimination tasks.

$$
\text { 1:30-1:50 (304) }
$$

Effects of Age on the Establishment, Retention, and Attenuation of Sucrose Taste. J. J. FRANCHINA, G. C. DOMATO, H. A. GRIESEMER, A. TRACY, \& J. M. BILlIG, Virginia Polytechnic Institute \& State University - The rat's age (19, 30, 90, or 180 days) at toxicosis directly affected the establishment of sucrose taste aversion. Despite differences in aversion learning, 19and 90-day-old rats similarly showed invariant retention of the aversion $24,48,72$, and $168 \mathrm{~h}$ later and an attenuation of the aversion following one or three sucrose preexposures.

$$
\text { 1:50-2:10 (305) }
$$

Rats Extrapolate Serially Ordered Stimuli. STEWART H. HULSE, Johns Hopkins University-Rats were repeatedly exposed to an element set of four, three, or two food quantities presented in a monotonically ordered condition or in a random condition. Then they learned to respond to a monotonic five-element serial pattern using some new food quantities. Rats, like people, can learn to abstract and extrapolate the structure of serially ordered patterns of stimuli.

\section{2:10-2:25 (306)}

Effects of CS Intensity on the Classically Conditioned Cat Nictitating Membrane Response. MICHAEL M. PATTERSON, Ohio University, \& JAN F. ONIK, Kirksville College of Osteopathic Medicine-Using our recently developed cat nictitating membrane preparation, CS intensity levels of 65,77 , and $90 \mathrm{~dB}$ were given to three paired and three unpaired groups of subjects. Results showed higher levels of responding with increasing intensity in both paired and unpaired conditions, indicating alpha response contamination at the highest intensity.

\section{$B R E A K-2: 25-2: 35$}

\section{2:35-2:50 (307)}

Discrimination Reversals and the Feature Positive Effect in Rats. EUGENE HEIM \& GEORGE HEISE, Indiana UniversityRats received feature positive and feature negative discriminations. The common stimulus was a tone and the feature was a panel light. A feature-positive effect was observed over successive reversals of the discrimination tasks. More responding occurred on feature-alone trials during extinction tests after feature positive than after feature negative training.

\section{2:50-3:00 (308)}

Stimulus Compounding During the Initial and Terminal Portions of an FI Schedule. LAURENCE P. MILLER \& BRIAN J. McMURRY, Western Washington University-A light or tone was correlated with the initial and terminal $10 \mathrm{sec}$ of a fixedinterval 30 -sec schedule. Either no $\mathrm{S} \Delta$ or a $45-\mathrm{sec} \mathrm{S} \Delta$ intervened between each portion. When stimuli were combined in each portion, rats' response rate increased in the initial portions; it was unchanged in the terminal portion with no $S \Delta$ and was decreased with an $\mathrm{S} \Delta$.

$$
\text { 3:00-3:15 (309) }
$$

Effects of CS Extent on Goal-Punished Extinction. HAROLD BABB \& W. BENNETT, SUNY at Binghamton-Albino rats were given different extents of a buzzer CS during shock-escape acquisition and extinction. Half were given regular extinction and half received shock-punishment in the goalbox. Self-punitive responding was facilitated by increasing extents of the CS. 
3:15-3:30 (310)

Polydipsia Contrast: Effects of Water Reinforcement Density on Schedule-Induced Drinking and Licking. JOSEPH D. ALLEN, RICHARD A. HOPPMANN, \& PHILIP J. BRANTLEY, University of Georgia-Using a modified Reynolds design, five hooded rats received food pellets at 1 -min intervals, while licks at a solenoidcontrolled tube concurrently produced $.05-\mathrm{ml}$ draughts according to scheduled rates that varied between 0.1 and $1.5 \mathrm{ml} / \mathrm{min}$. Drinking and licking contrast reached separate peaks at densities of 0.7 and $0.5 \mathrm{ml} / \mathrm{min}$, respectively, and both either disappeared or exhibited negative induction at densities below $0.3 \mathrm{ml} / \mathrm{min}$. 3:30-3:45 (311)

The Feature Positive Effect in the Rhesus Monkey. GARY M. PACE, GARY B. NALLAN, \& D. F. McCOY, University of Kentucky-Four rhesus monkeys were trained on feature positive (FP) and feature negative (FN) discriminations. Three response keys were illuminated on each trial. The "feature" array consisted of one red and two green keys, while the "common" array consisted of three green keys. Each monkey experienced both FP and FN phases. The feature positive effect was obtained.

$$
\text { 3:45-4:00 (312) }
$$

Black-White Discrimination Learning as a Function of Postnonreinforcement Events. CARL JOHNSON, Michigan State University, \& M. RAY DENNY, University of Wisconsin-Rats either retraced from the negative cue and were retrieved $10 \mathrm{sec}$ later from neutral gray sections of a Grice box or were confined in a negative end-box for 10-15 sec before retrieval. The latter group learned significantly faster than the retrace group, as did another control group manually removed from the negative end-box as soon as nosing an empty food dish.

\section{4:00-4:20 (313)}

The Role of Response-Unit Formation in FR Extinction. RICHARD B. DAY \& JOHN R. PLATT, McMaster UniversityThe response-unit hypothesis argues that the entire sequence of responses preceding reinforcement constitutes a single functional response. A modification of this hypothesis incorporating evidence concerning the relationshp between the length and number of response units emitted in extinction accounts for the effects on FR extinction performance of several acquisition and extinction variables.

\section{4:20-4:35 (314)}

Contextual Determination of the Value of a Reinforcement Schedule. WERNER K. HONIG \& JEFFREY WILLNER, Dalhousie University-Pigeons were trained on separate multiple schedules of reinforcement: green VI $30 \mathrm{sec}$ vs. blue VI $90 \mathrm{sec}$, and blue VI $90 \mathrm{sec}$ vs. red VI $270 \mathrm{sec}$. When given the opportunity to switch between the components of each discrimination, they advanced out of blue in the first discrimination, whereas they advanced into blue in the second one. Thus the values of a given schedule and of its associated stimulus are determined by the context in which they are embedded. In a second study, pigeons transferred the advance response from the green/blue discrimination to an orthogonal discrimination between vertical VI $90 \mathrm{sec}$ vs. horizontal VI $270 \mathrm{sec}$.

\section{4:35-4:50 (315)}

Amphetamine and an Internal Clock. SETH ROBERTS \& RUSSELL M. CHURCH, Brown University-A new timing procedure produces a peak in response rate in the middle of the trial. An experiment with rats showed that amphetamine makes the peak happen earlier. This and other results suggest that amphetamine speeds up the clock used in this task, and that the clock's pacemaker is internal.

$$
\text { 4:50-5:05 (316) }
$$

A Developmental Comparison of CER Extinction in the Rat. ALVIN M. BERK \& RALPH R. MILLER, Brooklyn College of $C U N Y$-Nineteen-day-old rat pups and adults were trained on Day 1 to an equal acquisition criterion in a CER paradigm such that ceiling effects were eliminated. On Day 2, both age groups were subjected to off-line extinction, and on Day 3, they were tested

for lick suppression without any food or water deprivation imposed. Pups consistently extinguished more rapidly than adults. These results have implications for theories of infantile amnesia.

BRAIN FUNCTION II

Victor Milstein, Lauren D. Carter Memorial Hospital, Indianapolis Forum Room, Friday afternoon, 1:00-5:15

\section{1:00-1:15 (317)}

Regulatory Effects of Preweanling and Postweanling VMH Destruction in Rats. ROBIN S. FISHER, C. ROBERT ALMLI, \& STEVEN PARSONS, Ohio University-Male and female rats received bilaterial lesions of the ventromedial hypothalamic nuclei or sham surgery at $\mathbf{1 0}$ or $\mathbf{4 0}$ days of age. All lesioned rats had significantly elevated Lee indices, indicating obesity and/or linear growth stunting. Only rats lesioned at $\mathbf{4 0}$ days of age had significantly elevated body weights.

1:15-1:25 (318)

Caudate Nucleus Lesions and Active Avoidance Performance. MARSHA O. GUILFORD, LESLIE H. HICKS, \& CAROLYN WOODFORK, Howard University-Two-way active avoidance performance was compared in three groups of rats: (1) bilateral lesions of the anterior caudate, (2) bilateral lesions of the posterior caudate, and (3) unoperated controls. Lesioned animals show a deficit when the warning signal duration is shortened. 1:25-1:35 (319)

The Effects of Lesions in the Subthalamic Nucleus on the Acquisition and Retention of an Active Avoidance Task. GARY THOMPSON, LESLIE H. HICKS, \& CHERYL BETHEA, Howard University-Rats with bilateral lesions in the subthalamic nucleus made fewer avoidance responses than unoperated and sham-operated controls in acquisition on a two-way shuttle avoidance task. Animals lesioned after acquisition training performed significantly more poorly on a retention measure of this task. 1:35-1:55 (320)

Visual Form Perception is a Function of the Visual Cortex. DAVE LAVOND, CHERI GECKLER, \& D. R. MEYER, Ohio State University-Rats prepared with serial visual-cortical ablations can relearn the horizontal-vertical stripes discrimination problem if given interoperative training. However, they fail to discriminate between obliquely oriented stripes. The findings are discussed in relation to the concept that pattern perception is completely dependent upon the integrity of cortically related systems. 1:55-2:10 (321)

An Explanation for some Instances of Recovery of Function in Brain-Damaged Cats. FRANCIS B. COLAVITA \& DANIEL $\mathbf{H}$. WEISBERG, University of Pittsburgh-Kittens and mature cats with lesions of insular-temporal cortex were tested on a temporal pattern discrimination. The typical relationship was seen between age at surgery and degree of recovery. However, the preoperative training data suggest that immature cats may initially adopt a different strategy to solve the problem. Caution is advised in interpreting "recovery of function" data where the "recovered" animals learn faster than normal controls. 2:10-2:25 (322)

Preference for Skin Cooling During Hypothalamic Warming. ELEANOR R. ADAIR, John B. Pierce Foundation \& Yale University-Squirrel monkeys, trained to regulated environmental temperature behaviorally, learned a new response to reduce an elevated hypothalamic temperature directly. During subsequent preference tests, they selected skin cooling over direct hypothalamic cooling when hypothalamic temperature was experimentally elevated. These results emphasize the importance of skin temperature change during behavioral thermoregulation.

\section{2:25-2:45 (323)}

Role of Pretectum and Ventral Lateral Geniculate Bodies in Black-White Discrimination. THACKERY S. GRAY, MARY GAYLE HATA, \& PATRICIA M. MEYER, Ohio State University-Rats with ablations of the pretectal region or ventral lateral 
geniculate bodies rapidly relearn a black-white discrimination. However, if combined with visual cortical ablations, pretectal ablations, but not LGNv ablations, markedly potentiate impairments of retention of the task. The results are discussed in relation to the putative role of sprouting in recoveries of functions.

\section{2:45-3:05 (324)}

Behavioral Effects of Forelimb Deafferentation During the Midprenatal Period in Monkeys. EDWARD TAUB, GILBERT BARRO, ROBERT HEITMANN, H. CANNON GRIER, Institute for Behavioral Research, Silver Spring, Maryland, \& DAVID F. MARTIN, Litton Bionetics, Inc., Kensington, Maryland-Rhesus monkey infants were exteriorized at either the end or the middle of the second trimester of pregnancy, subject to forelimb deafferentation, and then replaced in utero for completion of fetal development. After birth, the infants made extensive use of the limbs, though deprived of spinal reflexes and local somatosensory feedback.

$$
\text { BREAK-3:05-3:15 }
$$

\section{3:15-3:30 (325)}

Multiple Unit Activity in the Hippocampus as a Function of CS-US Interval During Classical Conditioning of the Rabbit's Nictitating Membrane Response. FRED K. HOEHLER \& RICHARD F. THOMPSON, University of California, Irvine-Rabbits were trained under three CS-US intervals $(50,150$, and $250 \mathrm{msec})$ as well as an unpaired control procedure. Both nictitating membrane and hippocampal multiple-unit response topographies were strongly influenced by CS-US interval, with peak response amplitudes occurring near the point of US onset. Hippocampal activity preceded and paralleled the nictitating membrane response.

$$
\text { 3:30-3:45 (326) }
$$

Additive Property of Human Evoked Brain Response Waveforms. DONALD I. TEPAS \& JAMES K. WALSH, St. Louis University-Evoked brain response waveforms combine using the additive laws of algebra. Inter- and intramodal experiments using auditory and/or visual stimuli confirm our previous suggestion that waveforms combine in this simple manner. In general, passive algebraic waveform interactions seem to be more likely contributors to naturally occurring waveforms than do neural interactions.

$$
\text { 3:45-4:05 (327) }
$$

Functional Division Among Hippocampal Cell Types During Classical Conditioning. THEODORE W. BERGER \& RICHARD F. THOMPSON, University of California, Irvine-Single-unit responses of hippocampal neurons were recorded during classical conditioning of the rabbit nictitating membrane reflex. During conditioning trials, response patterns for the majority of identified pyramidal cells were highly correlated with the amplitude-time course of the NM respose. The majority of cells presumed to be interneurons showed no such correlations. Thus, the major output neurons of the hippocampus-pyramidal cells-appear to be the anatomical substrate for the rapidly developing neural plasticity in this paradigm.

$$
\text { 4:05-4:20 (328) }
$$

Partial Recovery of Forelimb Motor Control Following Unilateral Motor Cortical Ablation in Rats. A. W. PRICE \& S. C. FOWLER, University of Mississippi-Two force transducers interfaced with a minicomputer were used as manipulanda to measure the effects of relatively small, unilateral motor cortical ablations on response force and rate in rats. These manipulanda were arranged in an operant chamber such that each subject could respond.on Transducer 1 only with his left paw and on Transducer 2 only with his right. Results showed clearly that lesions produced severe and permanent deficits in force and rate of response for the paw contralateral to the lesion.

$$
\text { 4:20-4:35 (329) }
$$

The Interrelationships Between Familial Sinistrality, Strength of Handedness, Sex, and Orientation of Writing Hand in a College Population. ALAN SEARLEMAN, JAMES TWEEDY, \&
SALLY P. SPRINGER, SUNY at Stony Brook-Numerous models exist which relate handedness and cerebral organization. Several predictions can be derived from these models regarding the relationships among a variety of subject variables. In the present study, empirical evidence to evaluate these predictions was obtained by means of a handedness questionnaire completed by 847 college students.

\section{4:35-4:50 (330)}

Sensorimotor and Regulatory Dysfunction Following Dorsal Pontine Destruction in Infant Rats. DAVID L. HILL \& C. ROBERT ALMI, Ohio University-Male and female rat pups sustained destruction of dorsal pontine structures (e.g., pontine taste area, trigeminal sensory pathway) at 10 days of age. Data from sensorimotor, feeding, and drinking tests conducted throughout development revealed a variety of sensorimotor dysfunctions, hyperdipsia, obesity, unusual growth of teeth, and abnormal taste preferences.

Visual Pathways that Guide Pain-Induced Defensive Boxing in Rats. DAVID B. ADAMS \& WALTER H. SEVERINI, Wesleyan University-Although tactile hairs of the face provide the primary guiding stimuli for shock-elicited defensive boxing of rats, the visual system also plays a role. As Thor and his co-workers have shown, rats continue boxing after facial anesthesia, and we have found that this boxing is visually mediated, since blinded animals do not show it. The visually mediated boxing is not abolished by superior colliculus lesions, but is abolished by visual cortex lesions. Rats with unilateral visual cortex lesions served as their own controls; closure of the ipsilateral eye abolished the visually mediated boxing, while closure of the contralateral eye did not.

\section{5:00-5:15 (331b)}

Visual Resolution of Neurons in the Cat's Striate Cortex. MARYSE C. LASSONDE, MAURICE PTITO, Université $d u$ Québec à Trois-Rivières, \& KARL H. BRIBRAM, Stanford University-Eighty-three striate cortex neurons were recorded with extracellular microelectrodes while presented with two lines of various separations and moving in the preferred direction and orientation. The cells' visual resolution was defined as the angle of separation at which the cell gave clearly separate responses to the single bars. Results show no significant difference between simple and complex cells in visual resolution (mean visual resolution: $1.49^{\circ}$ ). However, there is a correspondence between the resolution obtained using two lines and the receptive field size for simple cells. By contrast, the limit of resolution of complex cells is approximately one-half the width of their receptive field.

\section{ANIMAL BEHAVIOR I \\ Michael R. Best, Southern Methodist University Diplomat Room, Friday afternoon, 1:00-5:40}

\section{1:00-1:15 (332)}

Learning to Avoid Poisonous Foods under Free-Feeding Conditions. DONNA M. ZAHORIK \& ELIZABETH K. ADKINS, Cornell University-Quail readily learn to avoid liquids paired with illness in a standard learned aversion paradigm, but the strength of aversions to novel foods paired with illness is greatly reduced when the birds are trained and tested in a free-feeding situation.

\section{1:15-1:30 (333)}

Ordinal Volume Judgments by Squirrel Monkeys. ROGER K. THOMAS \& DONALD K. INGRAM, University of GeorgiaFour monkeys were to select the smallest, middle, or largest of three objects from a pool of 37 conditional upon their being presented on black (B), gray (G), or white (W) backgrounds, respectively. They were trained separately on B, W, B \& W, G, and B \& $W \& G$, in that order. Twenty-five sessions $(1,125$ trials) were allowed per condition. One monkey mastered the BWG problem, one failed on $\mathrm{G}$, one failed on BWG, and one is being trained on BWG. 
1:30-1:50 (334)

Food-Related Learning in Suckling Rat Pups. PAUL M. BRONSTEIN, Trenton State College, \& DAVID P. CROCKETT, Hunter College of CUNY-Lactating rats were fed one of two diets and, at weaning, fosterpups preferred the maternal rations. Furthermore, rat pups tended not to associate an illness with their mother's food. The preference of the pups for maternal diets seems mediated by learning (perhaps, "learned safety") rather than by any peripherally maintained trace of the dams' feeding histories. 1:50-2:10 (335)

Effects of Electroconvulsive Shock on Learned Helplessness in Rats. C. WILLIAM BRETT, THOMAS BURLING, \& WILLIAM B. PAVLIK, Virginia Polytechnic Institute and State University (read by W. B. Pavlik)-Rats given inescapable shocks in a Skinner box on Day 1 were "helpless" in a FR-2 shuttlebox task on Day 2 when compared to yoked escapable shocks or no-shock controls. ECS given following the shuttlebox test, following Skinner box training, or prior to Skinner box training greatly attenuated the "helplessness" effect.

$$
\text { 2:10-2:25 (336) }
$$

Delayed Go/No-Go Discrimination in Pigeons: Memory for Stimuli or Responses? ROGER K. R. THOMPSON, PAUL E. VAN HEMEL, \& KENNETH M. WINSTON, Franklin and Marshall College-Pigeons were trained on a delayed go/no-go discrimination. They were rewarded for pecking a white key presented $5 \mathrm{sec}$ after green and for not pecking the white key presented $5 \mathrm{sec}$ after red. Turning on the houselight during the delay interval decreased correct performance on the go/no-go task. Implications for trace and response theories of animal memory will be discussed.

$$
\text { 2:25-2:35 (337) }
$$

Stimuli Eliciting Ultrasonic Vocalizations of Defeated Male Rats. JAMES G. CORRIGAN, KEVIN J. FLANNELLY, \& HERMAN H. SPITZ, E. R. Johnstone Training \& Research Center (read by K. J. Flannelly)-Two experiments examined the stimulus properties of aggressive male rats which elicit $22-\mathrm{kHz}$ ultrasonic calls from previously defeated male conspecifics. Defeated males emitted calls in response to inaccessible agressive males but not to the soiled bedding of aggressive males, immobilized aggressive males, nonaggressive males, or castrated females.

$$
B R E A K-2: 35-2: 45
$$

$$
\text { 2:45-3:00 (338) }
$$

Effect of Variable Shocks on Feeding Patterns of Early Malnourished Rats. LUIZ DE OLIVEIRA, University of Sao Paulo, Brazil, \& DAVID A. LEVITSKY, Cornell University-A technique was developed to chronically measure the response to an environmental stress. Rats were trained to obtain food by pressing a bar. A CS was presented randomly from 6 to 48 times during the 12-h session. Previously malnourished rats showed a greater disruption in feeding patterns than controls.

$$
\text { 3:00-3:20 (339) }
$$

Representation of a Sequence by Pigeons. H. S. TERRACE, R. STRAUB, T. G. BEVER, \& M. SEIDENBERG, Columbia University-Three pigeons learned to peck different configurations of four colors, in a particular sequence, regardless of how these colors were positioned on four response keys. This demonstrates that complex sequence learning without step-by-step feedback following each response is possible in subprimate animals.

$$
\text { 3:20-3:35 (340) }
$$

Effects of Restricted Environments on Social Development of Acomys cahirinus. ETHEL TOBACH \& JOSEPH DE SANTIS, American Museum of Natural History (read by J. de Santis)Litters were reared in one of four environments [Factor A: burrow or "cleft"' nest site; Factor B: movable or nonmovable objects in environment $(2 \times 2$ design)]. Rearing experience was related to interactions with abiotic environmental features and social interactions during the litter period, at weaning and later.
3:35-3:50 (341)

The Social Context of Ultrasound Production by Infant Rats. MYRON A. HOFER \& HARRY SHAIR, Albert Einstein College of Medicine (sponsored by Abram Amsel)-Naturalistic observations and a series of analytic experiments explore the setting and the stimulus characteristics that regulate infant ultrasound production. Unlike the younger rats usually studied, 2-week-olds respond sensitively to the absence and to the return of familiar social companions by utilizing cues more specific than simple warmth and contour.

\section{3:50-4:05 (342)}

A Model of Antipredator Strategies of Fowl. CAROLYN KENT ROVEE \& WENDY HILL, Rutgers University-The initial component of a predation defense sequence is elicited by predator approach. Subsequent antipredator strategies are determined by the success or failure of preceding components in deterring predatory advance. A model of prey options and relative response intensities throughout the prey-predator interaction is described.

$$
\text { 4:05-4:25 (343) }
$$

Effects of Early Experience of Suckling on the Maintenance of Suckling. ELLIOTT M. BLASS \& JOHN T. KENNY, Johns Hopkins University (read by J. T. Kenny)-Preventing rats from suckling during Days 3 and 4 postpartum eliminated future suckling. This suckling deficit was prevented by allowing pups to locate and suckle nonlactating nipples of an anesthetized mother for 12 consecutive 5-min reattachments. Allowing pups' continuous suckling for $60 \mathrm{~min}$ did not prevent the deficit.

$$
\text { 4:25-4:45 (344) }
$$

Effects of Early Protein Malnutrition on Tail-Pinch Behavior of the Rat. THOMAS A. PICONE, University of Hartford, \& ROBERT D. HALL, Worcester Foundation for Experimental Biology (read by R. D. Hall)-In three experiments, tail-pinch behavior of rats subjected to early protein malnutrition differed, not in quantity but in kind, from that of well-nourished rats, whether or not there was postweaning rehabilitation. Malnourished rats were more likely to gnaw than to lick food and other objects; wellnourished rats were more likely to lick than to gnaw. Much tailpinch behavior was directed towards food, but ingestion was infrequent.

\section{4:45-5:00 (345)}

Schedule-Induced Eating? CORA LEE WETHERINGTON, University of North Carolina, Charlotte, \& AARON J. BROWNSTEIN, University of North Carolina, Greensboro-Waterdeprived rats exposed to fixed-time schedules of water ranging from 15 to $480 \mathrm{sec}$ failed to exhibit schedule-induced eating. Nevertheless, like schedule-induced behavior, the number of pellets consumed was a function of relative time since food and the rate of food consumption was a direct function of rate of water presentation.

\section{5:00-5:15 (346)}

Frustration and Social Rank in the Java Macaque. CORNELIA ADAMS, JOSEPH D. ALLEN, \& BRADFORD N. BUNNELL, University of Georgia-Two troops of adult java macaques barpressed for banana pellets on VI 60-sec schedules in which reinforcer collection by the animal was occasionally prevented. Response rates following omitted pellets exceeded those following collected pellets in four out of six animals in each troop, demonstrating frustration. Differences in frustration ratios were correlated with social rank among members of each troop.

$$
\text { 5:15-5:35 (347) }
$$

Pain and Aggression in the Rat. ROBERT J. BLANCHARD, D. CAROLINE BLANCHARD, \& LOREY K. TAKAHASHI, University of Hawaii-During "reflexive fighting," dominant colony rats switch abruptly from the attack pattern seen in colony fighting to the defensive pattern (boxing, freezing) typical of colony intruders in either task. Moreover, "striking" movements may be obtained by shocking a rat held alone on the grid. Finally, bites to a conspecific were potentiated by footshock or tailshock but only when the conspecific's snout could be bitten; such snout 
bites are typical of colony intruders but not of attacking colony rats. Pain therefore produces a pattern of behavior different in every detail from those of an attacking colony rat, but in excellent agreement with the defensive behaviors of strange rats placed in the colonies.

$$
\begin{aligned}
& \text { 5:35-5:40 (348) } \\
& \text { (Read by title only) }
\end{aligned}
$$

The Effects of Pinealectomy on Dominance in Male Syrian Golden Hamsters. DEBORAH L. LARSON, ROBERT J. MILLER, \& DAVID K. BLISS, School of Medicine, Southern Illinois University (read by R. J. Miller)-We examined the effects of pinealectomy on intermale dominance in Syrian Golden hamsters. We found that pinealectomized male hamsters were more dominant than sham-operated males. Sham-operated animals were paired with pinealectomized animals in the home cage of one animal. We also found that the home-cage animal was more submissive than the interloper animal.

\section{PSYCHOLINGUISTICS}

Ronald Cole, Carnegie-Mellon University Tudor Room, Friday afternoon, 1:00-5:35

\section{1:00-1:15 (349)}

Sow or Sow? Phonemic Coding and Ambiguity Decision. MICHAEL L. HILLINGER \& CARLTON T. JAMES, Rutgers University-Subjects were timed as they made ambiguous/unambiguous judgments to homographs, unambiguous words, and pronounceable nonwords. Decision times for homographs were significantly longer if the two meanings had different pronunciations (LEAD) than if they had the same pronunciation (BANK). These results are interpreted in light of the controversy over the necessity of phonemic coding in visual word recognition.

$$
\text { 1:15-1:30 (350) }
$$

Dynamic Information Specifies Vowel Identity. JAMES J. JENKINS, WINIFRED STRANGE, \& THOMAS R. EDMAN, University of Minnesota-Two studies investigated the importance of three kinds of information for the perception of selected American English vowels: steady-state frequencies, formant transitions, and syllabic duration. B + vowel + B syllables were electronically edited to remove various kinds of information. Vowel identity was specified best by dynamic information.

\section{1:30-1:40 (351)}

Effect of Telegraphic Prose on Reading Behavior. CLESSEN JAY MARTIN, Texas $A \& M$ University, \& CAROLYN BASSIN, TRATEC, Los Angeles-The effects of three telegraphic prose reduction methods were examined in relation to reading comprehension among 215 college students. No differences were associated with the method of reduction and no significant differences were associated with the $10 \%$ and $30 \%$ reduction levels on the comprehension measure. Reading rate and time decreased as reduction level increased.

\section{1:40-1:50 (352)}

The Word Frequency Effect and Orthographic Regularity. LEONARD KATZ, University of Connecticut-The word frequency effect (WFE) was investigated in a lexical decision task in which words and nonwords were equated for orthographic regularity. For nonwords, positive correlations between reaction time and measures of orthographic regularity were found. These and other data suggested that the WFE may be an orthographic regularity effect.

$$
\text { 1:50-2:10 (353) }
$$

Semantic Representation and Word Recognition While Listening to Main and Subordinate Clauses. DAVID J. TOWNSEND, Montclair State College \& Columbia University, \& THOMAS G. BEVER, Columbia University - The immediate representation of a main clause is more semantic than that of a subordinate clause. At the same time, word recognition appears to operate by a parallel scan in a main clause but by a serial scan in a subordinate clause. These results suggest that the form of representation may influence memory scanning strategy.

\section{2:10-2:25 (354)}

Metaphor Comprehension is an Automatic and Parallel Process. SAM GLUCKSBERG, DAVID E. HARTMAN, \& RONALD A. STACK, Princeton University-It takes longer to decide that a sentence is literally false when a metaphoric interpretation is implausible. This implies that people do not wait until a literal meaning is derived before deciding to process for metaphoric meaning. Instead, people seem to be unable to inhibit metaphoric processing, and do it in parallel with literal processing.

$$
B R E A K-2: 25-2: 35
$$

\section{2:35-2:55 (355)}

A Progressive-Refinement Theory of Text Understanding. ALLAN COLLINS, JOHN SEELY BROWN, \& KATHY M. LARKIN, Bolt Beranek and Newman, Inc.-We collected protocols from four subjects trying to make sense of five difficult-tounderstand texts. In these data, subjects construct an initial model, which they progressively refine by a process of constraint satisfaction. Subjects use systematic strategies to elaborate and revise their models, and to evaluate the model's plausibility. The audience will be asked to think along as we trace the protocols of subjects trying to understand two texts.

$$
\text { 2:55-3:10 (356) }
$$

Foregrounding and Discourse Comprehension. ALAN M. LESGOLD, MARY E. CURTIS, STEVEN R. ROTH, \& MARY S. RILEY, University of Pittsburgh-Sentences are understood faster if their definite references are to concepts that are in activated (short-term) memory. Activation of a concept can continue even if the concept is not directly referred to, so long as it is foregrounded. Illustrations do not appear to influence foregrounding in text processing.

\section{3:10-3:30 (357)}

A Model for Reading Comprehension. W. KINTSCH, University of Colorado, \& D. VIPOND, St. Thomas University-A process model for reading comprehension is outlined. A number of text samples are analyzed with this model, and the difficulty that the model has with these texts is used to predict their readability. These predictions are compared with behavioral data and standard readability formulas.

\section{3:30-3:45 (358)}

Hesitation Phenomena in English and Spanish Narratives. T. H. JOHNSON \& D. C. O'CONNELL, St. Louis University-Unfilled pauses and vocal hesitations (false starts, parenthetical remarks, filled pauses) were studied as to frequency and location. Results point to communalities shared by English and Spanish speakers and to language-specific use of hesitation devices. This type of analysis can be useful in the integration of cognitive and linguistic aspects of speech behavior.

\section{3:45-4:00 (359)}

The Subject of Attribution: A Linguistic Category of Preschool Children. MARTIN D. S. BRAINE \& JUDITH A. HARDY, New York University-Presented with pictures described by sentences with adjectival predicates, preschool children quickly learned to place a token on the subject of the attribution and not on other objects named in the sentence. The basis of the discrimination is a case-like category that is distinct from "agent," "patient,"' and "surface-structure subject."

\section{4:00-4:15 (360)}

Verbal Processing Speed and Reading Skill. CHARLES A. PERFETTI, LAURA BELL, THOMAS HOGABOAM, \& SUSAN GOLDMAN, University of Pittsburgh-Differences between skilled and less skilled young readers in verbal processing speed are obtained in RT tasks of vocalization, visual search, lexical decision, and sentence verification. Differences are absent from nonverbal stimuli, increase with word set size, and are unaffected when words appear in discourse. Basic context-free encoding speed at word and subword levels appears to be a major source of skill differences. 


\section{$4: 15-4: 35(361)$}

The Relative Accessibility of Semantic and Deep-Structure Syntactic Concepts. ALICE F. HEALY, Yale University and Haskins Laboratories, \& ANDREA LEVITT, Wellesley College and Haskins Laboratories-The accessibilities of the syntactic concept deep-structure subject and the semantic concept experiencer were compared in concept formation and recognition memory experiments. The semantic concept was more accessible than the syntactic in both experiments. These results favor case grammar to Chomsky's transformational grammar in a model of linguistic behavior.

\section{4:35-4:50 (362)}

Verbal Processing Speed and Reading Skill. CHARLES A. PERFETTI, LAURA BELL, THOMAS HOGABOAM, \& SUSAN GOLDMAN, University of Pittsburgh-Differences between skilled and less skilled young readers in verbal processing speed are obtained in RT tasks of vocalization, visual search, lexical decision, and sentence verification. Differences are absent for nondecision verbal stimuli, increase with word set size, and are unaffected when words appear in discourse. Basic context-free encoding speed at word and subword levels appears to be a major source of skill differences.

$$
\text { 4:50-5:05 (363) }
$$

Comprehension of Metaphor. JOHN L. SANTA, Rutgers University, \& PATRICIA E. PARSEGHIAN, University of Pittsburgh-Rated distance from the predicate term of a metaphor to the interpretation of the whole predicted recognition performance when subjects studied metaphors and had to recognize interpretations, or vice versa. Similarly, two experiments demonstrated that time to comprehend a metaphor was related to predicateinterpretation distance.

\section{5:05-5:10 (364)}

(Read by title only)

Retrieving and Verifying Episodic Facts. MICHAEL E. MCCLOSKEY \& SAM GLUCKSBERG, Princeton UniversityThe Anderson and Bower (1973) HAM and Anderson (1976) ACT models for fact retrieval were tested in a series of experiments involving speeded verification of simple episodic facts (e.g., John is a lawyer). The data were inconsistent with both models. Results suggested (a) that retrieval and verification of simple facts involves a comparison of the meanings of the concepts involved, and (b) that a fact is found to be false not when it cannot be located in memory, but rather when contradictory information is accessed. In these two respects, verifying episodic information is similar to verifying information in semantic memory.

\section{5:10-5:15 (365)}

(Read by title only)

The Effect of Source Credibility on the Interpretation of Implied Claims in Advertising. RICHARD J. HARRIS \& KAREN L. PERCH, Kansas State University-Subjects listened to a series of simulated radio advertisements and afterwards evaluated statements about the advertised products as true, false, or of indeterminate truth value, based on the commercial. Half of the critical test statements had been asserted (Crust prevents cavities) and half imlied (Crust fights cavities) in the ads. Half of the subjects heard prior favorable information about the selling company, while the other half heard unfavorable information. Results showed that favorable source information made subjects less likely to judge implied claims as true than did unfavorable information, especially when they were told to accept the original commercial as true.

$$
\text { 5:15-5:20 (366) }
$$

(Read by title only)

Visual Search and Reading. JAMES F. JUOLA, DENNIS A. McDERMOTT, \& TIMOTHY J. MILLER, University of Kansas -Subjects read through three-sentence paragraphs and were tested for comprehension after reading. On some trials, reading was concurrent with search for a specific word or syllable target or for an exemplar of a given semantic category. Comprehension, but not reading speed, was poorer with the concurrent search task.
Search times increased linearly with the sentence containing the target, and search rates were equivalent for all target types. However, word targets were found faster overall than syllables or category exemplars. Similar results were found for paragraphs composed of unrelated sentences and those made from unrelated words. The results did not replicate the "semantic superiority effect" reportedly found in similar experiments.

(Read by title only)

Probing the Meaning of a Scene. MARY C. POTTER \& BERNARD ELLIOT, M.I.T. (sponsored by Richard Held)-A scene can be understood in a glimpse. Is the representation of such pictorial knowledge different from verbal representation? Immediately after viewing a scene, subjects decided whether a probe object (a drawing or word) was relevant to it. Drawing and word probes were judged equally fast. Like sentence meaning, the meaning of a scene is represented amodally.

5:25-5:30 (368)

(Read by title only)

Explicit Scope Structure Facilitates Syntax Learning Better than Case. GEORGE M. ROBINSON, Duke University (sponsored by J. E. R. Staddon)-Each subject studied a miniature artificial syntax from drawings of simple events matched to strings of iconic ideomorphs under one of three conditions: Control-strings composed of ideomorphs only. Case-case category of each ideomorph in string marked by placing them on different colored squares, providing an ordered case frame. Scope-structure indicated by a set of nested rings around ideomorphs in string. When subjects were tested on new strings with ideomorphs only, the results were: Scope was better than Case and Control; Case was not better than Control.

\section{5:30-5:35 (369)}

(Read by title only)

Contextual Requirements for Inferential Cueing of Sentence Recall. MICHAEL E. J. MASSON, University of Colorado (sponsored by Edward J. Crothers)-Two experiments investigated inferential cueing of sentence recall. When standard instructions to learn were used, cued and free recall performance did not differ. Cueing was facilitative when the encoding task induced a specific contextual interpretation that was consistent with the inferential cue provided at recall. Memory for concrete sentences was facilitated by inferential cues to a greater degree than was memory for abstract sentences.

\section{MEMORY AND RECALL IV}

\section{Matthew H. Erdelyi, Brooklyn College, CUNY} Empire Room, Saturday morning, 8:30-12:25

\section{8:30-8:50 (370)}

Verbatim and Paraphrase Memory for Sentences. MICHAEL P. TOGLIA, Purdue University, \& GREGORY A. KIMBLE, Duke University - Two experiments employed unfamiliar facts to investigate memory for sentence content. Deeper processing produced better recall. While, immediately, verbatim sentences were verified more accurately than paraphrase statements, this advantage sometimes remained after a 15-min delay. This result and a related recognition experiment suggested that surface information does not always decay within a few minutes. Implications are discussed utilizing the episodic/semantic memory distinction, levels of processing, and Kintsch's model of text memory.

$$
\text { 8:50-9:10 (371) }
$$

Behavioral Contrast in Free Recall and in Discrimination Learning. STEPHEN GROSSBERG, Boston University-Behavioral contrast in discrimination learning can be ascribed to feedback interactions between feature detectors that can adapt to changing background activity levels as they store cues in STM. The adaptation is due to competition between feature detectors in shunting on-center off-surround networks. In the particular case that a peak shift occurs, the feature detectors respond to a net input pattern 
that is composed of an excitatory and inhibitory generalization gradient of incentive-motivational signals. A similar competition can occur when list items are presented through time, and can produce both primacy and recency effects in STM. The primacy effect can support correct immediate recall of short lists that have not been coded in LTM.

\section{9:10-9:30 (372)}

Hypermnesia in Memory for Words and Pictures. HENRY L. ROEDIGER, III, University of Toronto-Subjects increased the number of items recalled when given three successive 7-min recall trials following presentation of either 50 pictures or 50 words. However, these subjects did not recall more unique items than controls allowed one 21 -min recall period. Hypermnesia seems to result simply from allowing additional time for recall.

$$
\text { 9:30-9:45 (373) }
$$

Distinctiveness and Elaboration of Processing in Recognition and Recall Memory. WILLIAM F. BATTIG \& KATHLEEN R. WEISS, University of Colorado-Single word ratings on one of three unrelated semantic dimensions (concreteness, pleasantness, number of features) produced higher recognition than three related dimensions (concreteness, imagery, categorizability). Unrelated ratings facilitated recall only of words elaborated within an interpolated prose passage, implicating elaboration as more important for recall, while distinctiveness is central to recognition.

\section{9:45-10:05 (374)}

How a Story Schema Controls Recall. JEAN M. MANDLER, University of California, San Diego-Some characteristics of story schemata and their role in retrieval are briefly desribed. The effects of a story schema can be seen in the quantity, quality, and temporal sequencing of recall. Pronounced effects of a schema were shown in the types of distortions occurring in recall of irregular stories and in the tendency to recall such stories in canonical form. The latter tendency was more pronounced for children than for adults.

\section{0:05-10:25 (375)}

Semantics and Imagery in Sentence Recall. SHELDON ROSENBERG, University of Illinois at Chicago Circle-Normative investigations revealing positive correlations between rated imageability, comprehensibility, and familiarity of sentences have raised questions about many published studies of sentence memory. The present experiments, however, have helped to identify conditions under which the variables rated imageability and rated familiarity appear to have independent effects on sentence recall.

\section{BREAK-10:25-10:35}

\section{0:35-10:50 (376)}

Superior Memory for Generated Words. NORMAN J. SLAMECKA, University of Toronto-Input of a long list was either passive, with items being presented to the subject, or active, where they were generated by the subject. The identical targets were involved in both conditions. Several experiments showed that memory for actively generated words was consistently superior to the same words received passively.

\section{0:50-11:05 (377)}

The Influence of Homograph Polarization on Memory Access. DAVID S. GORFEIN \& JEANNE VIVIANI, Adelphi University - Lexical access is investigated employing homographs in a singleitem recognition latency measure in the Brown Peterson paradigm. To-be-remembered items prior to the homograph trial are chosen to prime either its weak or strong meaning. The items, subsequent to the homograph, are chosen from words associated with the nonprimed meaning. The degree of homograph polarization is related to the activation and reactivation of semantic memory.

\section{1:05-11:15 (378)}

Multiple Encodings and Trace Strength. NEAL KROLL \& DOUGLAS METZLER, University of California, Davis-
Memory performance (recall, recognition, and frequency estimation) within a "processing level" (semantic or structural attributes emphasized during incidental task) was better if the same question was asked on word repetition than if a different question was asked. Results discussed in terms of the "encoding variability" and "depth of processing" principles.

\section{1:15-11:30 (379)}

Retrieval Processes in Recall and Recognition. JUDITH C. NICHOLS \& MILTON H. HODGE, University of GeorgiaWhen subjects retrieved digits by same-order recall (SO), free recall (FR), natural serial-order recall (NSO), or a recognition task, RECOG $>$ NSO $>$ FR $>$ SO. These and other differences are related to a retrieval continuum defined by combinations of search and decision.

\section{1:30-11:45 (380)}

Motoric Components of Meaning: Effects on Memory for Words and Sentences. ELI SALTZ \& DAVID DIXON, Wayne State University-Meanings of words often have motoric dimensions (e.g., jump, runner). Predictions from the Saltz-Klein memory theory were tested: (a) enacting meaning should facilitate memory; (b) children should benefit more than adults; (c) motor and visual imagery should be separate factors; (d) identity of imput-output motor cues should not be the basis for memory facilitation.

\section{1:45-11:55 (381)}

The Influence of Payoffs on the Spacing Effect in Free Recall. JON WRIGHT, JOHN BRELSFORD, \& MARK PROVENZANO, Rice University-Deficient processing theories attribute the spacing effect to differential processing of items occurring at different lag values. In an overt rehearsal study, payoffs were introduced to manipulate processing in order to influence the spacing effect. The influence of payoffs on rehearsals and recall of adjacent items was also analyzed.

\section{1:55-12:10 (382)}

Memory for Unusual Faces. LEAH L. LIGHT, Pitzer College, FORTUNEE KAYRA-STUART, \& STEVE HOLLANDER, Claremont Graduate School-Results of two experiments in which faces rated as unusual were found to be recognized better than ordinary faces will be compared to those of Franks and Bransford for memory of category members at varying distances from a prototype. Interrelationships among rated unusualness, attractiveness, interitem similarity, and the presence of added features will be discussed, as will the relative efficacy of these variables as predictors of recognition accuracy.

\section{2:10-12:20(383)}

The Mnemonic Value of Orthography Among Beginning Readers. LINNEA C. EHRI, University of California, DavisThe mnemonic value of spellings in a sound-memory task was examined. First and second graders learned oral nonsense responses faster when spellings were provided during study periods. Correlations between learning trials with spellings and printed word recognition scores were very high, indicating the importance of this capability for reading acquisition.

$$
\text { 12:20-12:25 (384) }
$$

(Read by title only)

Repetition and Study-Phase Retrieval in an Incidental-Memory Paradigm. SAMUEL J. THIOS, Denison University, \& PAUL R. D'AGOSTINO, Gettysburg College-Two experiments investigated spacing and lag effects in an incidental-memory paradigm. In Experiment 1, subjects free-recalled object phrases repeated after 2, 6, or $12 \mathrm{sec}$ of a rehearsal prevention task. In Experiment 2, phrases were repeated where 0,4 , or 12 list events separated the two occurrences. In both experiments, on the second presentation of half the phrases, subjects actively retrieved first-occurrence information. Recall increased with spacing interval and lag only when study-phase retrieval was required. Spacing and lag effects appear to depend upon factors associated with study-phase retrieval and not upon subsequent processing of a repeated event after study-phase retrieval. 
INFORMATION PROCESSING V

Robert M. Lambert, Concordia University

Palladian Room, Saturday morning, 8:30-12:45

\section{8:30-8:40 (385)}

Irrelevant Information in the Stroop Color Word Test. ANGELA M. RIECK, University of Maryland, \& GLYNN D. COATES, Old Dominion University-The number of alternatives of both relevant (colors) and irrelevant (words) in the Stroop color word test were varied. Linear functions of RT on the number of colors and words were obtained. No interaction was obtained. Results are discussed in terms of the present theories of Stroop performance and attention.

\section{8:40-8:50 (386)}

S-R Compatibility Effects in Memory Scanning. GEORGE D. OGDEN, University of Maryland, \& EARL A. ALLUISI, Old Dominion University-CRT and memory-scanning RT functions to increasing set sizes (i.e., 2, 3, 4, 5, and 6) with verbal and motor response modes were compared. Both motor functions resulted in linear increases with increasing alternatives. Both verbal functions resulted in flat slopes. The implications of the flat-verbal-memory task for Sternberg's four-stage model of memory scanning and the importance of the total S-R ensemble are discussed.

\section{8:50-9:00 (387)}

An Analog Process for Multiplicative Judgment. LOLA L. LOPES, University of Wisconsin (sponsored by Norman $\mathrm{H}$. Anderson)-Subjects in judgments tasks often produce multiplicative data. Serial fractionation is a simple two-stage analog process which yields multiplicative data with either numerical or verbal input. Problem terms are evaluated serially and a mental quantity is reduced at each step. It differs from comparable computational routines in its stage structure, accuracy, error variance, and temporal characteristics.

\section{9:00-9:15 (388)}

Mental Distance in Knowledge Structures. DAVID A. TAYLOR \& JUNG-OH KIM, University of Rochester-The associative structures formed in the learning of symbol sets were explored using reaction-time techniques in a series of three experiments. The first two experiments dealt with previously learned sets, letters and digits, and the third examined the acquisition and integration of a new set formed from novel, letter-like symbols. The results of these experiments and those of other researchers indicate the emergence of powerful new tools for the analysis of knowledge structures.

9:15-9:25 (389)

Encoding Complex Stimuli. JOHN C. JAHNKE, Miami University-The present study showed that when the same color word appeared on three or nine consecutive Stroop color-word stimuli, color-naming was facilitated. Such an outcome poses a problem for information-processing schemes that envision automatic semantic analysis in the Stroop task.

\section{9:25-9:40 (390)}

Activation of Antonyms and Synonyms in Semantic Memory. ROBERT E. WARREN, JOHN P. GREEN, \& JAN H. BRESNICK, Columbia University-Priming of words related by antonymy or synonymy was observed in two experiments using naming latency facilitation and Stroop interference as measures of activation. Synonyms were less activated than antonyms, even when of equal associative. strength, and showed an irregular development of activation when encoding time was manipulated.

\section{9:40-10:00 (391)}

Two Ways of Transforming Visual Images: Implications of a Computer Simulation. STEPHEN M. KOSSLYN, Harvard University, \& STEVEN P. SHWARTZ, Johns Hopkins UniversityOur simulation of visual imagery includes a "pictorial" image that may be transformed in two ways: the image may be "moved" through the internal display structure, or may be "erased" and regenerated in the transformed state. This paper reports the relevant aspects of the simulation and some experiments that explore the validity of this distinction.
10:00-10:15 (392)

Retrieval of Information from Subjectively Organized Lis's. PATRICIA E. FRANKLIN, RONALD OKADA, York University, DAVID BURROWS, SUNY at Brockport, \& MICHAEL FRIENDLY, York University (read by D. Burrows)-Subjects learned supraspan lists by sorting list items into subgroups. RT for identifying probes as list items was a linear function of the number of subgroups in the list, but was not affected by the number of items in the probed item's subgroup. This suggests that processing is serial between, but not within, organized subgroups.

\section{BREAK-10:15-10:25}

\section{0:25-10:35 (393)}

Conscious Processing of Conceptually Related Faces. RONALD T. KELLOGG, University of Colorado (sponsored by Lyle E. Bourne, Jr.)-A class of Identakit faces defined in terms of common features was presented under conditions which either encouraged or attempted to prevent conscious encoding. A conscious process was defined in terms of (a) interference with concurrent performance on a dificult mental arithmetic task, and (b) a direct relation between recognition performance and subjective ratings of how much attention was paid to the faces during acquisition. Recognition confidence ratings indicate that subjects' ability to recognize exemplars and reject nonexemplars was slight, but reliable, even for those who did not consciously encode the faces. 10:35-10:45 (394)

Property Statement Verification: Effects of Typicality, Property Dominance, and Priming. MARK H. ASHCRAFT, Cleveland State University-Property statements, presented for reaction timed verification, had either typical or atypical subject nouns, high or low dominant predicate properties, and, in the second experiment, were primed by a related sentence. All high-dominant sentences were significantly primed, even in the atypical-atypical condition. Amount of accessible information predicts RT better than typicality. 10:45-10:55 (395)

Cognitive Arithmetic: Evidence for Two-Stage Decision and Search. MARK H. ASHCRAFT \& JOHN BATTAGLIA, Cleveland State University-Correct and incorrect single-column addition problems were presented for reaction timed verification. In contrast to Groen and Parkman's model, the evidence suggested that subjects can avoid searching or calculating by making a fast Stage 1 decision. Evidence for speeded decisions through repetition or priming is discussed.

\section{0:55-11:15 (396)}

Actualization of Knowledge: Question-Answering over the Adult Lifespan. ROY LACHMAN, JANET L. LACHMAN, \& CAMERON CAMP, University of Houston-Question-answering involves minimally three component systems: retrieval, inference, and metamemory control. Their properties and interactions are discussed. We report an experiment with retrieval efficiency expressed as a ratio of retrieved information to estimated data base. Efficiency may be constant over healthy adulthood. Universally anticipated decline probably reflects a judgmental heuristic.

\section{1:15-11:35 (397)}

Development of Metamemory Through Adulthood. JANET L. LACHMAN, ROY LACHMAN, \& CARROLL THRONESBERY, University of Houston-People aged 18 to 75 answered general world-knowledge questions while being timed, and supplied "feeling-of-knowing" judgments. Questions were readministered in multiple-choice format. Judgments were related to actual knowl-" edge, as were latencies to say "I don't know." Metamemory accuracy and efficient control appears to increase throughout the life-span of healthy persons.

$$
\text { 11:35-11:50 (398) }
$$

Control of Gaze Location in Pictures by Cognitive Factors. GEOFFREY LOFTUS, University of Washington-A series of pictures was presented to a subject at a 4 -sec rate. Any given picture was seen in one of two versions: One subject would see a version containing an unusual object (e.g., an octopus in a 
farm scene), while another subject would see the same picture containing a normal object (e.g., a tractor in a farm scene). Subjects tended to look faster and look more at unusual than at normal objects. These findings have implications both for the nature of peripheral processing and for the relationship between initial viewing of pictures and subsequent recognition of pictures.

\section{1:50-12:05 (399)}

Inference and Internal Structure in the Representation of Spatial Information. ALBERT STEVENS, Bolt Beranek and Newman Inc. (sponsored by Allan Collins)-In two sets of experiments, subjects judged the direction between cities from memorized maps. Subjects systematically distorted the direction of cities in different organizational units and were faster at making the direction judgment if they first judged the direction of the superordinate units. These results support a model in which spatial information is organized hierarchically and inference processes reconstruct information by combining superordinate and subordinate relationships. 12:05-12:25 (400)

Word Recognition from Fluent Speech. RONALD COLE, Carnegie-Mellon University-Experiments in which listeners detected mispronounced words in fluent speech reveals that (a) the first syllable of a word constrains recognition of subsequent syllables within that word, and (b) recognition of one word provides phonological, syntactic, and semantic information about an immediately following word. The results suggest that speech is typically processed syllable by syllable and word by word, and that recognition of one word constrains both the segmentation and recognition of an immediately following word.

12:25-12:40 (401)

Semantic Facilitation for Repeated Pictures and Words. FRANCIS T. DURSO, KATHLEEN FREITAG, SUNY at Stony Brook, \& ROGER W. SCHVANEVELDT, New Mexico State University-Subjects named pictures repeated as pictures (PP) or as words (PW) and words repeated as pictures (WP) or as words (WW). Naming latencies were shorter on the second presentation in all but the PW condition. Results are discussed in terms of abstract, verbal, and imaginal codes in semantic memory.

\section{2:40-12:45 (402) \\ (Read by title only)}

Inference as a Function of Sex and Political Attitudes. GREGORY E. MONACO, Kansas State University (sponsored by Richard J. Harris)-Speaker-hearer variables-attitude (toward the 1976 Presidential candidates), sex of speaker, and sex of heareroften ignored in information-processing research were examined in a debate prior to the election to determine effects upon the hearer's construction of inferences. Results were: First, subjects constructed more inferences about the candidate for whom they intended to vote. Second, pro-Ford females constructed more inferences about Ford when a male spoke pro-Ford, while pro-Carter females constructed more inferences about Carter when a female spoke pro-Carter. That pro-Ford females found a male to be a more credible source was consistent with the prevalence of anti-E.R.A. feelings among pro-Ford females, expressed in a pretest questionnaire.

\section{HEARING \\ Donald H. Mershon, North Carolina State University Club Room A, Saturday morning, 8:30-10:40}

\section{8:30-8:40 (403)}

Some New Data on the Lateralization of Noise Signals with Large Interaural Time Differences. W. A. WILBANKS, MICHAEL W. PATE, \& THOMAS F. ELLIOTT, University of GeorgiaBlodgett, Wilbanks, and Jeffress have reported that the human auditory system can utilize time differences considerably greater than those which can arise in a free sound field to lateralize noise signals. Some new data will be presented on the effect of large interaural time differences on the judgment of sidedness which show that the maximal time difference detectable as a difference in lateralization depends upon the envelope of the cross-correlation function of the noise signal.

\section{8:40-8:55 (404)}

Simultaneous Tone-on-Tone Masking. DAVID R. SODERQUIST \& ANDREA SAMMONS, University of North Carolina, Greensboro-A 10 -msec signal presented near the onset or just prior to the offset of a masker results in overshoot, an increase in the signal threshold. Overshoot was investigated by manipulating signal frequency, temporal delay, and mode of stimulus presentation (monaural or dichotic) in the presence of a 250 -msec masker. Three main effects and a Frequency by Mode interaction were significant.

\section{8:55-9:10 (405)}

Binaural Summation of the Loudness of Pure Tones. LAWRENCE E. MARKS, John B. Pierce Foundation Laboratory-A series of experiments, using the methods of magnitude estimation and loudness matching, showed that the loudness of a pure tone $(100,400$, or $1,000 \mathrm{~Hz}$ ) presented at equal or unequal intensities to two ears equaled the simple linear sum of the loudnesses of the components presented to the left and right ears.

\section{9:10-9:30 (406)}

Effects of a Rigid Surround on Vibrotactile Thresholds. GEORGE A. GESCHEIDER, ROBERT D. FRISINA, Hamilton College, \& RONALD T. VERRILLO, Syracuse University-Vibrotactile thresholds were found to depend on whether or not a rigid surround was used to confine the stimulus on the skin to the region of the contactor. The effects of the rigid surround were determined as the frequency, area, duration, and amount of adaptation were varied. Implications for a duplex theory of mechanoreception were considered.

\section{9:30-9:50 (407)}

Effects of Age on Vibratactile Thresholds and on Receptor Morphology. RONALD T. VERRILLO, Institute for Sensory Research, Syracuse University-Vibrotactile thresholds were determined at 11 frequencies between 25 and $700 \mathrm{~Hz}$ in four groups of subjects aged 10, 20,50, and 65 years (means). Changes in slope and sensitivity in the frequency function are consistent with changes observed in the morphological structure that occur with age in the Pacinian corpuscle.

\section{9:50-10:10 (408)}

Effect of Tactile Stimulation on Thermal Localization. BARRY G. GREEN, John B. Pierce Foundation Laboratory \& Yale University (sponsored by James C. Craig)-Mislocalization of thermal sensations occurs when the spatial pattern of thermal stimulation is inconsistent with the spatial pattern of tactile stimulation. Specifically, when the first and third fingers touch a warm (or cool) surface and the second finger touches a thermally neutral surface, all three fingertips feel warm (or cool). This result and the results of additional experiments raise interesting possibilities concerning the role tactile stimulation plays in thermal localization.

\section{0:10-10:25 (409)}

Time Course of Gustatory Adaptation. DONALD H. McBURNEY \& JANNEANE F. GENT, University of Pittsburgh-Subjects rated the taste of solution-soaked filter paper over time. Adaptation was complete for all compounds at most concentrations. Time course was exponential with similar half-life for all conditions. Adaptation was not the result of stimulus loss. The filter-paper technique allows greater stability of stimulus, hence complete adaptation.

\section{0:25-10:40 (410)}

Developmental Changes in the Storage and Retrieval of Pictorial Information. RICHARD A. CHECHILE, Tufts University, CHARLES L. RICHMAN, Wake Forest University, C. TOPINKA, \& K. EHRENSBECK, Tufts University (to be read by R. A. Chechile \& C. L. Richman)-First and sixth graders plus college students were examined with the Chechile and Meyer (1976) storage-retrieval analysis for a serial probe task. The recall improvement from first to sixth grade was due to both storage and retrieval, but the further improvement for college students was due to retrieval alone. Both primacy and recency serial position effects were found for correct recall. Primacy and recency were of equal magnitude for storage, but retrieval showed only primacy. 


\section{PSYCHOPHYSICS \\ David Burrows, SUNY at Brockport \\ Club Room A, Saturday morning, 11:00-12:40}

11:00-11:10 (411)

Subjective Probability Assessment and the Shape of the Distribution. RICHARD S. JOHN \& WARD EDWARDS, University of Southern California-Seventy-two subjects were presented with three samples of pick-up sticks, each painted yellow and blue. After viewing each sample distribution, subjects assessed subjective probability distributions over the "length of yellow" painted on sticks in each population sampled. Each subject utilized one of three popular probability assessment techniques in making the uncertainty judgments. The shape of the distribution of lengths of yellow was found to interact with assessment technique, suggesting that biases introduced in subjective probability distributions vary as a function of the uncertain quantity being assessed.

\section{1:10-11:20 (412)}

Obsolescing ROC. W. A. GIBSON, Queens College of CUNYif $\mathrm{k}$ is the ratio of dispersion in the signal-plus-noise distribution to that for noise alone, then $d^{\prime}$ is $Z_{0}+k Z_{1}$, where $Z_{0}$ and $Z_{1}$ are normal deviates for false alarm and hit rates, respectively. For every pair of criterion locations, then, $k$ is estimable. A least-squares solution for $\mathrm{k}$ and a minimum-variance estimate for $\mathrm{d}^{\prime}$ are presented for multiple criterion locations.

$$
\text { 11:20-11:40 (413) }
$$

Stimulus Information and Sequential Dependencies in CrossModality Matching. LAWRENCE M. WARD, University of British Columbia-The theory of "fuzzy" cross-modality matching presented by Ward (1976) predicts that the amount of stimulus information available will affect the magnitude of sequential dependencies (among other things) in such data. Results of an experiment in which stimulus information was manipulated were in general consistent with the theory. However, some deviations from the initial predictions indicated that the manipulation affected several different aspects of the judgment processes involved in cross-modality matching.

11:40-12:00 (414)

A New Theory of Paired Comparison. STEPHEN W. LINK, McMaster University-This new theory of paired comparison provides predictions of both response probability and response time. As a consequence, the theory permits relationships between response times to various pairs of stimuli to be explored. The theory makes several predictions that are compatible with previous theories but also suggests some rather surprising new findings relating choice probability and response time.

12:00-12:15 (415)

Signal Detection and Matching. JOHN A. NEVIN, PETER JENKINS, STEPHEN WHITTAKER, \& PETER YARENSKY, University of New Hampshire-Reinforcement for errors in a signal-detection task with animal subjects leads to reductions in conventional measures of sensitivity. A new model is proposed which integrates signal detection with the matching law for operant choice behavior, and in which a sensitivity index remains constant despite reinforcement for errors. Some preliminary research is described.

\section{2:15-12:30 (416)}

To Honor Fechner and Reveal His Law. SCOTT R. PARKER, The American University, \& BRUCE A. SCHNEIDER, University of Toronto (sponsored by Walter C. Stanley)-Fechner's proposal that equally often noticed differences are subjectively equal fits the data of seven published studies on the discrimination of $1,000-\mathrm{Hz}$ tones differing in intensity. Constant discriminability corresponds to constant loudness difference. Loudness is nonetheless a power function of sound energy, since Weber's law fails.

$$
\text { 12:30-12:40 (417) }
$$

Haptic and Visual Judgment of Proportionality. STUART APPELLE, SUNY at Brockport, \& PHILIP DAVIDSON, Univer- sity of Rochester (sponsored by David Burrows)-To determine whether proportionality emerges as a unique property of form or reduces to simple measurement of the component linear extents, judgments of proportion were made for rectangular stimuli and compared with judgments of length. Both visual and haptic judgment of proportion were seen to emerge as a unique property of form, independent of linear extent or absolute size.

HUMAN LEARNING

Gediminas Namikas, University of Windsor

Forum Room, Saturday morning, 8:30-11:40

\section{8:30-8:50 (418)}

The Judgment of Contingency in Depressed and Nondepressed Students: Sadder but Wiser? LAUREN B. ALLOY, University of Pennsylvania (sponsored by Richard L. Solomon)-Depressed and nondepressed college students judged the degree of contingency between their responses and the occurrence of an outcome in one of a series of contingent or noncontingent problems. In the contingent problems, all subjects' iudgments of contingency were accurate, and were uncorrelated with the frequency of occurrence of the outcome. In the noncontingent problems, however, nondepressed students accurately judged that they had little control when the outcome occurred infrequently, but showed an "illusion of control" when the outcome occurred frequently. Depressed students, on the other hand, accurately judged that they had no control in both of the noncontingent problems.

\section{8:50-9:00 (419)}

Work Distribution and Practice Methods in Human Selective Learning. CLYDE E. NOBLE, \& H. ROGER WILKERSON, University of Georgia (read by H. R. Wilkerson)-Previous studies have failed to support the hypothesis that $I_{R}$ plays an important role in human selective learning, indicating that work distribution on the Selective Mathometer may affect ${ }_{S} \mathrm{H}_{R}$ directly. This experiment used 480 college subjects and ISIs of $2,6,10$, or $20 \mathrm{sec}$ in a 40-trial transfer design. Our data suggest that the effects of distribution on ${ }_{S} \mathrm{H}_{R}$ are different for the correction and noncorrection methods of practice.

\section{9:00-9:20 (420)}

Self-Punitive Behavior in Humans: Effects of a Self-Fulfilling Prophecy. JED E. ROSE \& EDMUND FANTINO, University of California, San Diego-Human subjects were exposed to a situation in which a self-fulfilling prophecy was in effect; their trial-by-trial predictions regarding the occurrence of an aversive loud noise in a modified classical conditioning paradigm were automatically confirmed. Two experiments demonstrated that self-punitive behavior could be successfully manipulated without subjects becoming aware of the existing contingencies, and that expectancy responses could be profitably employed in studying human self-punitive behavior.

$$
\text { 9:20-9:40 (421) }
$$

Text Comprehension and the Effective Visual Field. JOHN R. FREDERIKSEN, Bolt Beranek and Newman-The effects of textual context and the sequential redundancy of words in the test phrase on effective visual field width were evaluated. Texts used had Bormuth readability levels extending above and below the subject's comprehension level. Effective field width was broader when a semantically constraining context was provided and depended upon the skill level of the reader.

\section{9:40-10:00 (422)}

The Roles of Encoding Specificity and Organization in Mnemonic Devices. FRANCIS S. BELLEZZA, B. GOVERDHAN REDDY, \& DANIEL R. YOUNG, Ohio University-A series of experiments demonstrated that (a) recall performance will not improve if a different mnemonic is used on each trial, and (b) organization of items may be more important than the specificity of the recall cue. Ten items associated with a peg word instead of one item improved recall performance. 
10:00-10:15 (423)

On Changing Children's Metamemory: Effects of Strategy Transfer and Awareness. JOHN C. CAVANAUGH \& JOHN G. BORKOWSKI, University of Notre Dame-Substantial long-term improvement in specific metamemorial skills were shown by children who successfully acquired and transferred a cumulativecluster rehearsal strategy, and then received feedback. Significant correlations were found between metamemory pretest scores and strategy form (and recall) at transfer, and between posttest metamemory and transfer form.

\section{BREAK-10:15-10:30}

\section{0:30-10:45 (424)}

Subproblem Learning in the Four-Category Concept Problem. JOHN L. GIFFORD \& IRWIN D. NAHINSKY, University of Louisville-The solution of concepts involving two relevant (nonredundant) dimensions was assessed using a subproblem analysis. Indepence of performance on the two dimensions was tested in two ways. Within-trial independence was demonstrated, in contrast to longitudinal dependence. Tests for stationarity of performance prior to solution yielded mixed results.

\section{0:45-11:00 (425)}

Response Cost and Impulsive Word Recognition Errors in Reading-Disabled Children. DEBORAH E. BRENT, University of North Carolina, \& DONALD K. ROUTH, University of Iowa (read by D. K. Routh)-Thirty fourth-grade reading-disabled children were given a pretest word recognition list and then a second list under one of three experimental conditions: control, positive reinforcement, and response cost. Positive reinforcement only increased response latency, while response cost increased latency and significantly reduced reading errors, relative to the control condition.

\section{1:00-11:20 (426)}

Learning the Layout of a Kinesthetically Experienced Space: Movement Patterns and Visual Transfer. MICHAEL DENNY, Michigan State University (sponsored by Lauren J. Harris)-The locations of six points in a planar space (table-top) were learned under different patterns of movement within the space. Kinesthetic knowledge of the spatial layout was assessed by measuring the response time of movements between points. Visual knowledge was assessed by measuring the accuracy and speed of responding on a visual recognition-detection task. "Uniform" and "random" movement patterns led to equivalent acquisition and kinesthetic transfer performance, but different visual transfer performance. The difference was related to the level of egocentric reference apparent in the visual representation of the layout. Implications of the results for a theory of spatial learning will be discussed. 11:20-11:30 (427)

Analytic vs. Synthetic Encoding and Long-Term Retention. SHAHIN HASHTROUDI, George Washington University (sponsored by Marcia K. Johnson)-In three experiments, an incidental learning paradigm was used to investigate the effect of various semantic orienting tasks on long-term retention. Tasks activating salient aspects of the meaning of words led to a slower forgetting rate than tasks activating situation-specific or idiosyncratic aspects. Implications of these findings are discussed.

$$
\text { 11:30-11:35 (428) }
$$

(Read by title only)

Reducing Avoidance Behavior in a Retarded Adult by Withholding Reinforcement. GEORGE P. E. CAESER, III, \& HENRY E. MARKS, O'Berry Center, Goldsboro, North Carolina-Jane was absent of $94 \%$ of the time from a workshop for the retarded. Requiring attendance, even with high-density reinforcement, resulted in severe self-injurious behavior. Her living unit withdrew all reinforcement (snuff and edibles) during the time she was scheduled at the workshop. At the same time, the workshop delivered highdensity reinforcement contingent on attendance. Duration of scheduled attendance at the workshop was increased from 90 10 $180 \mathrm{~min}$ in increments of $15 \mathrm{~min}$ over a 17 -week period. Her absence from the workshop dropped to $5 \%$. There were no incidents of self-injurious behavior at the workshop.

11:35-11:40 (429)

(Read by title only)

Control of Hoarding Behavior in a Severely Retarded Adult Using Satiation. HENRY E. MARKS, O'Berry Center, Goldsboro, North Carolina-John hoarded and carried rags in his hands for over 40 years. Baseline measures found less than $1 \mathrm{~h}$ per day when did not have his rags. Forcible removal of the rags produced aggression. A satiation program required him to carry his rags in two large bags and carry both bags or nothing. Rags were continually added to the bags until total weight reached $50 \mathrm{~kg}$. John was allowed to carry the bags anywhere within his living unit, but he was required to leave them inside when he left the unit. Eleven weeks after the start of the program, the time with his hands free of rags had increased to an average of $16 \mathrm{~h}$ per day.

\section{ANIMAL BEHAVIOR II \\ David A. Levitsky, Cornell University \\ Diplomat Room, Saturday morning, 8:30-11:20}

\section{8:30-8:45 (430)}

Discrimination of Clicks from Artificial Echos in Young and Old Rats. V. HOEFFDING \& J. M. HARRISON, Boston University-The precedence effect was measured in rats using clicks of equal intensity, clicks with the "echo" reduced in intensity as a function of arrival time, and simultaneous clicks of different intensities. The precedence effect was clearly different from the behavioral effects of intensity difference. There were no age effects. 8:45-8:55 (431)

Preferences of Female Rats for Odors of Dominant vs. Subordinate Males. DOMINIC J. COSTANZO \& JAMES W. RENFREW, Muskingum College-Sexually experienced and naive female rats who were in estrous or in anestrous condition were preference tested for the odors of dominant vs. subordinate males. Only experienced females demonstrated significant preferences. When in estrous they preferred the subordinate male odor, and when in anestrous they preferred the dominant male odor.

\section{8:55-9:10 (432)}

Genesis of Precopulatory Arousal in the Male Rat. D. H. THOR, E. R. Johnstone Training \& Research Center, Bordentown, New Jersey-Mature male rats gonadectomized at 1, 10, 30, and 60 days of age were compared with controls on initial social-investigatory response to a novel conspecific. All castrate groups revealed a substantial depression in arousal as determined by olfactory-related criteria. An androgen- and sensory-dependent model is proposed for the precopulatory arousal mechanism.

\section{9:10-9:20 (433)}

Gender Composition of the Litter Influences Aggression in Male Mice. FRANCINE WEHMER \& JESSIE NAMIKAS, Wayne State University (read by J. Namikas)-Mice were reared in litters composed of 6 males, 6 females, or 5 females and 1 male. Some social behaviors occurred earlier among pups in the mixed litters than in litters of one sex. No differences in maternal behavior were observed. In adulthood, males raised as the single male in the litter engaged in more intermale aggression than those from allmale litters.

\section{9:20-9:30 (434)}

Juvenile Mouse Urine as an Aggression Inhibitor. GEORGE T. TAYLOR, University of Missouri-St. Louis-Two experiments examined the attack latencies of resident adult male mice toward intruders. Juvenile or adult male mice served as intruders. The intruders were painted either with the urine from another adult male, the urine from another juvenile, or distilled water. The results suggest that juvenile urine serves as an aggression-inhibiting pheromone in mice, though other stimuli may be equally important. 


\section{9:30-9:45 (435)}

Baroreceptor Involvement in the Immobility Reflex. DANIEL C. HATTON \& MERLE E. MEYER, University of Florida-The initiation of the immobility reflex in rabbits may be related, in part, to baroreceptor activity. Denervation of the carotid sinus significantly reduces the incidence of immobility and markedly reduces the fluctuations in blood pressure occurring during the induction procedure.

\section{9:45-10:05 (436)}

Multiple Category Classification by Pigeons. SHEILA CHASE, Hunter College of $C U N Y$-Eight pigeons were given extensive training in choosing among up to five key's, with the correct choice cued by luminance. Results obtained can be described by a model based on statistical decision theory.

\section{0:05-10:20 (437)}

Choice Behavior: Local Reinforcement Contingencies. JOHN M. HALE, University of California, Santa Barbara, \& CHARLES P. SHIMP, University of Utah-Different response requirements cued different local reinforcement contingencies in a discrete-trials choice experiment with pigeons. These contingencies rapidly acquired control over choice behavior. As the number of local reinforcement contingencies was decreased, preference more closely approximated probability maximizing. These results support a molecular, rather than a molar, analysis of behavior.

$$
\text { BREAK-10:20-10:35 }
$$

\section{0:35-10:55 (438)}

The Role of Short-Term Processes in Flavor-Mediated Latent Inhibition. MICHAEL R. BEST \& GAIL A. GEMBERLING, Southern Methodist University-A brief flavor preexposure $(5 \mathrm{cc})$ transiently reduces subsequent conditioned aversions, whereas more extensive preexposure $(15 \mathrm{cc})$ results in permanent disruptions of taste-aversion learning. That the transient latent inhibition effect is mediated by short-term memory processes is suggested by the susceptibility of this phenomenon to the intervention of "unexpected,"' disruptive interoceptive events.

$$
\text { 10:55-11:15 (439) }
$$

Repeated Learning, Unlearning, and Relearning of Choice Discriminations by Pigeons. JULIE SAGE-DAY \& ERIC G. HEINEMANN, Brooklyn College-Training periods during which sound intensity was correlated with reinforced key choice alternated with periods of no correlation. The analyses to be presented deal with the effect of repeated cycles of such training upon the presolution period, and upon the rate of acquisition and loss of the discrimination.

$$
\begin{aligned}
& \text { 11:15-11:20 (440) } \\
& \text { (Read by title only) }
\end{aligned}
$$

Schedule-Induced Drinking Facilitates Schedule-Controlled Feeding. J. D. KEEHN \& ROSA RIUSECH, York University-Four hungry rats barpressed for food reinforcement scheduled at 1-min fixed intervals in 7-h sessions with water either present or absent. Three rats barpressed and ate more when drinking was possible, and all rats drank most early in sessions. We concluded that schedule-induced polydipsia is toxic apropos drinking but adaptive apropos eating.

\section{REINFORCEMENT \\ Ralph M. Chinn, Clark College \\ Tudor Room, Saturday morning, 8:30-12:20}

\section{8:30-8:40 (441)}

Choosing Signaled Shock: Some Answers to Recent Criticisms. BRUCE ABBOTT \& PIETRO BADIA, Bowling Green State University-Two studies addressed specific criticisms of previous research on preference for signaled over unsignaled shock. In one, signaled shocks occurred at twice the density of unsignaled shocks, yet subjects chose the signaled condition, despite the impossibility of carry-over, which was suggested as the cause of similar results in a previous study. In another experiment, subjects' contact with the shock grid was monitored under signaled and unsignaled shock conditions. Results failed to support the contention by some that preference for signaled shock depends upon differential shock avoidance in the two conditions.

$$
\text { 8:40-8:55 (442) }
$$

Component Duration and Local Contrast. BEN A. WILLIAMS, University of California, San Diego-The local basis of behavioral contrast was assessed by examining which types of local contrast covaried with component duration. Shorter components produced greater contrast effects, with this the result of increased effects of the schedule in the following component, not of the schedule in the preceding component.

\section{8:55-9:05 (443)}

Signaled Delay of Reinforcement: Effects of Double Intermittency. MARC N. BRANCH, University of Florida-Pigeon pecks produced a delay stimulus $(25 \mathrm{sec})$ according to a fixed-ratio 15 schedule. One delay stimulus signaled that a 3-sec blackout would occur at its end. Another signaled that either food or a blackout might occur. As the probability that the second stimulus would appear was reduced, response rate during the fixed ratio increased.

\section{9:05-9:20 (444)}

Reinforcement Schedules: Retroactive and Proactive Inhibitory Effects of Reinforcers Interpolated into Fixed-Interval Performances. A. CHARLES CATANIA \& KENNETH KELLER, University of Maryland, Baltimore County, Catonsville-Total responding with pigeons' pecks maintained by fixed-interval schedules on two keys equals that with both schedules operating on one key. This finding is used to show how a reinforcer consistently interpolated at one point in a fixed-interval schedule reduces responding both earlier and later in that interval.

$$
\text { 9:20-9:35 (445) }
$$

Preference for Signaled Shock With and Without Shock Modifiability. NANCY A. MARLIN \& RALPH R. MILLER, Brooklyn College of $C U N Y$-Research seeking the theoretical basis and implications of why animals prefer to receive a signal prior to an unavoidable, unmodifiable shock has, for the most part, involved the use of scrambled footshock. In our first study, which appeared to obtain a preference for signaled shock (PSS), each of 24 rats was consistently observed to be subtly modifying or avoiding the scrambled footshock. Such modifiability renders scrambled footshock, even of duration as brief as $.5 \mathrm{sec}$, inappropriate for investigation of the PSS phenomenon. An efficient technique using fixed tail electrodes on rats that yields a true PSS will be described, and several studies using it to probe the nature of PSS will be presented.

$$
\text { 9:35-9:55 (446) }
$$

Delay of Reward and Punishment. CHARLES C. PERKINS, JR., Kansas State University-Performance during training with delayed rewards or punishments is explained in the tradition of Spence's (1947) theory. Experimental results which support this interpretation are described. It is concluded that this conventional reinforcement theory interpretation is both viable and parsimonious and that claims to the contrary are unjustified.

$$
\text { 9:55-10:10 (447) }
$$

Some Investigations of a Relational Principle of Reinforcement. JOHN W. DONAHOE \& MICHAEL A. CROWLEY, University of Massachusetts-The findings obtained from several studies stimulated by a relational principle of reinforcement will be described. The findings bear on the accommodation of such phenomena as conditioned reinforcement and punishment and on the determination of an appropriate metric for time allocation.

$$
\text { BREAK-10:10-10:25 }
$$

\section{0:25-10:45 (448)}

Reinforcing Characteristics of Schedules of Electric-Shock Presentation. E. F. MALAGODI, MICHAEL L. GARDNER, REGIS MAGYAR, \& SUSAN WARD, University of Florida-Leverpressing 
in squirrel monkeys was maintained under conditions in which presentation of noxious electric shock was the only scheduled consequence of responding. In one experiment, responding was at a higher overall rate under fixed-interval (FI) schedules than under comparable fixed-time (FT) schedules. In the second experiment, responding was well maintained under FI schedules when each FI shock was followed by a signaled 2-min period during which as many as 64 unavoidable shocks were presented. The results support Morse and Kelleher's contention that responding maintained by schedules of electric-shock presentation exemplifies the process of reinforcement.

\section{0:45-11:00 (449)}

Some Observations with Long Fixed Interval Reinforcer Schedules. DAVID A. ECKERMAN, University of North Carolina-A pigeon's keypecking was compared under fixed interval food reinforcer schedules of 0.5 to 2.0 days. Added ratio requirements in tandem or in conjunction with fixed interval 1.0 day were assessed. The role of stimulus change preceding food was observed for fixed time and fixed interval schedules of about a day.

$$
\text { 11:00-11:15 (450) }
$$

Task-Dependent Aspects of Reward. HELEN I. LYONS \& NELSON L. FREEDMAN, Queen's University at Kingston-A videotaped presentation will show rats leverpressing and wheelrunning for intracranial stimulation. While leverpressing, rats with different characteristic responses show temporal patterning varying directly with reward duration. Rats in an activity wheel illustrate the relative invariance of responding on this task.

\section{1:15-11:30 (451)}

Influence of Chlordiazepoxide on Gustatory Contrast. CHARLES FLAHERTY, Rutgers University-The influence of chlordiazepoxide (various dosages) on concurrent and successive contrast obtained in sucrose ingestion was investigated in four experiments. Concurrent contrast was uninfluenced by the drug under a number of different test conditions. Successive contrast was reduced only when initial drug administration occurred during postshift; administration during both pre- and postshift resulted in no effect of the drug. Results were interpreted in terms of stimulus, rather than emotion-reducing, properties of chlordiazepoxide.

$$
\text { 11:30-11:45 (452) }
$$

Alternative Reinforcement Effects on Fixed-Interval Responding. KENNON A. LATTAL \& SUSAN J. BOYER, West Virginia University-Pigeon's keypecks were reinforced with food on a fixedinterval schedule. Food was also available at varying time periods for not keypecking (DRO schedule). The time spent pausing increased as the duration of the pause required for reinforcement increased and as the frequency of reinforcement for pausing increased. The distribution of keypeck responses within each FI was more linear with more frequent DRO reinforcement.

$$
\text { 11:45-12:05 (453) }
$$

Licking One Saccharin Solution for Access to Another: Associative Learning or Substitution? WILLIAM TIMBERLAKE, Indiana University - When rats were required to lick one saccharin solution for access to another, neither the single nor paired baselines of licking separated the associative and nonassociative effects of the contingency. Of six models or empirical procedures tested, two within-subjects yoking procedures and a choice model best estimated nonassociative effects.

$$
\text { 12:05-12:20 (454) }
$$

Developmental Differences in the Effects of Ethanol on Extinction in Rats. A. JOHN ERNST, Washington State UniversityYoung and adult rats were trained to respond for positive reinforcement in a Y-maze for seven sessions. On the eighth and ninth sessions, responding in one of the three arms was extinguished. After the extinction sessions, reinforcement was again available in all arms. During the extinction sessions, half the subjects in each age group received saline and half received alcohol. During the recovery sessions, half the subjects in each of these four groups were further divided into saline or ethanol groups. Results indicated that ethanol significantly reduced the impact of extinction and had a greater effect on the adult rats. 